Prepared in cooperation with

Department of Navy,

Naval Facilities Engineering Command,

Engineering Field Activity, Northwest

\title{
Continued Biodegradation of Chloroethene Compounds in Ground Water at Operable Unit 1, Naval Undersea Warfare Center, Division Keyport, Washington
}

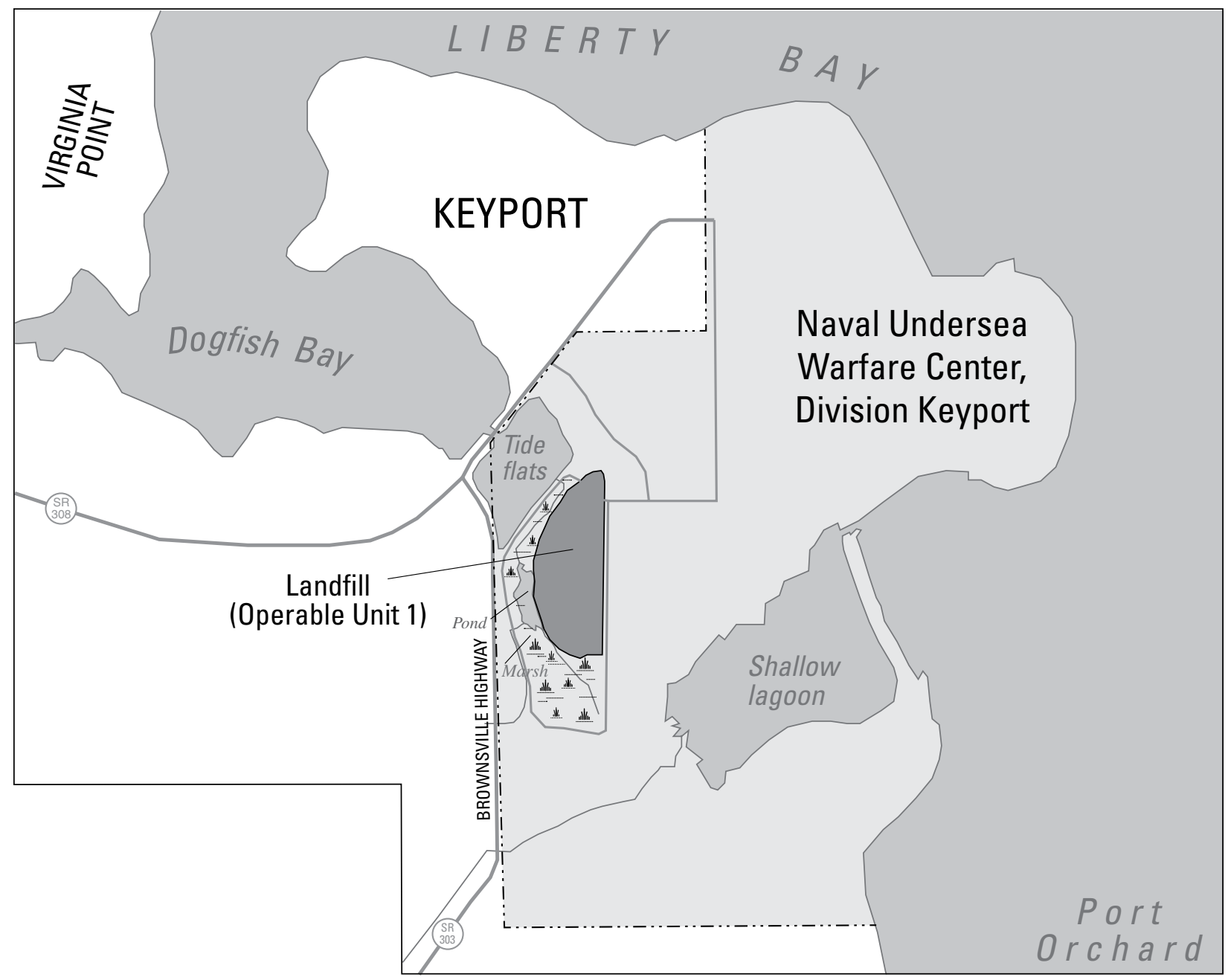

Scientific Investigations Report 2006-5056

U.S. Department of the Interior

U.S. Geological Survey 


\section{Continued Biodegradation of Chloroethene Compounds in Ground Water at Operable Unit 1, Naval Undersea Warfare Center, Division Keyport, Washington}

By R.S. Dinicola

Prepared in cooperation with

Department of the Navy Naval Facilities Engineering Command

Engineering Field Activity, Northwest

Scientific Investigations Report 2006-5056 


\title{
U.S. Department of the Interior \\ Gale A. Norton, Secretary \\ U.S. Geological Survey \\ P. Patrick Leahy, Acting Director
}

\section{U.S. Geological Survey, Reston, Virginia: 2006}

\author{
For sale by U.S. Geological Survey, Information Services \\ Box 25286, Denver Federal Center \\ Denver, CO 80225 \\ For more information about the USGS and its products: \\ Telephone: 1-888-ASK-USGS \\ World Wide Web: http://www.usgs.gov/
}

\footnotetext{
Any use of trade, product, or firm names in this publication is for descriptive purposes only and does not imply endorsement by the U.S. Government.

Although this report is in the public domain, permission must be secured from the individual copyright owners to reproduce any copyrighted materials contained within this report.

Suggested citation:

Dinicola, R.S., 2006, Continued biodegradation of chloroethene compounds in ground water at Operable Unit 1, Naval Undersea Warfare Center, Division Keyport, Washington: U.S. Geological Survey Scientific Investigations Report 2006-5056, 42 p.
} 


\section{Contents}

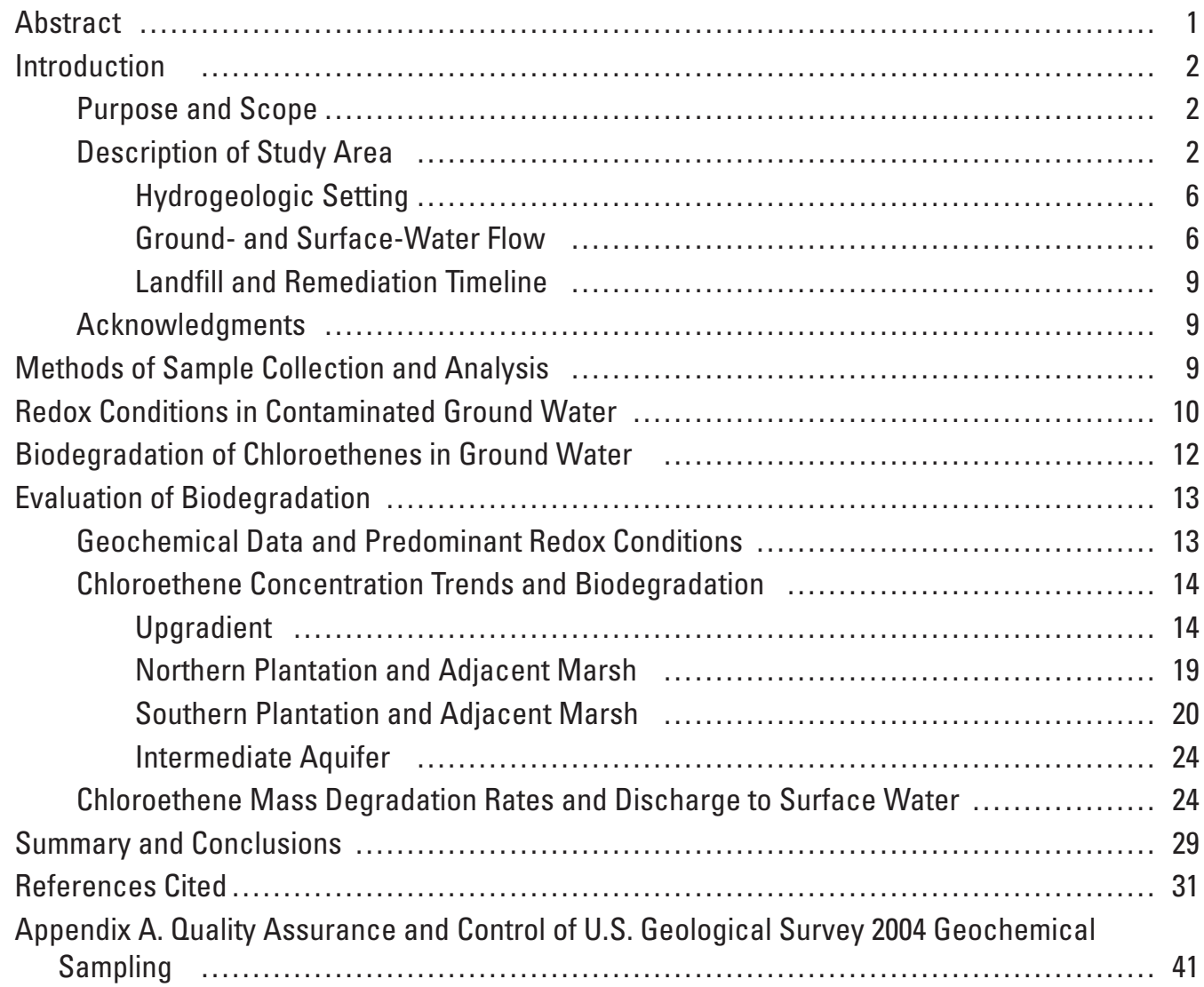




\section{Figures}

Figure 1. Map showing location of Operable Unit 1 study area, Naval Undersea Warfare Center, Division Keyport, Washington

Figure 2. Map showing locations of former landfill, two phytoremediation plantations, and data-collection sites at Operable Unit 1, Naval Undersea Warfare Center (NUWC), Division Keyport, Washington.

Figure 3. Map showing ground-water levels and flow directions in the unconfined upper aquifer during low tide at Operable Unit 1, Naval Undersea Warfare Center (NUWC), Division Keyport, Washington, September 1996

Figure 4. Map showing ground-water levels and flow directions in the confined intermediate aquifer during low tide at Operable Unit 1, Naval Undersea Warfare Center (NUWC), Division Keyport, Washington, September 1996

Figure 5. Map showing total concentrations of chlorinated volatile organic compounds (CVOCs) in upper-aquifer ground water at Operable Unit 1, Naval Undersea Warfare Center (NUWC), Division Keyport, Washington, 2004

Figure 6. Map showing concentrations of total chlorinated volatile organic compounds (CVOCs) in upper-aquifer ground water at Operable Unit 1, Naval Undersea Warfare Center (NUWC), Division Keyport, Washington, 1999 (wells and piezometers) and 2000 (passive-diffusion samplers)

Figure 7. Graphs showing chloroethene concentration and ratio of cis-1,2-dichloroethene to vinyl chloride concentrations at northern plantation sites 1MW-1, MW1-2, and P1-4 at Operable Unit 1, Naval Undersea Warfare Center, Division Keyport, Washington, 1991-2004

Figure 8. Graphs showing chloroethene concentration and ratio of cis-1,2-dichloroethene to vinyl chloride concentrations at southern plantation sites MW1-16, P1-6, P1-8, and P1-10 at Operable Unit 1, Naval Undersea Warfare Center, Division Keyport, Washington, 1995-2004 .

Figure 9. Graphs showing chloroethene concentration and ratios of trichloroethene to cis-1,2-dichloroethene and cis-1,2-dichloroethene to vinyl chloride concentrations at southern plantation sites MW1-4, P1-7, and P1-9 at Operable Unit 1, Naval Undersea Warfare Center, Division Keyport, Washington, 1991-2004

Figure 10. Graph showing chloroethene concentration at surface-water site MA-12 at Operable Unit 1, Naval Undersea Warfare Center, Division Keyport, Washington, 1996-2004

Figure 11. Graphs showing chloroethene concentration at intermediate aquifer sites MW1-25 and MW1-28 at Operable Unit 1, Naval Undersea Warfare Center, Division Keyport, Washington, 1995-2004

Figure 12. Map showing transects and sub-transects where mass chloroethene fluxes were estimated for the upper aquifer at Operable Unit 1, Naval Undersea Warfare Center (NUWC), Division Keyport, Washington 


\section{Tables}

Table 1. Wells and piezometers sampled and water levels measured at Operable Unit 1, Naval Undersea Warfare Center, Division Keyport, Washington, June 2004

Table 2. Potential relative efficiency of chloroethene biodegradation through reductive dechlorination or microbial oxidation as a function of ground-water reduction-oxidation (redox) conditions

Table 3. Concentrations of selected volatile organic compounds in water samples collected by the U.S. Geological Survey from selected monitoring wells, piezometers, and passive-diffusion samplers at Operable Unit 1, Naval Undersea Warfare Center, Division Keyport, Washington, 2004

Table 4. Estimated chloroethene mass degradation rates and fluxes to surface water at Operable Unit 1, Naval Undersea Warfare Center, Division Keyport, Washington, 1999-2000 and 2004

Table 5. Chloroethene flux comparison to southern marsh surface water estimated from ground-water flux and chloroethene concentrations from passive-diffusion samplers and surface-water flux and chloroethene concentrations from surface water, Operable Unit 1, Naval Undersea Warfare Center, Division Keyport, Washington, 1999-2000 and 2004

Table 6. Predominant redox conditions at selected wells and piezometers, and ground-water geochemical data collected at Operable Unit 1, Naval Undersea Warfare Center, Division Keyport, Washington, 1996-2004

\section{Conversion Factors, Datums, Abbreviations, and Acronyms}

\begin{tabular}{lcl}
\hline Multiply & \multicolumn{1}{c}{ By } & To obtain \\
\hline inch (in.) & 2.54 & centimeter \\
inch (in.) & 25.4 & millimeter \\
foot (ft) & 0.3048 & meter \\
mile (mi) & 1.609 & kilometer \\
acre & 4,047 & square meter \\
acre & 0.4047 & hectare \\
acre & 0.4047 & square hectometer \\
acre & 0.004047 & square kilometer \\
foot per day (ft/d) & 0.3048 & meter per day \\
gallon per minute (gal/min) & 0.06309 & liter per second \\
gram per day (g/d) & 0.03527 & ounce per day, avoirdupois \\
\hline
\end{tabular}

Temperature in degrees Celsius $\left({ }^{\circ} \mathrm{C}\right)$ may be converted to degrees Fahrenheit $\left({ }^{\circ} \mathrm{F}\right)$ as follows:

$$
{ }^{\circ} \mathrm{F}=\left(1.8 \times^{\circ} \mathrm{C}\right)+32 \text {. }
$$

Specific conductance is given in microsiemens per centimeter at 25 degrees Celsius $(\mu \mathrm{S} / \mathrm{cm}$ at $\left.25^{\circ} \mathrm{C}\right)$.

Concentrations of chemical constituents in water are given either in milligrams per liter (mg/L) or micrograms per liter ( $\mu \mathrm{g} / \mathrm{L})$. 


\section{Conversion Factors, Datums, Abbreviations, and Acronyms-Continued}

Datums

Vertical coordinate information is referenced to North American Vertical Datum of 1988 (NAVD 88).

Horizontal coordinate information is referenced to North American Datum of 1927 (NAD 27).

Altitude, as used in this report, refers to distance above the vertical datum.

Abbreviations and Acronyms

\begin{tabular}{ll}
\hline $\begin{array}{l}\text { Abbreviations } \\
\text { and Acronyms }\end{array}$ & \\
\hline 1,1-DCA & 1,1-dichloroethane \\
1,2-DCA & 1,2-dichloroethane \\
1,1-DCE & 1,1-dichloroethene \\
cis-DCE & cis-1,2-dichloroethene \\
CVOC & chlorinated volatile organic compound \\
DO & dissolved oxygen \\
EFANW & Naval Facilities Engineering Command, Engineering Field Activity, Northwest \\
mL & milliliter \\
mV & millivolt \\
nM & nanomolar \\
NUWC & Naval Undersea Warfare Center \\
NWOL & USGS National Water Ouality Laboratory \\
ORP & oxidation-reduction potential \\
OU-1 & Operable Unit 1 \\
PCE & tetrachloroethene \\
STL & Severn Trent Laboratories \\
TCA & $1,1,1$-trichloroehtane \\
TCE & trichloroethene \\
trans-DCE & trans-1,2-dichloroethene \\
USGS & U.S. Geological Survey \\
VC & vinyl chloride \\
VOC & volatile organic compound \\
\hline & \\
\hline
\end{tabular}




\title{
Continued Biodegradation of Chloroethene Compounds in Ground Water at Operable Unit 1, Naval Undersea Warfare Center, Division Keyport, Washington
}

\author{
By R.S. Dinicola
}

\section{Abstract}

The U.S. Geological Survey evaluated the biodegradation of chloroethene compounds in ground water beneath the former landfill at Operable Unit 1 (OU-1) of the Naval Undersea Warfare Center (NUWC), Division Keyport. The predominant contaminants in ground water are the chloroethene compounds trichloroethene (TCE), cis-1,2-dichloroethene (cis-DCE), and vinyl chloride (VC). The remedy selected for ground-water contamination at OU-1 includes phytoremediation and natural attenuation. In 1999, the Navy planted two hybrid poplar plantations, referred to as the northern and southern plantations, over the most contaminated parts of the landfill. The Navy monitors tree health, ground-water levels, and contaminant concentrations to assess the effectiveness of phytoremediation. The U.S. Geological Survey began a cooperative effort with the Navy in 1995 to monitor the effectiveness of natural attenuation processes for removing and controlling the migration of chloroethenes and chloroethanes. Field and laboratory studies from 1996 through 2000 demonstrated that natural attenuation, particularly biodegradation, of chloroethenes and chloroethanes in shallow ground water at OU-1 was substantial. The U.S. Geological Survey monitored geochemical and contaminant concentrations in ground water annually from 2001 through 2004. This report presents ground water geochemical and contaminant data collected by the U.S. Geological Survey during June and July 2004, and evaluates evidence for continued biodegradation of chloroethenes in ground water through 2004.

Geochemical and contaminant concentration data through 2004 indicate that substantial biodegradation of chloroethenes in ground water continued beneath the landfill at OU-1. Contaminant concentrations in ground water decreased beneath most of the 9-acre landfill between 1999 and 2004. The evidence indicating biodegradation was a primary cause for the decreased concentrations includes decreasing ratios of more highly chlorinated compounds to less chlorinated compounds over time, and widespread detection on non-chlorinated biodegradation end-products ethane and ethene. No widespread changes in ground-water reduction-oxidation (redox) conditions were observed since 1996 that could result in either more- or less-efficient biodegradation. Anaerobic redox conditions prevailed at the site and, despite interannual variation in the predominant electron-accepting process, no consistent trend was determined indicating either more strongly or more mildly reducing conditions.

Even with continued biodegradation, dissolved-phase contaminant concentrations in the tens of milligrams per liter have persisted beneath the southern part of the 0.7 -acre southern plantation. The magnitude and persistence of those concentrations indicate that non-aqueous phase liquid chloroethenes likely are present beneath the southern plantation and are not substantially affected by biodegradation. During 2004, chloroethenes continued to discharge to the adjacent marsh at concentrations exceeding quantitative remediation goals for the site. Chloroethene concentrations in ground water discharging to a 100-foot long reach in the southern part of the marsh were at least 300 times greater than concentrations in ground water discharging elsewhere in the marsh.

Flux calculations based on 2004 data indicate that 87 percent of dissolved-phase chloroethenes in the upper aquifer beneath the landfill were degraded before they discharged to surface water. The flux calculations based on 1999-2000 data indicate a larger dissolved contaminant flux from the landfill than in 2004, along with a larger percentage (93 percent) that was biodegraded and a smaller contaminant flux to surface water. Flux calculations were extremely sensitive to a few measured chloroethene concentrations at highly contaminated wells and passive-diffusion samplers near the southern plantation where the interannual variability was expected to be high. Comparison of calculated fluxes to measured surface-water concentrations indicated that not all TCE flux from the landfill was represented by measured concentrations from the passive-diffusion sampler sites. VC concentrations continued to attenuate in the upper 2 feet of organic-rich marsh sediments, likely due to microbial degradation in the sediments and volatilization from the overlying surface water. 
In the intermediate aquifer near the downgradient margin of the landfill, chloroethene concentrations decreased inconsistently between 1999 and 2004. At the farthest downgradient monitoring points in the intermediate aquifer, TCE remained undetected and cis-DCE and VC were consistently measured at low but detectable concentrations. Biodegradation of chloroethenes in the most contaminated part of the intermediate aquifer was uncertain based on the 1995-2000 data, but the data through 2004 reliably indicate that some reductive dechlorination in the intermediate aquifer occurred.

Overall, biodegradation of chloroethenes in ground water throughout OU-1 continued through 2004 and is responsible for preventing most of the mass of dissolved-phase chloroethenes in the upper aquifer beneath the landfill from discharging to surface water.

\section{Introduction}

Chlorinated volatile organic compounds (CVOCs) have migrated to ground water beneath a former 9-acre landfill at Operable Unit 1 (OU-1) of the Naval Undersea Warfare Center (NUWC), Division Keyport, Washington (fig. 1). The predominant ground-water contaminants are the chloroethene compounds-trichloroethene (TCE), cis-1,2-dichloroethene (cis-DCE), and vinyl chloride (VC). Less predominant contaminants include tetrachloroethene (PCE), trans1,2-dichloroethene (trans-DCE), 1,1-dichloroethene (1,1-DCE) 1,1,1-trichloroethane (TCA), 1,1-dichloroethane (1,1-DCA), and 1,2-dichloroethane (1,2-DCA). A need for remedial action was identified because some of the contaminants present a potential risk to humans, primarily through drinking contaminated ground water or through ingesting seafood harvested from contaminated surface water (URS Consultants, Inc., 1998).

The Navy began a cooperative effort with the U.S. Geological Survey (USGS) in 1995 to evaluate the effectiveness of natural attenuation processes for removing and controlling the migration of CVOCs in ground water at OU-1. Field and laboratory studies from 1996 through 2000 demonstrated that natural attenuation and biodegradation of CVOCs in shallow ground water at OU-1 is substantial (URS Consultants, Inc., 1997a; Bradley and others, 1998; Dinicola and others, 2002). In 1998, a remedy was developed for contaminated ground water at OU-1 that includes phytoremediation and on-going natural attenuation processes to remove and control the migration of CVOCs in shallow ground water (URS Consultants, Inc., 1998). In 1999, the Navy planted two hybrid poplar plantations in two areas on the landfill where contaminant concentrations in ground water were exceptionally high (fig. 2) (URS Greiner, Inc., 1999). The Navy regularly monitored contaminant concentrations in ground and surface water, along with tree health and water levels, to determine the effectiveness of phytoremediation (CH2M Hill Constructors, Inc., 2002, 2003, 2004, and 2005). The USGS monitored geochemistry and contaminant concentrations in ground and surface water annually from 2001 through 2004 to evaluate reduction-oxidation (redox) conditions and CVOC biodegradation.

\section{Purpose and Scope}

This report presents ground-water geochemical and selected CVOC data collected by the USGS at OU-1 during June and July 2004, and evaluates evidence for continued biodegradation of chloroethenes in ground water at OU-1. Biodegradation of chloroethanes was not specifically evaluated because those contaminants are greatly limited in extent at the site. Data used for the evaluation included CVOC and geochemical data collected during 2001-04 by the USGS (Dinicola, 2003; 2004; Dinicola and Huffman, 2004) and the Navy (CH2M Hill Constructors, Inc., 2002, 2003, 2004, and 2005 ) in addition to data presented in a prior evaluation of natural attenuation (Dinicola and others, 2002).

In June 2004, the USGS collected water samples from 19 wells and 9 piezometers (table 1, fig. 2) to determine volatile organic compound (VOC) and geochemical concentrations. The USGS also sampled VOCs in shallow ground water directly beneath the marsh stream and pond (fig. 2) using passive-diffusion samplers. Samplers were deployed in the same locations that were sampled by the USGS in June 2000.

\section{Description of Study Area}

NUWC, Division Keyport is on a small peninsula in Kitsap County, Washington, in an extension of Puget Sound called Liberty Bay (fig. 1). The landfill at OU-1 is on the narrow strip of land connecting the peninsula to the mainland and is adjacent to tidal flats that are an extension of Dogfish and Liberty Bays. The OU-1 landfill is unlined at the bottom and was constructed in a marshland. The landfill was the primary disposal area for domestic and industrial wastes generated by NUWC, Division Keyport from the 1930s through 1973. Paints, thinners, solvents, acids, dried sludge from a wastewater-treatment plant, and other industrial wastes were disposed in the landfill. The most concentrated disposal area for waste paints and solvents was at the southern end of the landfill (fig. 2). 


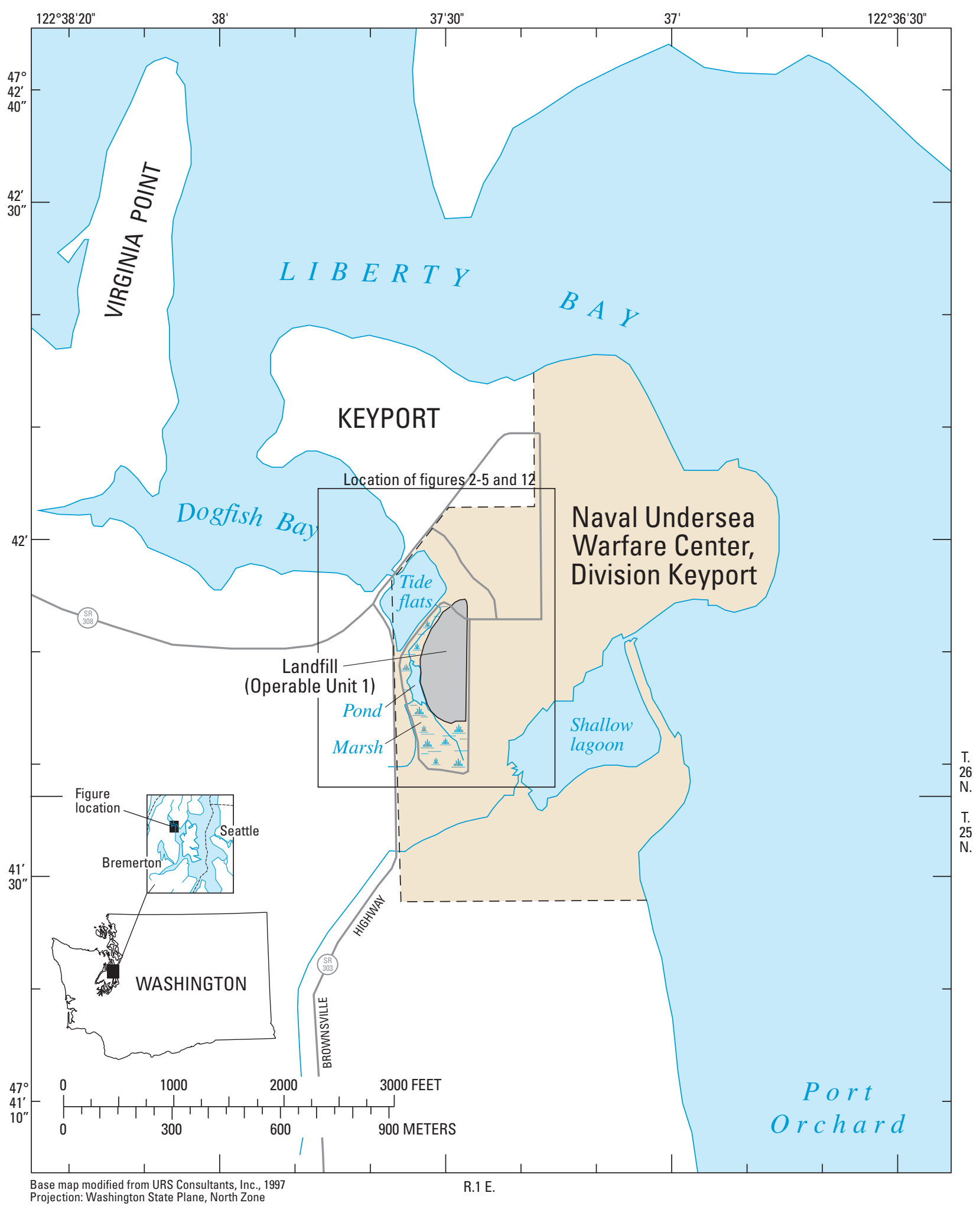

Figure 1. Location of Operable Unit 1 study area, Naval Undersea Warfare Center, Division Keyport, Washington. 


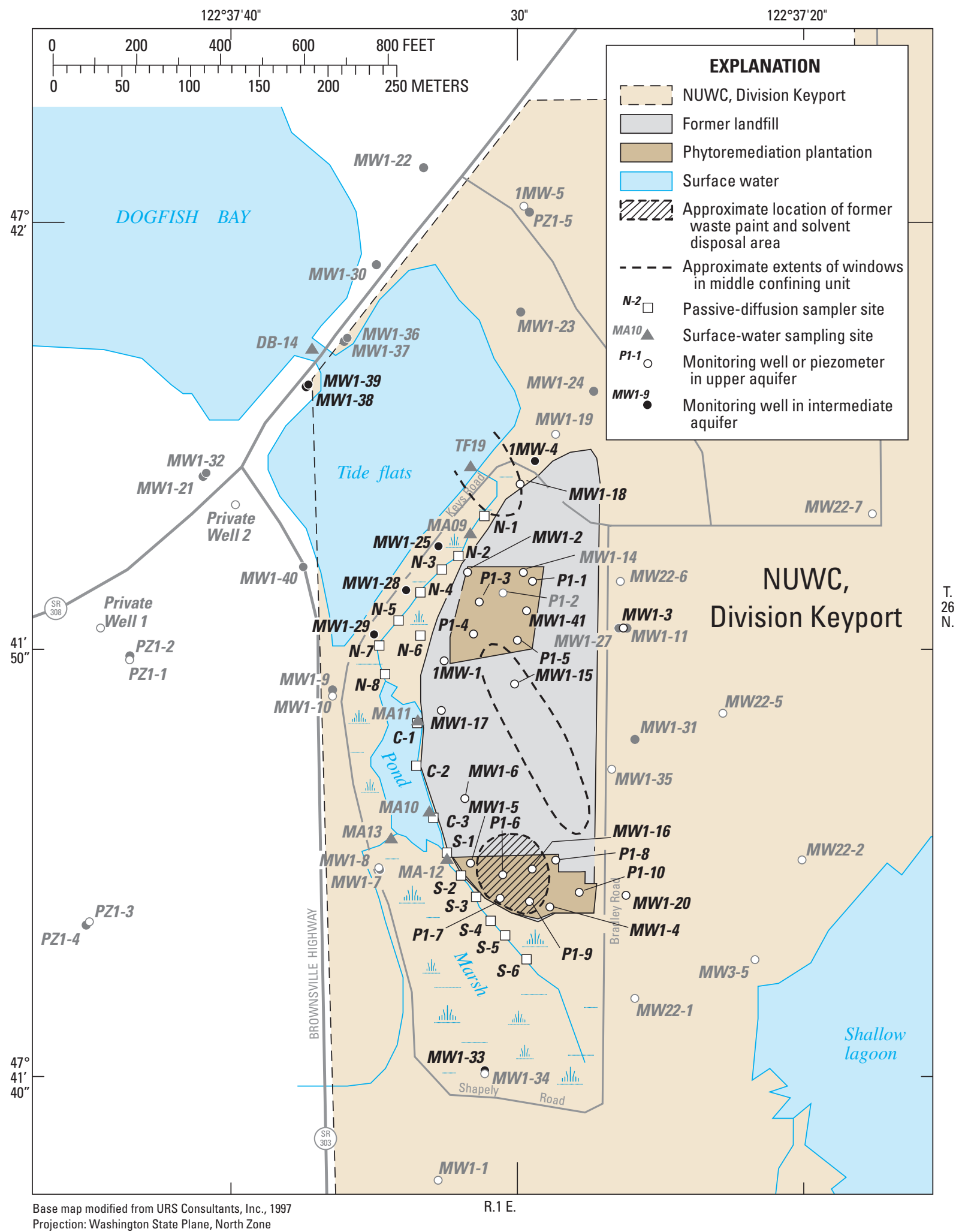

Figure 2. Locations of former landfill, two phytoremediation plantations, and data-collection sites at Operable Unit 1, Naval Undersea Warfare Center (NUWC), Division Keyport, Washington. 
Table 1. Wells and piezometers sampled and water levels measured at Operable Unit 1, Naval Undersea Warfare Center, Division Keyport, Washington, June 2004.

[Study site No.: MW, monitoring well; P, piezometer. Location of sites are shown in figure 2. USGS site No.: Unique number for each site based on latitude and longitude of the site. First six digits are latitude, next seven digits are longitude, and final two digits are a sequence number to uniquely identify each site. Altitudes of water levels and measuring points are given in feet above or below (-) NAVD88. Water level is in feet below measuring point (bmp). Depth of well and screened interval are in feet below land surface. Measuring point: Water levels in wells usually are reported as depths below land surface, although the measuring point can be any convenient fixed place near the top of the well. For these wells and piezometers, the measuring points are marked points on the tops of well casings - they vary from being near the land surface to a few feet above land surface. The altitude of the measuring point commonly is recorded so that static water levels also can be reported as altitudes. VOCs sampled by USGS: Y, yes, N, no. Abbreviations: USGS, U.S. Geological Survey; VOC, volatile organic compounds; ft, foot; $\mathrm{ft} b \mathrm{bmp}$, foot below measuring point; in., inch]

\begin{tabular}{|c|c|c|c|c|c|c|c|c|c|c|}
\hline $\begin{array}{l}\text { Study site No. } \\
1 \mathrm{MW}-1\end{array}$ & $\begin{array}{c}\text { USGS site No. } \\
474151122373201\end{array}$ & \multicolumn{2}{|c|}{$\begin{array}{l}\text { Date and time } \\
\text { measured }\end{array}$} & $\begin{array}{c}\begin{array}{c}\text { Water-level } \\
\text { altitude } \\
\text { (ft) }\end{array} \\
3.16\end{array}$ & $\begin{array}{c}\begin{array}{c}\text { Water } \\
\text { level } \\
\text { (ft bmp) }\end{array} \\
6.90\end{array}$ & $\begin{array}{c}\begin{array}{c}\text { Altitude of } \\
\text { measuring } \\
\text { point (ft) }\end{array} \\
10.06\end{array}$ & $\begin{array}{c}\begin{array}{c}\text { Depth of } \\
\text { well } \\
\text { (ft) }\end{array} \\
16.5\end{array}$ & $\begin{array}{c}\begin{array}{c}\text { Casing } \\
\text { diameter } \\
\text { (in.) }\end{array} \\
2\end{array}$ & $\begin{array}{c}\begin{array}{c}\text { Screened } \\
\text { interval } \\
\text { (ft) }\end{array} \\
5.5-15.5\end{array}$ & $\begin{array}{c}\text { VOCs } \\
\text { sampled by } \\
\text { USGS }\end{array}$ \\
\hline $1 \mathrm{MW}-4$ & 474156122373201 & 06-17-04 & $14: 45$ & 3.96 & 8.40 & 12.36 & 25.0 & 2 & $15-25$ & $\mathrm{Y}$ \\
\hline MW1-2 & 474153122373101 & 06-17-04 & $11: 25$ & 2.14 & 9.75 & 11.89 & 18.5 & 4 & $12.5-17.5$ & $\mathrm{Y}$ \\
\hline MW1-3 & 474152122372501 & $06-15-04$ & $12: 45$ & 9.20 & 4.35 & 13.55 & 11.5 & 4 & $5.5-10.5$ & $\mathrm{~N}$ \\
\hline MW1-5 & 474146122373201 & 06-18-04 & $11: 20$ & 4.30 & 8.78 & 13.08 & 12.0 & 4 & $6-11$ & $\mathrm{Y}$ \\
\hline MW1-6 & 474148122373101 & $06-22-04$ & $11: 30$ & 4.11 & 9.12 & 13.23 & 14.0 & 4 & $8-13$ & $\mathrm{Y}$ \\
\hline MW1-15 & 474151122372901 & $06-15-04$ & $15: 30$ & 5.28 & 6.97 & 12.25 & 12.0 & 2 & $6-11$ & $\mathrm{Y}$ \\
\hline MW1-16 & 474146122372801 & $06-22-04$ & $12: 30$ & 5.36 & 7.47 & 12.83 & 12.0 & 2 & $6-11$ & $\mathrm{Y}$ \\
\hline MW1-17 & 474150122373201 & 06-17-04 & $14: 45$ & 6.44 & 5.50 & 11.94 & 13.5 & 2 & $7.5-12.5$ & $\mathrm{Y}$ \\
\hline MW1-29 & 474152122373501 & 06-16-04 & $11: 30$ & 1.67 & 10.97 & 12.64 & 37.5 & 2 & $31.5-36.5$ & $\mathrm{~N}$ \\
\hline MW1-33 & 474140122373201 & $06-15-04$ & $13: 00$ & 11.01 & .48 & 11.49 & 41.0 & 2 & $30-40$ & $\mathrm{~N}$ \\
\hline MW1-38 & 474156122373701 & 06-16-04 & $11: 30$ & -.76 & 10.59 & 9.83 & 50.0 & 2 & $44-49$ & $\mathrm{~N}$ \\
\hline MW1-39 & 474157122373701 & $06-16-04$ & $13: 15$ & -.84 & 10.69 & 9.85 & 33.7 & 2 & $27.7-32.7$ & $\mathrm{~N}$ \\
\hline MW1-41 & 474152122372901 & $06-17-04$ & $12: 00$ & 6.52 & 8.75 & 15.27 & 15.0 & 2 & 5-15 & $\mathrm{Y}$ \\
\hline (duplicate) & & $06-17-04$ & $12: 01$ & & & & & & & $\mathrm{Y}$ \\
\hline (field blank) & & $06-17-04$ & $15: 05$ & & & & & & & $\mathrm{Y}$ \\
\hline $\mathrm{P} 1-1$ & 474153122372801 & $06-17-04$ & $13: 15$ & 5.91 & 8.45 & 14.36 & 15.0 & 1 & $10-15$ & $\mathrm{Y}$ \\
\hline P1-3 & 474153122373102 & 06-17-04 & $12: 20$ & 3.22 & 9.57 & 12.79 & 15.0 & 1 & $10-15$ & $\mathrm{Y}$ \\
\hline P1-4 & 474152122373101 & 06-17-04 & $11: 30$ & 4.35 & 8.20 & 12.55 & 15.0 & 1 & $10-15$ & $\mathrm{Y}$ \\
\hline
\end{tabular}




\section{Hydrogeologic Setting}

CVOCs are present in the upper and intermediate aquifers and in surface water at OU-1. Ground water beneath OU-1 occurs in a series of aquifers composed of permeable sand, gravel, or fill materials separated by fine-grained silt or clay layers. Contamination at OU-1 occurs only in about the top $60 \mathrm{ft}$ of the unconsolidated deposits in the hydrogeologic units referred to locally as the unsaturated zone, the upper aquifer, the middle confining unit, and the intermediate aquifer.

The unsaturated zone primarily consists of fill materials including a mix of silt, sand, gravel, clay, and trash debris. The unit also includes organic-rich silt or silty-sand marsh deposits and silt or silty-sand estuary and tide flats deposits. The unit ranges from 0 - to about 20 -ft thick. The permeability of the unsaturated zone is highly variable due to its heterogeneity.

The upper aquifer consists primarily of sand or silty-sand and gravel with localized zones of marsh, estuary, and tide flat deposits. The unit is nearly continuous across OU-1 and ranges from about 4- to 22-ft thick. The permeability of the upper aquifer is variable and scattered deposits of finer grained materials indicate that preferential flow pathways are likely over short distances. Estimated hydraulic conductivity for the upper aquifer ranges from 0.2 to $4.1 \mathrm{ft} / \mathrm{d}$ (URS Consultants, Inc., 1997a).

The middle confining unit separates the upper and intermediate aquifers and consists primarily of silt, clay, and fine sand with localized peat. The unit is nearly continuous across OU-1 and ranges from about 1 - to 40 -ft thick. The middle confining unit is notably absent beneath the central part of the landfill; an eroded window of about 1 acre extends northwest for about $500 \mathrm{ft}$ from the southeastern edge of the landfill (fig. 2). The permeability of the middle confining unit is mostly low, with an estimated vertical hydraulic conductivity of $0.0001 \mathrm{ft} / \mathrm{d}$ (URS Consultants, Inc., 1993).

The intermediate aquifer consists primarily of sand and gravel with localized silt and glacial-till lenses. The unit is continuous across OU-1 except near well MW1-7 (southwest of the marsh pond), where it is truncated by fine-grained glaciolacustrine clay and silt deposits. The intermediate aquifer thins to less than $1 \mathrm{ft}$ and is indistinct near the northwestern margin of the landfill, and it increases to about $30-40 \mathrm{ft}$ in thickness upgradient (south) and downgradient (northwest) of the landfill. Beneath the tide flats and in the vicinity of State Highway 308 causeway, the aquifer is divided into an upper and lower permeable zone by as much as $16 \mathrm{ft}$ of a compacted glacial till deposit. Estimated hydraulic conductivity for the intermediate aquifer is $3.3 \mathrm{ft} / \mathrm{d}$ (URS Consultants, Inc., 1997a).
The Clover Park confining unit is a regionally extensive unit consisting of hard silt, peat, and clay that lies beneath the intermediate aquifer. The unit is continuous beneath OU-1 and ranges from $100-$ to $200-\mathrm{ft}$ thick. The estimated vertical hydraulic conductivity of the Clover Park confining unit is 0.01-0.0001 ft/d (URS Consultants, Inc., 1993).

\section{Ground- and Surface-Water Flow}

Water in the unconfined upper aquifer generally flows from east to west beneath the landfill toward Dogfish Bay (fig. 3). Water in the predominately confined intermediate aquifer flows from the south and west toward the landfill, and then northwest from the landfill toward Dogfish Bay (fig. 4). Some ground water in the contaminated portion of the upper aquifer flows downward into the intermediate aquifer. Measured water levels indicate that a downward gradient for ground-water flow is between the upper and intermediate aquifers beneath the northeastern one-third of the landfill, and that an upward gradient is beneath the remainder of the landfill and perhaps the entire marsh (URS Consultants, Ins., 1997a). Although upper-aquifer water levels and flow directions beneath the northwestern part of the landfill are influenced by tidal changes, ground-water salinity and water-levels frequently measured by the Navy indicated little seawater flux entered the upper aquifer during high tides (URS Consultants Inc., 1997a). Ground-water levels and flow directions in the intermediate aquifer beneath and adjacent to the tide flats also are influenced by tidal changes, but the seawater flux into and out of the aquifer beneath OU-1 during the tidal cycle was negligible (URS Consultants Inc., 1997a). More detailed descriptions of study area hydrogeology and contamination are available in URS Consultants Inc., (1997a) and Dinicola and others (2002).

The entire area bordered by Bradley, Shapely, and Keys Roads, and the former landfill is referred to as the marsh in this report (fig. 2). Two creeks flow into the perennial pond in the marsh, and a single perennial creek drains the marsh and discharges into the tide flats of Dogfish Bay (fig. 2). The outlet creek flows through a culvert and tide gate and into the tide flats. During periods of no runoff, freshwater inflow into the marsh is entirely ground-water discharge. Seawater flows into the marsh due to the 10-12 ft diurnal tidal fluctuations in Dogfish Bay. During high tides, water levels in the tide flats are at the same water-level altitude as Dogfish Bay. However, the tide gate at the marsh outlet automatically closes during high tide cycles and prevents seawater from flowing upstream beyond the marsh pond. 


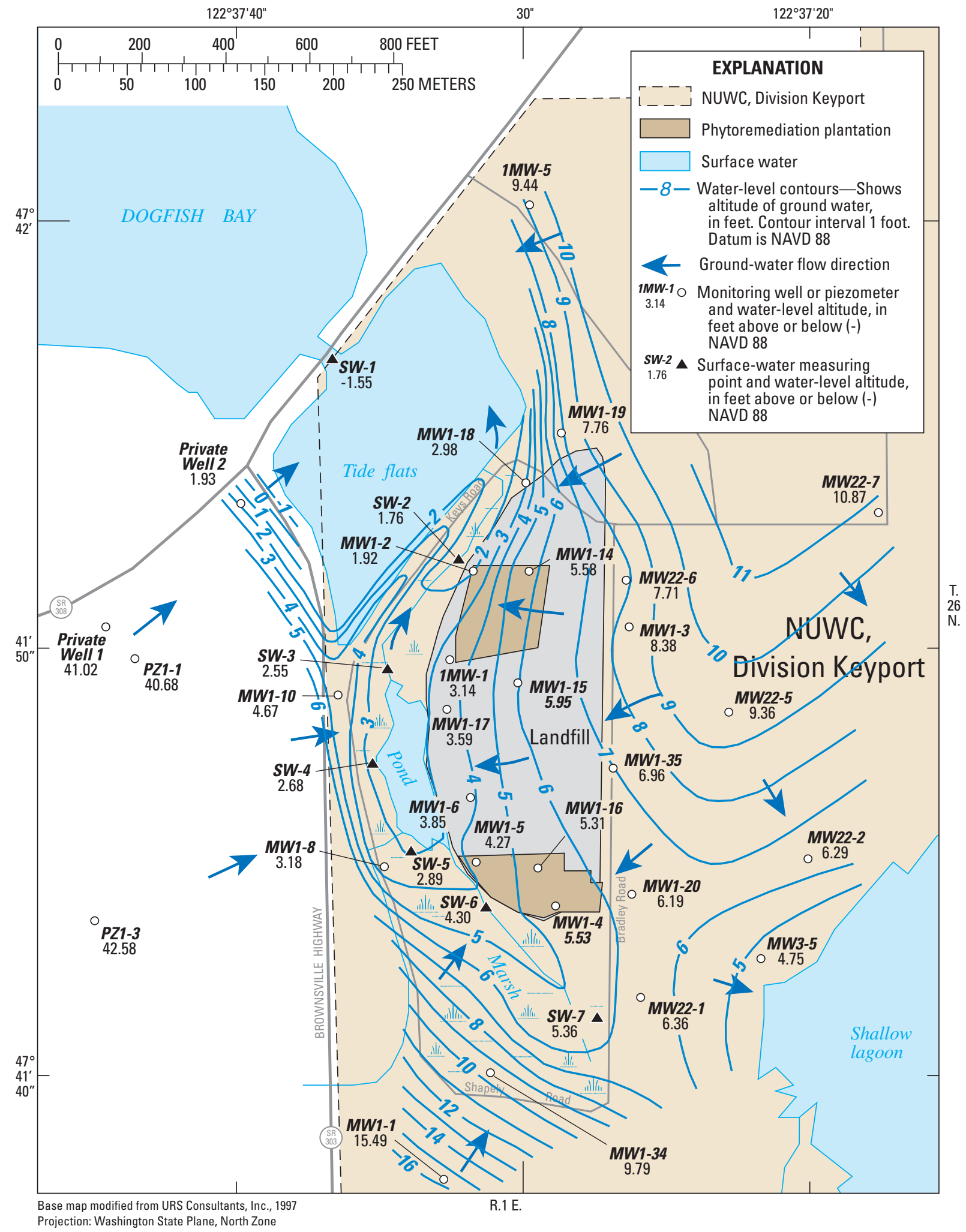

Figure 3. Ground-water levels and flow directions in the unconfined upper aquifer during low tide at Operable Unit 1, Naval Undersea Warfare Center (NUWC), Division Keyport, Washington, September 1996. 


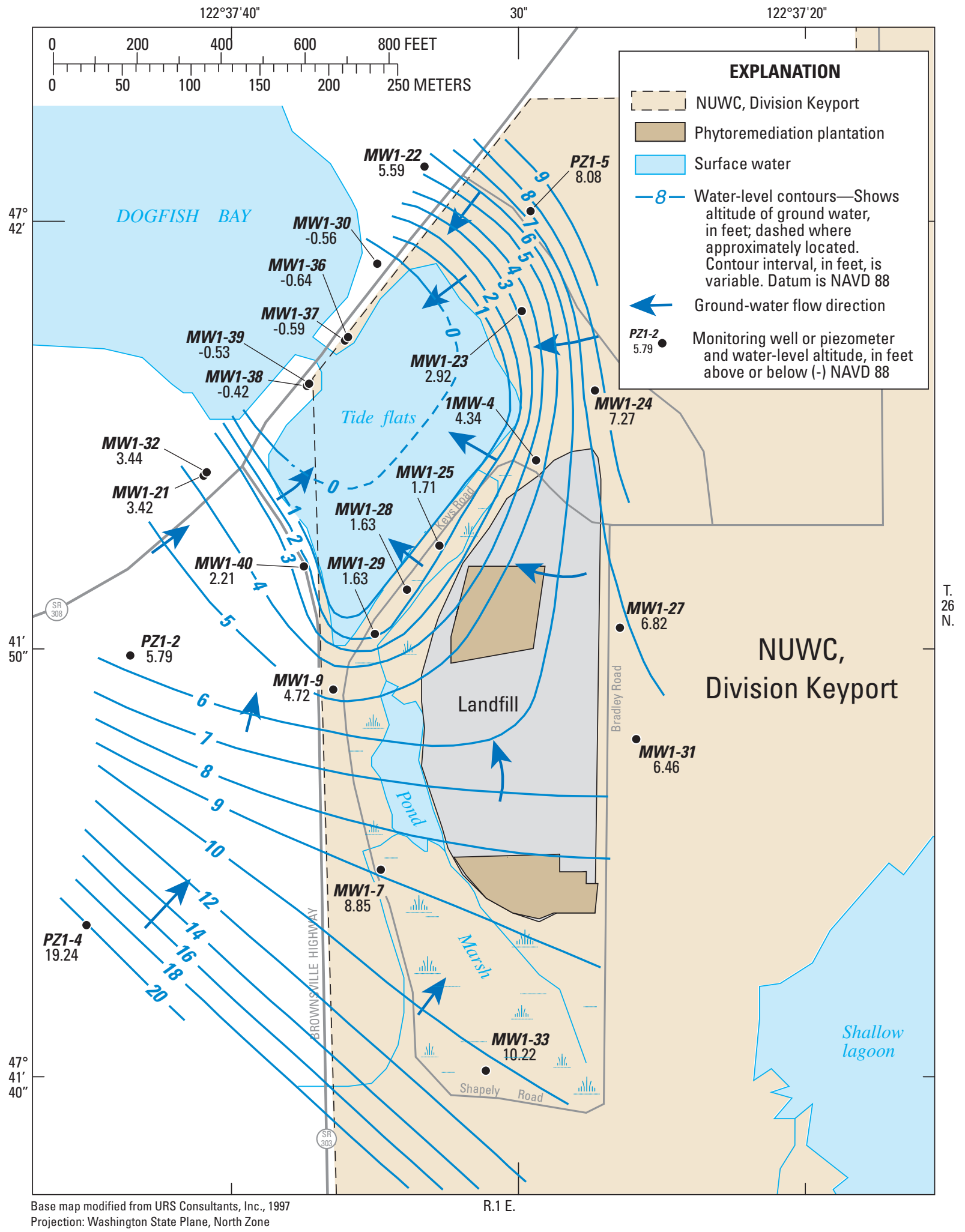

Figure 4. Ground-water levels and flow directions in the confined intermediate aquifer during low tide at Operable Unit 1, Naval Undersea Warfare Center (NUWC), Division Keyport, Washington, September 1996. 


\section{Landfill and Remediation Timeline}

The landfill was constructed on a tidal marsh and was the primary disposal area for domestic and industrial wastes generated by NUWC, Division Keyport from the 1930s through 1973. The bottom of the landfill was unlined, and the top was kept covered with a thin veneer of soil as filling progressed. The Navy burned mixed trash and demolition debris in the northern part of the landfill, and disposed of unburned materials including paints, thinners, solvents, acids, dried sludge from a wastewater-treatment plant, and other industrial wastes at various locations in the landfill from the 1930s through 1973. The most concentrated area for waste paint and solvent disposal was at the southern end of the landfill (fig. 2). Few, if any, intact and full drums of waste were thought to be buried in the landfill. Instead, most drum contents were emptied into the landfill and the drums were reused or crushed and buried. After closure, the southern two-thirds of the landfill was covered with asphalt, while the northern one-third was covered with gravel, fine-grained soils, and grass.

Preparation for phytoremediation began in February 1999 at the two plantation sites, referred to as the "northern plantation" and the "southern plantation." Asphalt, which covered all of the northern plantation site and the south 25 percent of southern plantation, was removed and the top 18-in. of the plantation sites were cultivated using agricultural equipment and amended with about $0.5-1.5 \mathrm{ft}$ of clean topsoil (URS Greiner, Inc., 1999). The Navy planted the two hybrid poplar plantations on the landfill in April and May 1999. The plantations were irrigated when the trees showed sign of stress during the latter part of most summers. Test pits by the Navy confirmed that tree roots reached the water table during the 2002 growing season (URS Greiner, Inc., 2002), and the plantation canopies closed during the 2003 growing season (URS Greiner, Inc., 2003).

\section{Acknowledgments}

The authors thank the many people and agencies for their significant contributions to the study. Douglas Thelin and Matthew Butler of the Naval Facilities Engineering Command, Engineering Field Activity, Northwest (EFANW) provided guidance and funding for the investigation. Gene Ellis of NUWC, Division Keyport and Mick Butterfield of EFANW provided logistic support for field activities. Michael Meyer of URS Corporation and Bernard Wong of CH2M Hill Constructors, Inc., provided logistic support and additional data.

\section{Methods of Sample Collection and Analysis}

Water-level measurements and sample collection, processing, and field analyses during 2004 were in accordance with applicable USGS procedures (U.S. Geological Survey, 1997-2004) except that samples were collected using a peristaltic pump. Geochemical measurements and concentrations determined for samples from 19 wells and 9 piezometers included dissolved hydrogen $\left(\mathrm{H}_{2}\right)$, dissolved oxygen (DO), filtered organic carbon, filtered nitrate plus nitrite, filtered manganese, filtered iron (II), filtered sulfate, unfiltered sulfide, dissolved methane, dissolved carbon dioxide, $\mathrm{pH}$, specific conductance, oxidation-reduction potential (ORP), and filtered chloride. Concentrations of 64 volatile organic compounds (VOCs) were determined for samples from 11 of the 19 wells, from all 9 piezometers, and from 12 of the 17 passive-diffusion samplers deployed (five samplers were damaged during either deployment or retrieval). The concentrations of dissolved gasses ethane, ethene, and methane also were determined for samples from all but one well, from all piezometers, and from the 12 undamaged passive-diffusion samplers.

After measuring depth to water, all well and piezometer samples were collected with a peristaltic pump and single-use polyurethane tubing. A stainless-steel weight attached to the bottom of the tubing facilitated sample collection from the mid-screen altitude in each well. Samples were collected after about three casing-volumes of water were purged from the wells and after allowing $\mathrm{pH}$, specific conductance, and DO to stabilize to within 0.1 unit, 5 percent, and $0.3 \mathrm{mg} / \mathrm{L}$, respectively. Those three analytes and ORP were measured in a flow-through chamber using temperature-compensated probes from a YSI ${ }^{\mathrm{TM}}$ data sonde. The specific conductance probe was calibrated daily with standard reference solutions; the $\mathrm{pH}$ probe was calibrated daily with two $\mathrm{pH}$ standards; and the DO probe was calibrated daily using the water-saturated air method and occasionally verified with zero DO solution. Dissolved-oxygen analyses were confirmed for most samples using 0 to $1 \mathrm{mg} / \mathrm{L}$ CHEMets Rhodazine- $\mathrm{D}^{\mathrm{TM}}$ colorimetric ampoules (manufactured by CHEMetrics, Inc., Calverton, Virginia.). These ampoules were filled directly from the sampling tube after well purging was complete.

Concentrations of iron (II) were measured in field samples filtered through a $0.45-\mu \mathrm{m}$ membrane filter using a colorimetric 1,10-phenanthroline indicator method and a Hach Model 2010 spectrophotometer following Hach Method 8146 [Hach Company, 1998; adapted from American Public Health 
Association (1980)]. Sulfide concentrations were measured in the field with a colorimetric methylene-blue indicator method immediately using the same spectrophotometer according to Hach Method 8131 [Hach Company, 1998; procedure is equivalent to U.S. Environmental Protection Agency method 376.2 (U.S. Environmental Protection Agency, 1983)]. Dissolved carbon dioxide $\left(\mathrm{CO}_{2}\right)$ concentrations were measured in the field with Titret ${ }^{\circledR}$-Sodium hydroxide tirtrant with a $\mathrm{pH}$ indicator (manufactured by CHEMetrics, Inc., Calverton, Virginia).

Dissolved $\mathrm{H}_{2}$ in ground water was sampled using the bubble-strip method of Chapelle and others (1997), and concentrations were measured in the field using a gas chromatograph equipped with a reduction gas detector. Initial gas samples from each well were collected and analyzed after at least $20 \mathrm{~min}$. of stripping; subsequent samples were collected and analyzed at about 5-min. intervals until consecutive $\mathrm{H}_{2}$ concentrations stabilized to within 10 percent, a process that often required 1 hour or longer.

Samples for determination of nitrate plus nitrite, manganese, sulfate, and chloride concentrations were filtered through a $0.45-\mu \mathrm{m}$ membrane filter into polyethylene bottles, chilled, and sent to the USGS National Water Quality Laboratory (NWQL) in Lakewood, Colo. Manganese samples were acidified in the field with nitric acid to a $\mathrm{pH}$ of less than 2, and then analyzed at NWQL by inductively coupled plasma as described by Fishman (1993). Chloride and sulfate were analyzed using ion chromatography as described by Fishman and Friedman (1989). Nitrate plus nitrite were analyzed colorimetrically by cadmium reduction and diazotization as described by Fishman (1993). The results for the nitrate plus nitrite analyses are referred to simply as "nitrate" in this report because nitrite was not detected at the site (Dinicola and others, 2002).

Samples for dissolved organic carbon analysis were filtered through a $0.45-\mu \mathrm{m}$ filter, collected in amber glass bottles, acidified in the field with sulfuric acid to a $\mathrm{pH}$ of less than 2, chilled to less than $4^{\circ} \mathrm{C}$, and shipped to the NWQL. Organic carbon concentrations were determined using persulfate oxidation as described by Brenton and Arnett (1993).

Samples for VOC analysis were collected in preacidified 40-mL glass vials, placed on ice, and shipped to the NWQL for subsequent analysis at Severn Trent Laboratories (STL) in Denver, Colo., using purge and trap capillarycolumn gas chromatography/mass spectrometry (U.S. Environmental Protection Agency Method SW846 8260B; accessed November 2005 at http://www.epa.gov/epaoswer/ hazwaste/test/pdfs/8260b.pdf). Samples for analysis of ethane, ethene, and methane were collected in pre-acidified $40-\mathrm{mL}$ glass vials, placed on ice, and shipped to the NWQL for subsequent analysis at STL using gas chromatography with a flame-ionization detector (U.S. Environmental Protection Agency Method RSK SOP-175; Kampbell and Vandegrift, 1998).
Seventeen passive-diffusion samplers were deployed in the marsh stream and pond to collect VOC samples in shallow ground water. (fig. 2). The samplers consisted of 8-in.-long by 2-in.-diameter polyethylene lay-flat tubing filled with de-ionized water and heat sealed at both ends. Samplers were built by the USGS, Tacoma, Wash. Filled bags were inserted into plastic mesh sleeves to protect them from damage. Sixteen samplers were buried by hand in about 12-in. of mud at various locations beneath the marsh creek and pond, and one sampler was buried beneath an isolated puddle. The holes were backfilled with native materials, tamped down, and left to equilibrate with the surrounding pore water for more than 2 weeks. Sampling sites were marked with wooden stakes and were approximately located on a site map. Samplers were retrieved by hand and immediately processed. A corner of each bag was cut and three $40-\mathrm{mL}$ glass VOC vials were filled, acidified to a $\mathrm{pH}$ of less than 2 with hydrochloric acid $(\mathrm{HCl})$, sealed, and kept on ice for shipment to the NWQL for VOC analysis at STL. Five of the 17 deployed samplers lacked enough water for analyses, presumably due to damage during deployment or retrieval.

Quality assurance and control of geochemical and contaminant sampling included collecting duplicate samples for selected redox-sensitive analytes and VOCs and analyzing a field blank sample for VOCs. No substantial quality issues were identified in those samples (Appendix A).

\section{Redox Conditions in Contaminated Ground Water}

Evaluation of redox conditions in ground-water contaminant plumes is a prerequisite for evaluating the effectiveness of natural attenuation processes because ground-water redox conditions greatly control the occurrence and rate of nearly all biodegradation processes (Bradley, 2003). Most biodegradation processes involve redox reactions in which electrons are transferred from one compound (the electron donor) to another (the electron acceptor). Depending on the particular compound and redox condition, CVOCs can serve as either electron donors or electron acceptors. Possible electron donors in contaminated ground water include various organic-carbon compounds in landfill leachate and hydrocarbon fuels. The less chlorinated VOCs, such as VC and dichlorinated ethenes and ethanes, also can act as electron donors under aerobic or mildly reducing redox conditions. Possible electron acceptors include the inorganic constituents oxygen, nitrate, manganese (IV), iron (III), sulfate, and carbon dioxide, as well as highly chlorinated VOCs such as PCE, TCE, and TCA. VC and dichlorinated ethenes and ethanes also may act as electron acceptors under strongly reducing redox conditions. 
Indigenous microorganisms that require carbon and energy to sustain their growth facilitate most ground-water redox reactions (Chapelle, 1992). A variety of microorganisms often competes indiscriminately for the supply of available electron donors in the ground water; however, these microorganisms generally are more specialized in their use of the available electron acceptors. Oxygen-reducing microorganisms (those that use oxygen as an electron acceptor) can out-compete all others when DO is present. However, if the supply of DO in ground water is depleted and electron-donating compounds are still available, oxygen reducers will become dormant and nitrate reducers will predominate until the supply of nitrate is depleted. This sequence continues through manganese reduction, iron reduction, sulfate reduction, and carbon-dioxide reduction (methanogenesis). The result of this competitive exclusion is the formation of somewhat discrete redox zones in an aquifer.

Redox conditions generally are considered either aerobic when DO concentrations are about $1 \mathrm{mg} / \mathrm{L}$, or anaerobic when DO concentrations are less than $1 \mathrm{mg} / \mathrm{L}$. Anaerobic redox conditions usually can be further specified (and are named) according to the inorganic compound acting as the predominant electron acceptor in a given part of an aquifer. Common anaerobic redox conditions in ground water are nitrate reducing, manganese reducing, iron reducing, sulfate reducing, and carbon-dioxide reducing (methanogenic). Nitrate reduction, manganese reduction, and iron reduction commonly are together referred to as mildly reducing conditions, whereas sulfate reduction and methanogenesis commonly are referred to as strongly reducing conditions. That distinction is made because different types of biodegradation processes are favored under mildly and strongly reducing conditions.

Determination of redox conditions in contaminated ground water is not a simple task and no universally accepted procedures exist. The rationale behind characterizing redox conditions in ground water at OU-1 is summarized here. Additional information about characterizing redox conditions is available in Wiedemeier and Chappelle (1998); Weidemeier and others (1998); Christensen and others (2000); and Cozzarelli and others (2000).

Redox conditions in contaminated ground water can sometimes be deduced by quantifying various oxidized and reduced inorganic compounds in ground-water samples (Wiedemeier and Chappelle, 1998; Christensen and others, 2000; and Cozzarelli and others, 2000). Identifying aerobic conditions is relatively simple; they are predominant if DO concentrations in ground water are greater than about $1 \mathrm{mg} / \mathrm{L}$. Identifying various anaerobic redox conditions (in which DO concentrations are less than $1 \mathrm{mg} / \mathrm{L}$ ) is more difficult. If nitrate concentrations exceed about $0.5 \mathrm{mg} / \mathrm{L}$ in anaerobic ground water, then nitrate reduction is likely. If anaerobic ground water lacks nitrate, and if reduced manganese (Mn(II)) or iron $(\mathrm{Fe}(\mathrm{II}))$ concentrations increase along a ground-water flow path, then manganese or iron reduction is indicated.
If anaerobic ground water lacks nitrate, if sulfate (oxidized sulfur) concentrations decrease along a ground-water flow path, and if hydrogen sulfide (reduced sulfur) concentrations exceed about $0.05 \mathrm{mg} / \mathrm{L}$, then sulfate reduction is indicated. Finally, if anaerobic ground water lacks nitrate, sulfate, and hydrogen sulfide, and if methane concentrations exceed about $0.2 \mathrm{mg} / \mathrm{L}$, then carbon dioxide reduction (methanogenesis) is indicated.

Many conditions at the OU-1 landfill complicate the determination of redox conditions. Contaminated ground water beneath landfills often is not at a thermodynamic equilibrium, so several electron-accepting processes may occur simultaneously (Christensen and others, 2000; Cozzarelli and others, 2000). As non-saline ground water mixes with saline ground water in a near shore environment such as the OU-1 landfill, the natural supply of sulfate may increase substantially along a flow path and effectively mask any sulfate consumption by redox reactions. Redox-sensitive constituents such as sulfate, methane, or iron (II) may leach to ground water from many locations in a landfill, and could mask any concentration changes resulting from redox reactions in local ground water. Redox-sensitive constituents such as methane, iron (II), and manganese (II) often migrate away from their point of production, which blurs interpretation of where one redox zone ends and another begins.

Precipitation of iron, manganese, and sulfur constituents also can affect identification of a redox condition at a given point. Redox conditions and concentrations of redoxsensitive constituents can change dramatically over very short distances in contaminant plumes, making it difficult to obtain a ground-water sample representing a single discrete redox zone, even in monitoring wells with relatively short $(5 \mathrm{ft})$ open intervals. These confounding conditions cannot be avoided, but an awareness of the conditions can put the interpretation and use of identified redox zones into the proper perspective.

An alternative method for identifying the predominant redox processes in anaerobic ground water is through direct measurement and interpretation of dissolved $\mathrm{H}_{2}$ concentrations in ground water (Lovely and others, 1994; Chapelle and others, 1995). Hydrogen is continuously produced and consumed by different microorganisms during anaerobic decomposition of organic matter. For natural ground waters, different microorganisms that facilitate nitrate-, manganese-, iron-, sulfate-, and carbon dioxide-reduction reactions exhibit different efficiencies using $\mathrm{H}_{2}$ (Lovely and Goodwin, 1988). Nitrate-reducers are efficient at using $\mathrm{H}_{2}$ and keeping dissolved $\mathrm{H}_{2}$ concentrations in ground water at levels of less than $0.1 \mathrm{nM}$. Manganese- and iron-reducers use $\mathrm{H}_{2}$ less efficiently and keep $\mathrm{H}_{2}$ concentrations between $0.1-0.2$ and $0.2-0.8 \mathrm{nM}$, respectively. Sulfate-reducers are less efficient still and keep $\mathrm{H}_{2}$ concentrations at between 1 and $4 \mathrm{nM}$, and carbon-dioxide reducers are relatively inefficient, resulting in $\mathrm{H}_{2}$ concentrations greater than $5 \mathrm{nM}$. The result of competition for $\mathrm{H}_{2}$ is that each anaerobic redox condition is characterized by a distinct $\mathrm{H}_{2}$ concentration in ground water (Lovely and others, 1994; Chapelle and others, 1995). 
In practice, identifying redox conditions from specific steady-state $\mathrm{H}_{2}$ concentrations is not applicable to all contaminant plumes (Hoehler and others, 1998; Jakobsen and others, 1998; Christensen and others, 2000). Uncertainty in identifying a predominant redox condition from $\mathrm{H}_{2}$ concentrations alone is due to factors such as variation in the iron-oxide minerals that serve as electron acceptors, ground-water temperature effects on equilibrium $\mathrm{H}_{2}$ concentrations, and overlapping and non-exclusive redox conditions. Despite those limitations, $\mathrm{H}_{2}$ concentrations do indicate redox conditions in a relative sense, in that higher $\mathrm{H}_{2}$ concentrations are consistently detected in more strongly reduced ground waters. In terms of contaminant biodegradation, identifying the presence of strongly reducing conditions or knowing where $\mathrm{H}_{2}$ concentrations exceed $1 \mathrm{nM}$ may be more critical than knowing the specific inorganic compound that is the predominant electron acceptor. Quantifying oxidized and reduced inorganic compounds as well as steady-state $\mathrm{H}_{2}$ concentrations throughout a contaminant plume can be used with reasonable confidence to identify favorable and less favorable conditions for contaminant biodegradation.

\section{Biodegradation of Chloroethenes in Ground Water}

Contaminant degradation is the transformation of a chemical compound (the parent compound) into one or more other compounds (daughter products). Biodegradation reactions are mediated by subsurface microorganisms, whereas abiotic degradation reactions are not. Over the past two decades, numerous field and laboratory studies have shown that microbes indigenous to ground-water systems can degrade chloroethenes (see Bradley, 2003 for a historical review). The most relevant degradation mechanisms for TCE, cis-DCE, and $\mathrm{VC}$ are summarized here.

Abiotic degradation of chloroethenes occurs slowly under conditions commonly found in aquifers (Vogel, 1994). Although considerable variability exists, reported half-lives for abiotic degradation of TCE and DCE are as long as 108 years (Jeffers and others, 1989). Abiotic degradation half-lives for TCE can be as short as minutes or a few days in systems amended with an abundance of zero-valent iron (Gillham and O'Hannesin, 1994), but abundant zero-valent iron is uncommon in natural settings.

Biodegradation mechanisms for chloroethenes can be categorized into two groups-reductive dechlorination and microbial oxidation (Bradley, 2003). The occurrence and efficiency of chloroethene biodegradation are sensitive to the redox conditions of ground water (table 2). Reductive dechlorination mechanisms are most favorable under strongly reducing redox conditions (sulfate reduction and methanogenesis), and are most efficient for biodegradation of the highly chlorinated compounds PCE and TCE. Reductive dechlorination of the parent compounds PCE and TCE to form the daughter products cis-DCE and VC commonly occurs in anaerobic ground water. The potential for reductive dechlorination of VC to form ethane and ethene is less common and requires strongly reducing redox conditions.

Table 2. Potential relative efficiency of chloroethene biodegradation through reductive dechlorination or microbial oxidation as a function of ground-water reduction-oxidation (redox) conditions (from Bradley, 2003).

[Abbreviations: PCE, tetrachloroethene; TCE, trichloroethene; cis-DCE, cis-1,2-dichloroethene; VC, vinyl chloride; -, indicates no evidence for this mechanism under this redox condition; $\mathrm{RD}$, reductive dechlorination; $\mathrm{MO}$, microbial oxidation]

\begin{tabular}{ccccccc}
\hline \multirow{2}{*}{ Contaminant } & Biodegradation & \multicolumn{5}{c}{ Predominant redox condition } \\
\cline { 3 - 7 } mechanism & Aerobic & $\begin{array}{c}\text { Manganese } \\
\text { reduction }\end{array}$ & $\begin{array}{c}\text { Iron } \\
\text { reduction }\end{array}$ & $\begin{array}{c}\text { Sulfate } \\
\text { reduction }\end{array}$ & Methanogenesis \\
\hline \multirow{2}{*}{$\mathrm{PCE}$} & $\mathrm{RD}$ & - & Good & Good & Excellent & Excellent \\
& $\mathrm{MO}$ & Fair $^{1}$ & - & - & - & - \\
$\mathrm{TCE}$ & $\mathrm{RD}$ & - & Fair & Good & Good & Excellent \\
& $\mathrm{MO}$ & Good $^{1}$ & - & - & - & - \\
cis-DCE & $\mathrm{RD}$ & Poor & Poor & Poor & Fair & Good \\
& $\mathrm{MO}$ & Excellent & Good & Poor & Poor & Poor \\
& $\mathrm{RD}$ & Poor & Poor & Poor & Fair & Fair \\
& $\mathrm{MO}$ & Excellent & Excellent & Excellent & Good & Good $^{2}$ \\
\hline
\end{tabular}

\footnotetext{
${ }^{1}$ Aerobic cometabolism only-considered to be a transient mechanism.

${ }^{2}$ Associated with humic-acids reduction rather than methanogenic activity.
} 
In contrast, microbial oxidation mechanisms are most favorable under aerobic or mildly reducing redox conditions (manganese and iron reduction), and are most efficient for biodegradation of the less-chlorinated compounds cis-DCE and VC. Widespread occurrence of microbial oxidation mechanisms is not as well documented as that of reductive dechlorination, in large part because the oxidation daughter products carbon dioxide and chloride are not uniquely diagnostic to chloroethene biodegradation. The potential for microbial oxidation mechanisms under aerobic conditions is substantial where an anaerobic contaminant plume encounters aerobic water (such as at a discharge point to surface water). Likewise, the potential for microbial oxidation of $\mathrm{VC}$ and $c i s$-DCE under anaerobic conditions is substantial in contaminant plumes where redox conditions are only mildly reducing.

\section{Evaluation of Biodegradation}

In the previous USGS evaluation of natural attenuation at OU-1 (Dinicola and others, 2002), biodegradation was determined to be responsible for significantly reducing the contaminant mass at OU-1, although natural attenuation overall was not effective enough in 2000 to meet quantitative remediation goals. Those goals were not met because of the relatively short distance between the landfill and the adjacent marsh, and because of extremely high chloroethene concentrations at a few locations beneath the landfill.

For this report, the 2001-04 data were examined for evidence of continued biodegradation of chloroethenes. Geochemical data and redox conditions were examined to determine if any changes occurred that could result in either more or less efficient biodegradation. Changes in absolute and relative concentrations of contaminants were examined as direct evidence of continued biodegradation. The rate at which the contaminant mass at OU-1 was degraded in ground water and the rate at which contaminants were discharged to surface water during 2004 were calculated and compared to rates previously calculated using 1999-2000 data.

\section{Geochemical Data and Predominant Redox Conditions}

The June 2004 and previous geochemical data collected by USGS at OU-1 (Dinicola and others, 2002; Dinicola, 2003; 2004; Dinicola and Huffman, 2004) are shown in table 6 (at back of report). The predominant redox conditions shown in $\underline{\text { table } 6}$ were inferred using all geochemical data collected and best professional judgment. For convenience in following the discussion, the sampled wells and piezometers are grouped by location and aquifer. "Upgradient" sites are the two upper aquifer wells and one intermediate aquifer well upgradient from the landfill. "Northern plantation" and "southern plantation" sites are all upper aquifer wells and piezometers in or near the respective phytoremediation plantations. "Intermediate aquifer" sites are all intermediate aquifer wells downgradient from the landfill. No intermediate aquifer wells are in the footprint of the former landfill.

At the upgradient wells within the upper aquifer (wells MW1-3 and MW1-20), predominant redox conditions from 1998 to 2004 varied between aerobic, iron-reducing, and sulfate-reducing (table 6). Dissolved organic carbon concentrations consistently were less than $2 \mathrm{mg} / \mathrm{L}$, and methane concentrations were consistently less than $0.3 \mathrm{mg} / \mathrm{L}$. Although these wells are upgradient from the landfill, they are downgradient from the military base industrial and office areas and are near stormwater swales; therefore, upper-aquifer water flowing into OU-1 is not pristine. In the upgradient well in the intermediate aquifer (MW1-33), redox conditions were consistently aerobic. Well MW1-33 is in a forested area downgradient from low density off-base residential areas and does not appear to be influenced by local land use.

At the northern plantation sites, predominant redox conditions in shallow ground water were consistently anaerobic during 1996-2004 (table 6). The specific redox conditions ranged from iron-reducing to sulfate-reducing, although the widespread detection of methane (0.22-7.4 mg/L during 2004) indicated methanogenic conditions also were present. Dissolved organic carbon concentrations in the northern part of the landfill (6.7-27 mg/L in 2004) were consistently greater than concentrations measured in upgradient wells, indicating that the landfill is a source of organic substrate essential for reductive dechlorination. Throughout the northern plantation and vicinity, no consistent trends developed in predominant redox conditions or in most redox related geochemical concentrations since 1996.

At the southern plantation sites, predominant redox conditions in shallow ground water also were consistently anaerobic during 1996-2004 (table 6). The specific redox conditions ranged from iron/manganese-reducing to methanogenic, although mildly reducing conditions were more common than strongly reducing conditions. Dissolved organic carbon concentrations in the southern part of the landfill (2.7-36 mg/L during 2004) also were consistently greater than concentrations measured in upgradient wells. Similar to the northern plantation, no consistent trends developed in predominant redox conditions or in most redox related geochemical concentrations since 1996 throughout the southern plantation. 
At the intermediate aquifer sites, predominant redox conditions were consistently anaerobic during 1996-2004 (table 6). For intermediate aquifer wells at the downgradient margin of the landfill (1MW-4, MW1-25, MW1-28, and MW1-29), the specific redox conditions ranged from iron/ manganese-reducing to methanogenic with iron-reducing conditions measured most frequently. For intermediate aquifer wells northwest of the tide flats (MW1-38 and MW1-39), the specific redox conditions ranged from iron-reducing to methanogenic. Redox conditions at the only contaminated well northwest of the tide flats (MW1-39) were predominantly sulfate-reducing. Dissolved organic carbon concentrations in the intermediate aquifer downgradient from the landfill (2.4-15 mg/L during 2004) were consistently greater than concentrations measured in the upgradient well MW1-33. Similar to the upper aquifer, no consistent trends in redox conditions or in most redox-related geochemical concentrations developed since 1996 in intermediate aquifer wells downgradient from the landfill.

Overall, no widespread changes in geochemical data and redox conditions occurred since 1996 at OU-1 that could result in either more or less efficient biodegradation. Redox conditions varied substantially from year to year (particularly in the upper aquifer), but no consistent trend developed towards either more strongly or more mildly reducing conditions. Occasional detections of sulfide, widespread detections of methane, and frequent detections of dissolved $\mathrm{H}_{2}$ at concentrations greater than $1 \mathrm{mg} / \mathrm{L}$ indicated that the strongly reducing conditions of sulfate-reduction and methanogenesis were present in much of the upper aquifer beneath the landfill and in parts of the intermediate aquifer downgradient from the landfill. These redox conditions are most favorable for reductive dechlorination of all chloroethenes (table 2). Mildly reducing conditions, which are moderately favorable for reductive dechlorination of TCE but are less favorable for reductive dechlorination of $c i s-\mathrm{DCE}$ and $\mathrm{VC}$, are present in the remainder of the contaminated parts of the upper and intermediate aquifers. Mildly reducing ground water is favorable for microbial oxidation of $\mathrm{VC}$ (and to a lesser extent, cis-DCE), so the lack of strongly reducing conditions and reductive dechlorination throughout the system likely would not lead to an accumulation of VC in downgradient wells.

\section{Chloroethene Concentration Trends and Biodegradation}

CVOC data collected by the USGS from piezometers, selected wells, and passive-diffusion samplers at OU-1 in June 2004 are shown in table 3. Data from wells and piezometers are grouped and presented as upgradient, northern plantation, southern plantation, and intermediate aquifer. CVOC data from all passive-diffusion samplers are presented in a final group labeled "marsh (passive-diffusion samplers)" in table 3 . Complete analytical results (including data qualifiers) are available from the USGS National Water Information System web site http://nwis.waterdata.usgs.gov/ wa/nwis/qwdata. A cumulative summary of the 1991-2000 CVOC data collected by various agencies at OU-1 is available in Dinicola and others (2002). Cumulative summaries of the 2001-03 CVOC data collected by the Navy and the USGS are available in CH2M Hill Constructors, Inc. (2005) and Dinicola and Huffman (2004), respectively. Selected historical chloroethene data previously published are presented graphically in this report. In the following discussions of trends in contaminant concentrations, there is uncertainty that results from relatively few samples available at some sites, and from varying minimum reporting levels for selected contaminants. Trends in contaminant concentrations are uncertain because of the relatively few sample results available for some sites and the various minimum reporting levels for selected contaminants.

In the upper aquifer (including all upgradient, northern plantation, southern plantation, and marsh sites), the 2004 concentrations of total CVOCs (table 3 and fig. 5) generally were less than those measured in 1999-2000 (fig. 6). The term "total CVOCs" as used in this report is the sum of the six chloroethene and three chloroethane compounds of concern at OU-1. Lower concentrations were most apparent throughout the northern plantation, in the northern part of the southern plantation, and in areas outside the plantation boundaries. Lower concentrations in areas outside the plantation boundaries confirm that contaminant attenuation processes other than phytoremediation are active at the landfill. The 2004 total CVOC concentrations remained exceptionally high $(49,000-103,000 \mu \mathrm{g} / \mathrm{L})$ in the southern part of the southern plantation at sites MW1-4, P1-7, and P1-9. Non-aqueous phase liquids in the subsurface likely caused both the persistence and magnitude of CVOC concentrations in that area. USGS did not determine CVOC concentrations in the intermediate aquifer during 2004, but the Navy measured concentrations similar to those measured since 2000.

\section{Upgradient}

Chloroethenes were not detected at upgradient wells MW1-10 and MW1-33 since monitoring began at those sites in 1996 (table 3 and Dinicola and others, 2002; Dinicola and Huffman, 2004; and CH2M Hill Constructors, Inc., 2005). TCE was detected once during 1999 at upgradient well MW1-3 at a concentration of $0.70 \mu \mathrm{g} / \mathrm{L}$, although no other chloroethenes have been detected there since monitoring began in 1991 (Dinicola and others, 2002; Dinicola and Huffman, 2004; and CH2M Hill Constructors, Inc., 2005). 
Table 3. Concentrations of selected volatile organic compounds in water samples collected by the U.S. Geological Survey from selected monitoring wells, piezometers, and passive-diffusion samplers at Operable Unit 1, Naval Undersea Warfare Center, Division Keyport, Washington, 2004.

[Volatile organic compounds (VOCs); PCE, tetrachloroethene; TCE, trichloroethene; cis-DCE, cis-1,2-dichloroethene; trans-DCE, trans-1,2-dichloroethene; VC, vinyl chloride; TCA, 1,1,1-trichloroethane; 1,1-DCA, 1,1-dichloroethane; CA, chloroethane; 1,1-DCE, 1,1-dichloroethene; Total BTEX, sum of benzene, toluene, ethylbenzene, and xylene concentrations; Total CVOCs, sum of all chloroethenes and chloroethene concentrations shown in table. Methane data are presented for passive-diffusion samplers only. Abbreviations: $\mu \mathrm{g} / \mathrm{L}$, microgram per liter; <, actual value is less than value shown at various method reporting limits; nd, not detected; -, not analyzed]

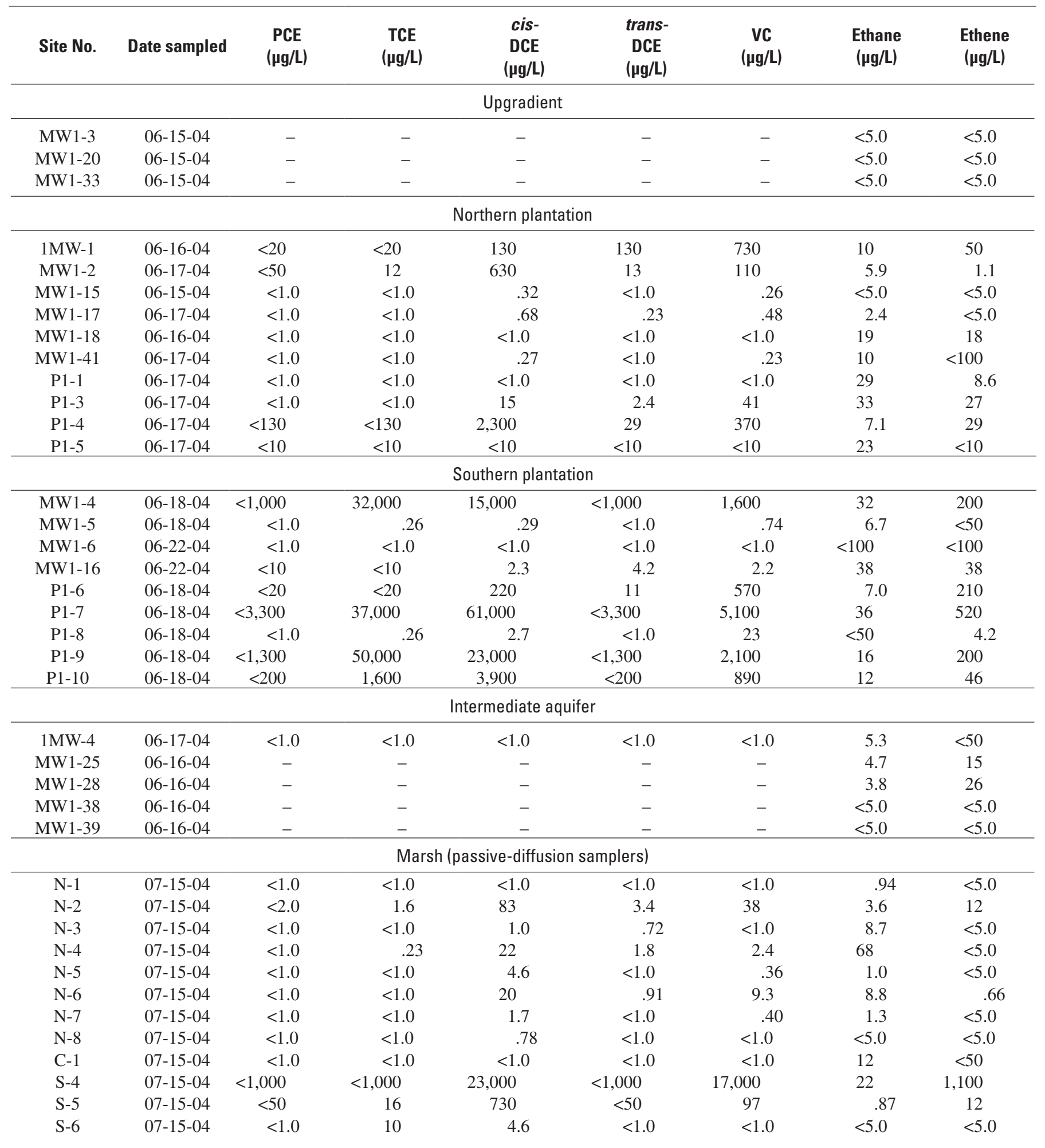


Table 3. Concentrations of selected volatile organic compounds in water samples collected by the U.S. Geological Survey from selected monitoring wells, piezometers, and passive-diffusion samplers at Operable Unit 1, Naval Undersea Warfare Center, Division Keyport, Washington, 2004.—Continued

[Volatile organic compounds (VOCs); PCE, tetrachloroethene; TCE, trichloroethene; cis-DCE, cis-1,2-dichloroethene; trans-DCE, trans-1,2-dichloroethene; VC, vinyl chloride; TCA, 1,1,1-trichloroethane; 1,1-DCA, 1,1-dichloroethane; CA, chloroethane; 1,1-DCE, 1,1-dichloroethene; Total BTEX, sum of benzene, toluene, ethylbenzene, and xylene concentrations; Total CVOCs, sum of all chloroethenes and chloroethene concentrations shown in table. Methane data are presented for passive-diffusion samplers only. Abbreviations: $\mu \mathrm{g} / \mathrm{L}$, micrograms per liter; <, actual value is less than value shown at various method reporting limits; nd, not detected; -, not analyzed]

\begin{tabular}{|c|c|c|c|c|c|c|c|c|}
\hline Site No. & Date sampled & $\begin{array}{c}\text { Methane } \\
\text { (mg/L) }\end{array}$ & $\begin{array}{c}\text { TCA } \\
(\mu \mathrm{g} / \mathrm{L})\end{array}$ & $\begin{array}{c}1,1-D C A \\
(\mu \mathrm{g} / \mathrm{L})\end{array}$ & $\begin{array}{c}\mathrm{CA} \\
(\mu \mathrm{g} / \mathrm{L})\end{array}$ & $\begin{array}{c}\text { 1,1-DCE } \\
(\mu \mathrm{g} / \mathrm{L})\end{array}$ & $\begin{array}{l}\text { Total } \\
\text { BTEX } \\
\text { ( } \mu \mathrm{g} / \mathrm{L})\end{array}$ & $\begin{array}{c}\text { Total } \\
\text { CVOCs } \\
\text { ( } \mu \mathrm{g} / \mathrm{L})\end{array}$ \\
\hline \multicolumn{9}{|c|}{ Upgradient } \\
\hline MW1-3 & 06-15-04 & - & - & - & - & - & - & - \\
\hline MW1-20 & $06-15-04$ & - & - & - & - & - & - & - \\
\hline 1MW-1 & 06-16-04 & - & $<20$ & 11 & $<40$ & $<20$ & nd & 1,000 \\
\hline MW1-2 & 06-17-04 & - & $<50$ & $<50$ & $<100$ & $<50$ & nd & 770 \\
\hline MW1-15 & $06-15-04$ & - & $<1.0$ & $<1.0$ & .88 & $<1.0$ & 30 & 1.5 \\
\hline MW1-17 & 06-17-04 & - & $<1.0$ & $<1.0$ & $<2.0$ & $<1.0$ & .31 & 1.4 \\
\hline MW1-18 & 06-16-04 & - & $<1.0$ & $<1.0$ & $<2.0$ & $<1.0$ & nd & nd \\
\hline $\mathrm{P} 1-5$ & 06-17-04 & - & $<10$ & $<10$ & 23 & $<10$ & 4.5 & 23 \\
\hline \multicolumn{9}{|c|}{ Southern plantation } \\
\hline MW1-4 & 06-18-04 & - & $<1,000$ & $<1,000$ & $<2,000$ & $<1,000$ & nd & 49,000 \\
\hline MW1-5 & $06-18-04$ & - & $<1.0$ & .36 & 3 & $<1.0$ & 0.92 & 4.6 \\
\hline MW1-6 & $06-22-04$ & - & $<1.0$ & $<1.0$ & 1.7 & $<1.0$ & 1.9 & 1.7 \\
\hline MW1-16 & $06-22-04$ & - & $<10$ & 590 & 290 & $<10$ & 370 & 900 \\
\hline P1-6 & 06-18-04 & - & $<20$ & 200 & 88 & $<20$ & nd & 1,100 \\
\hline $\mathrm{P} 1-7$ & $06-18-04$ & - & $<3,300$ & $<3,300$ & $<6,700$ & $<3,300$ & nd & 103,000 \\
\hline P1-8 & 06-18-04 & - & $<1.0$ & $<1.0$ & $<2.0$ & $<1.0$ & nd & 20 \\
\hline P1-9 & 06-18-04 & - & $<1,300$ & $<1,300$ & $<2,700$ & $<1,300$ & nd & 75,000 \\
\hline \multicolumn{9}{|c|}{ Marsh (passive-diffusion samplers) } \\
\hline N-1 & $07-15-04$ & 53 & $<1.0$ & $<1.0$ & $<2.0$ & $<1.0$ & nd & nd \\
\hline $\mathrm{N}-2$ & $07-15-04$ & 290 & $<2.0$ & .76 & $<4.0$ & $<2.0$ & nd & 130 \\
\hline $\mathrm{N}-3$ & $07-15-04$ & 190 & $<1.0$ & $<1.0$ & $<2.0$ & $<1.0$ & 0.43 & 2 \\
\hline $\mathrm{N}-4$ & $07-15-04$ & 110 & $<1.0$ & $<1.0$ & $<2.0$ & $<1.0$ & 1.1 & 26 \\
\hline $\mathrm{N}-5$ & $07-15-04$ & 10 & $<1.0$ & $<1.0$ & $<2.0$ & $<1.0$ & nd & 5 \\
\hline N-6 & $07-15-04$ & 180 & $<1.0$ & $<1.0$ & $<2.0$ & $<1.0$ & .25 & 30 \\
\hline $\mathrm{N}-7$ & $07-15-04$ & 110 & $<1.0$ & $<1.0$ & $<2.0$ & $<1.0$ & nd & 2 \\
\hline $\mathrm{N}-8$ & $07-15-04$ & 1.9 & $<1.0$ & $<1.0$ & $<2.0$ & $<1.0$ & nd & 1 \\
\hline $\mathrm{C}-1$ & $07-15-04$ & 2,100 & $<1.0$ & $<1.0$ & $<2.0$ & $<1.0$ & .71 & nd \\
\hline S-4 & $07-15-04$ & 530 & $<1,000$ & $<1,000$ & $<2,000$ & $<1,000$ & nd & 40,000 \\
\hline S-5 & $07-15-04$ & 43 & $<50$ & $<50$ & $<100$ & $<50$ & nd & 840 \\
\hline S-6 & $07-15-04$ & 100 & $<1.0$ & $<1.0$ & $<2.0$ & $<1.0$ & nd & 15 \\
\hline
\end{tabular}




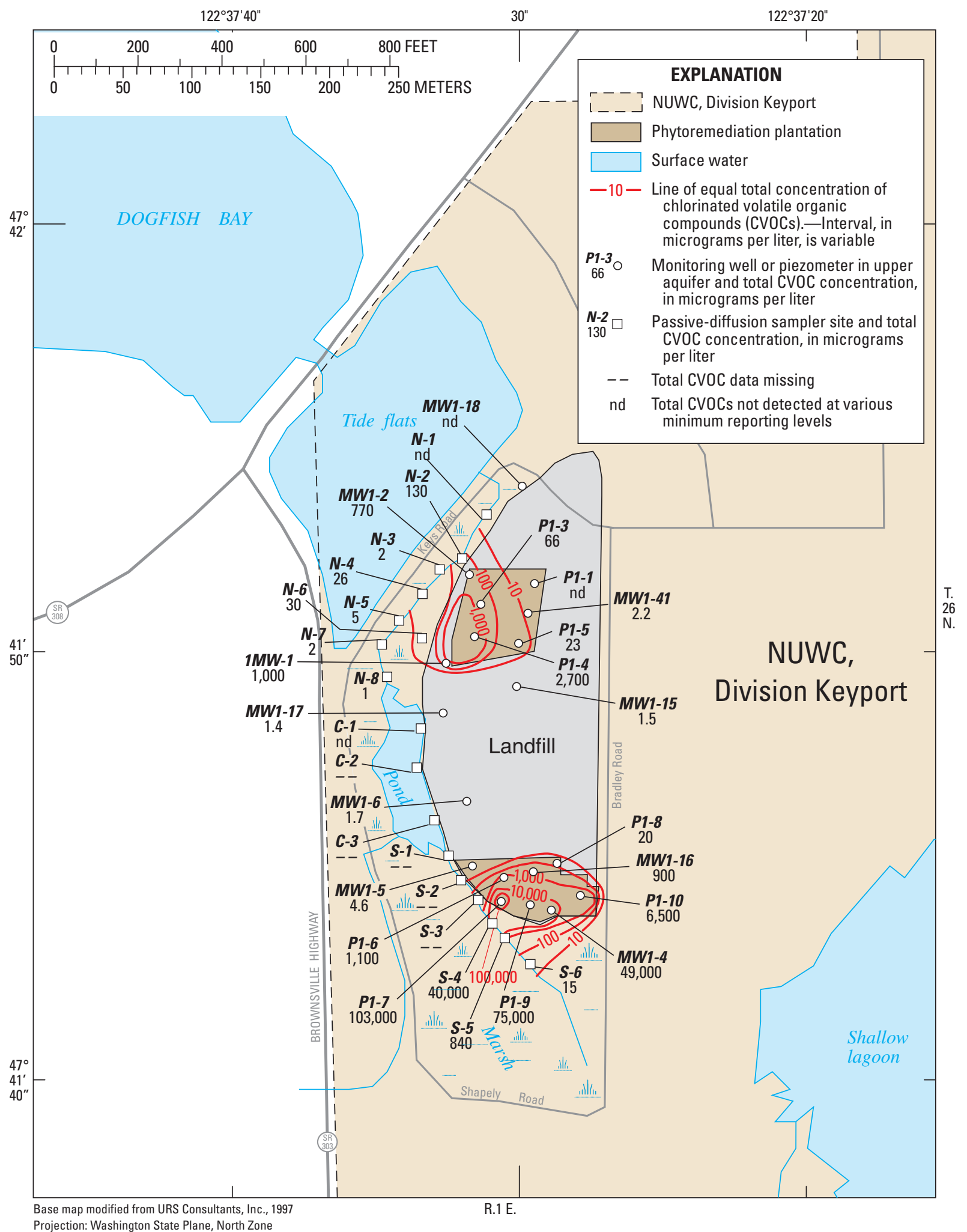

Figure 5. Total concentrations of chlorinated volatile organic compounds (CVOCs) in upper-aquifer ground water at Operable Unit 1, Naval Undersea Warfare Center (NUWC), Division Keyport, Washington, 2004. 


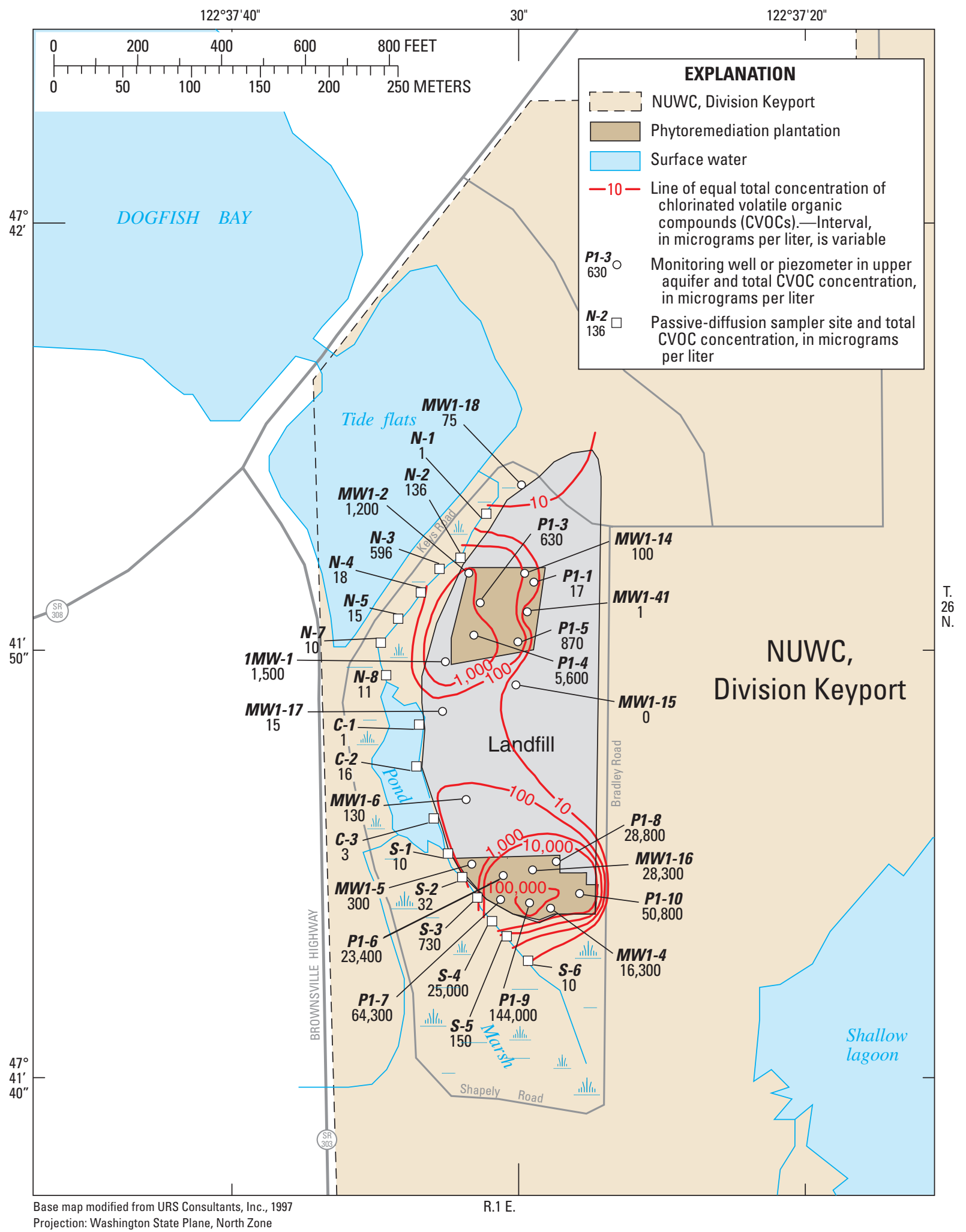

Figure 6. Concentrations of total chlorinated volatile organic compounds (CVOCs) in upper-aquifer ground water at Operable Unit 1, Naval Undersea Warfare Center (NUWC), Division Keyport, Washington, 1999 (wells and piezometers) and 2000 (passive-diffusion samplers). 


\section{Northern Plantation and Adjacent Marsh}

Chloroethene concentrations at the three most contaminated sample sites in the northern plantation (1MW-1, MW1-2, and P1-4) generally decreased over the periods of record (fig. 7). Chloroethene concentrations at piezometers P1-1, P1-3, and P1-5 in the northern plantation have also decreased substantially since 1999 (table 3 and Dinicola and others, 2002; Dinicola and Huffman, 2004; and CH2M Hill Constructors, Inc., 2005).

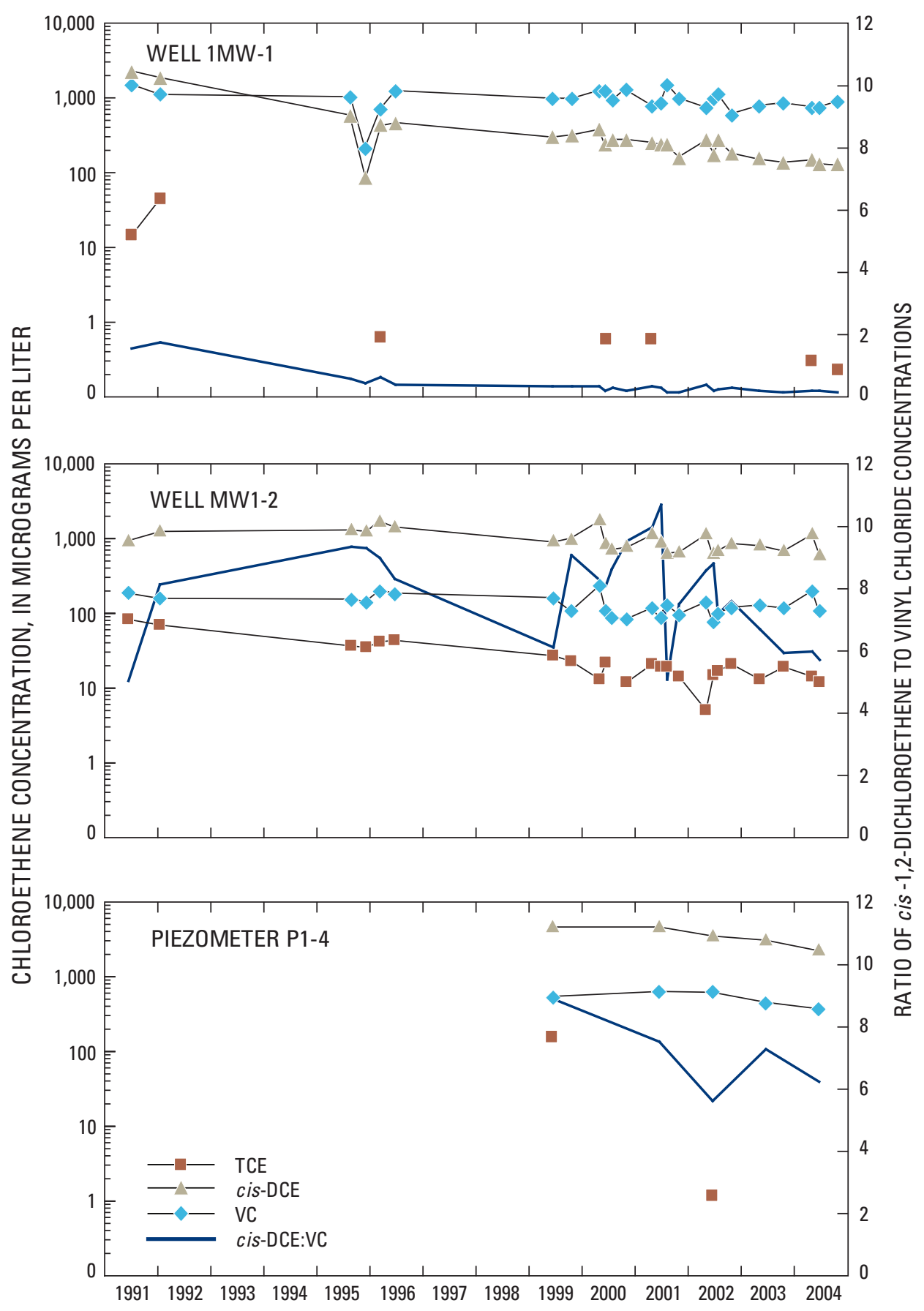

Figure 7. Chloroethene concentration and ratio of cis-1,2-dichloroethene to vinyl chloride concentrations at northern plantation sites 1MW-1, MW1-2, and P1-4 at Operable Unit 1, Naval Undersea Warfare Center, Division Keyport, Washington, 1991-2004. 
Decreasing concentration ratios of more highly chlorinated compounds to less chlorinated compounds (TCE:cis-DCE and cis-DCE:VC) over time indicate that biodegradation is a substantial cause for the downward trend in contaminant concentrations beneath the northern plantation. The TCE:cis-DCE ratios for ground water beneath the northern plantation exceeded 1 at only two sites (P1-1 and P1-5) during only one year (Dinicola and others, 2002; Dinicola and Huffman, 2004; and CH2M Hill Constructors, Inc., 2005). At all other sites, TCE:cis-DCE ratios were less than 0.1 and have decreased over time, indicating continued reductive dechlorination of TCE. The cis-DCE: VC ratios, as well as cis-DCE concentrations, decreased over time at most northern plantation sites (fig. 7) indicating continued reductive dechlorination of cis-DCE. Although VC concentrations have not consistently decreased throughout the vicinity of the northern plantation, they also have not increased despite the continued production of $\mathrm{VC}$ through reductive dechlorination of $c i s$-DCE. VC appears to be biodegraded at a rate similar to its rate of production. Reductive dechlorination of $\mathrm{VC}$ is reliably indicated by ethane plus ethene concentrations as high as $60 \mu \mathrm{g} / \mathrm{L}$ in the northern plantation (table 3). Microbial oxidation of VC (and cis-DCE to a lesser extent) also may be occurring in the iron- and manganese-reducing parts of the aquifer, but no unique diagnostic byproducts reliably indicate that process.

Chloroethenes migrating from beneath the northern plantation are further biodegraded beneath the marsh before discharging to surface water. Chloroethene concentrations decreased between 2000 and 2004 in six of the eight passive-diffusion sampler sites near the northern plantation (marsh sites N-1 through N-5, N-7, and N-8; table 3), and the concentration at the site with the highest 2000 concentration $(570 \mu \mathrm{g} / \mathrm{L}$ at N-3) decreased to about $2 \mu \mathrm{g} / \mathrm{L}$ in 2004 (table 3). The Navy measured VC concentrations in a seep $50 \mathrm{ft}$ north of well MW1-2 that decreased from a high of $420 \mu \mathrm{g} / \mathrm{L}$ during 1996 to less than $0.5 \mu \mathrm{g} / \mathrm{L}$ during 2004 (CH2M Hill Constructors, Inc., 2005). Methane concentrations during 2004 at the passive-diffusion sampler sites were as high as $290 \mathrm{mg} / \mathrm{L}$ (table 3), suggesting the presence of methanogenic redox conditions in marsh ground water that are favorable for reductive chlorination of all chloroethenes. Ethane plus ethene concentrations as high as $68 \mu \mathrm{g} / \mathrm{L}$ at passive-diffusion sampler sites near the northern plantation are reliable evidence for reductive dechlorination of $\mathrm{VC}$ (table 3 ).

\section{Southern Plantation and Adjacent Marsh}

Chloroethene concentrations at all sampling sites in the northern part of the southern plantation (MW1-5, MW1-16, P1-6, P1-8, and P1-10) decreased by one to three orders of magnitude over the periods of record (fig. 8; data for MW1-5 not shown). In contrast, chloroethene concentrations at sites in the southern part of the southern plantation (MW1-4, P1-7, and $\mathrm{P} 1-9)$ remained high with no consistent downward trend (fig. 9).

Dilution may cause some of the measured decrease in chloroethene concentrations in the northern part of the southern plantation. Coincidental downward trends in chloride (table 6) and chloroethene concentrations (fig. 8) were measured at sites MW1-16, P1-6, P1-8, and P1-10, although no downward trend in chloride concentrations developed at the upgradient site MW1-20. These data indicate that ground-water recharge with relatively low chloride concentrations led to increased contaminant dilution in the northern part of the southern plantation. Recharge presumably is the result of pavement removal for tree planting in 1999. However, chloroethene concentrations decreased proportionally more compared to chloride concentrations, so the observed downward trends in chloroethene concentrations can be partly attributed to increased dilution and partly attributed to biodegradation. In contrast, chloride concentrations were relatively consistent over time in the southern part of the southern plantation at sites MW1-4, P1-7, and P1-9 (table 6), which does not indicate an increase in dilution over time.

Although TCE and other chloroethene concentrations decreased over time in ground water beneath the northern part of the southern plantation (fig. 8), no corresponding decreases in TCE:cis-DCE ratios have been measured to clearly indicate continued reductive dechlorination of TCE (calculated from data in Dinicola and others, 2002; Dinicola and Huffman, 2004; and CH2M Hill Constructors, Inc., 2005). Continued reductive dechlorination of $c i s$-DCE was indicated by decreasing cis-DCE: VC ratios (fig. 8), and reductive dechlorination of $\mathrm{VC}$ is reliably indicated by ethane plus ethene concentrations as high as $217 \mu \mathrm{g} / \mathrm{L}$ (table 3). A likely explanation for those data is that reductive dechlorination of all chloroethenes continued, but that a continuing (and waning) source of dissolved TCE from residual non-aqueous phase contaminants was present. As was noted for the northern plantation, microbial oxidation of VC (and cis-DCE to a lesser extent) also may be occurring in the iron- and manganese-reducing portions of the aquifer, but there are no unique microbial-oxidation byproducts by which to diagnose that process. To reliably attribute the measured contaminant concentration trends to phytoremediation activities is difficult because of the substantial inter-annual variation in chloroethene concentrations measured at site MW1-16 (fig. 8), the only nearby site with pre-1999 data. The post-1999 variation at site MW1-16 in part may be due to more frequent than annual sampling and to different sampling techniques used by the Navy and the USGS. 


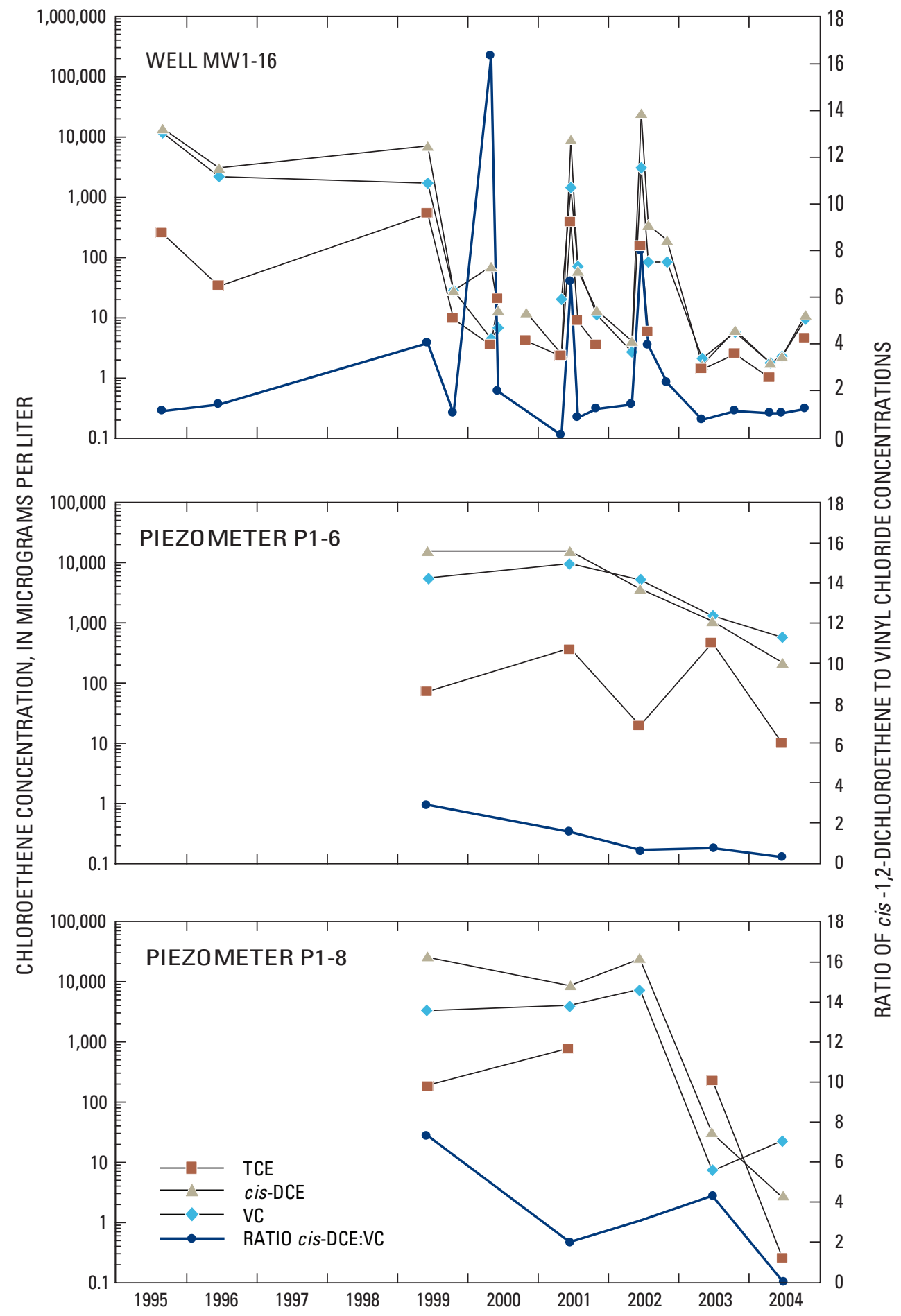

Figure 8. Chloroethene concentration and ratio of cis-1,2-dichloroethene to vinyl chloride concentrations at southern plantation sites MW1-16, P1-6, P1-8, and P1-10 at Operable Unit 1, Naval Undersea Warfare Center, Division Keyport, Washington, 1995-2004. 


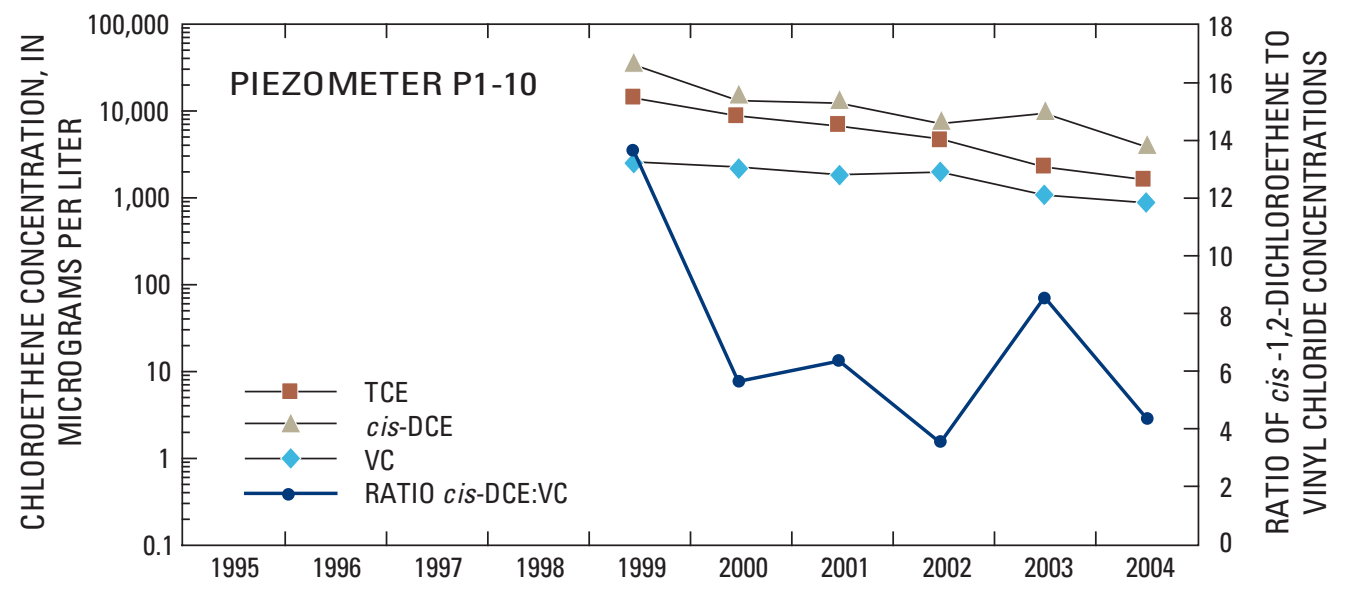

Figure 8.-Continued.

In contrast to all other parts of the landfill, chloroethene concentrations in the southern part of the southern plantation have been exceptionally high, with no consistent decrease (fig. 9). No downward trends were revealed in TCE:cis-DCE or cis-DCE: VC ratios at sites MW1-4, P1-7, and P1-9 to clearly indicate continuing reductive dechlorination of TCE, even though reductive dechlorination to non-chlorinated end products was reliably indicated by ethane plus ethene concentrations ranging from 216 to $556 \mu \mathrm{g} / \mathrm{L}$ (table 3). A likely explanation for those data is that reductive dechlorination of all chloroethenes is ongoing, but that a continuing persistent source of dissolved TCE is present.

Beneath the marsh near the southern plantation, chloroethene concentrations increased between 2000 and 2004 at all three passive-diffusion sampler sites with data available for both years (marsh sites S-4 through S-6, table 3). Chloroethene concentrations in ground water discharging to the 100-foot long reach in the southern part of the marsh between sites S-4 and S-6 were at least 300 times greater than concentrations in ground water discharging elsewhere in the marsh (table 3). Total CVOC concentration in the most contaminated passive-diffusion sampler site (S-4) increased from 25,000 to 40,000 $\mu \mathrm{g} / \mathrm{L}$ (Dinicola and others, 2002, and table 3 ). For comparison, the highest total CVOC concentrations measured beneath the landfill ( $\mathrm{P} 1-7)$ increased from 75,000 to $103,000 \mu \mathrm{g} / \mathrm{L}$ between 2000 and 2004 (Dinicola and others, 2002, and table 3), a proportionally similar amount. TCE:cis-DCE and cis-DCE:VC ratios between P1-7 in the landfill (fig. 9) and S-4 in the marsh (ratios not shown) decreased substantially during both 2000 and 2004, indicating substantial reductive dechlorination of both TCE and cis-DCE between the landfill and the marsh.
Reductive dechlorination of $\mathrm{VC}$ beneath the marsh is indicated by the 2004 ethane plus ethene concentrations of $1,122 \mu \mathrm{g} / \mathrm{L}$ at S-4 in the marsh and $556 \mu \mathrm{g} / \mathrm{L}$ at P1-7 in the landfill (table 3). Methane concentrations at S-4 in the marsh during 2004 were $530 \mathrm{mg} / \mathrm{L}$, indicating methanogenic redox conditions in marsh ground water that are highly favorable for reductive chlorination of chloroethenes.

Considering the southern plantation as a whole, the only clear and consistent trends are decreasing chloroethene concentrations measured at the northern part of the southern plantation. Both dilution and biodegradation are reducing concentrations in that vicinity, and there appears to be only a small and decreasing amount of non-aqueous phase chloroethene source, likely TCE, to continue replenishing ground-water contamination. Biodegradation also is active in the southern part of the southern plantation, but chloroethene concentrations did not decrease. A more substantial amount of non-aqueous phase chloroethene source appears to continue replenishing ground-water contamination in that vicinity, and no measurable increase in dilution followed the 1999 asphalt removal. Although chloroethene concentrations increased during 2004 at the marsh passive-diffusion sampler sites, the 2000 and 2004 data were not sufficient to define a trend in contaminant migration beyond the southern plantation. Chloroethene concentrations in marsh surface water were measured at least twice per year by the Navy at site MA-12 just upgradient from the marsh pond (fig. 10). Concentrations increased between 1996 and early 1999 (after pavement removal), decreased through late 2003, and began to increase again during 2004. More data are needed to determine if the 2004 concentrations at site MA-12 represent an upward trend in contaminant discharge to the marsh. 


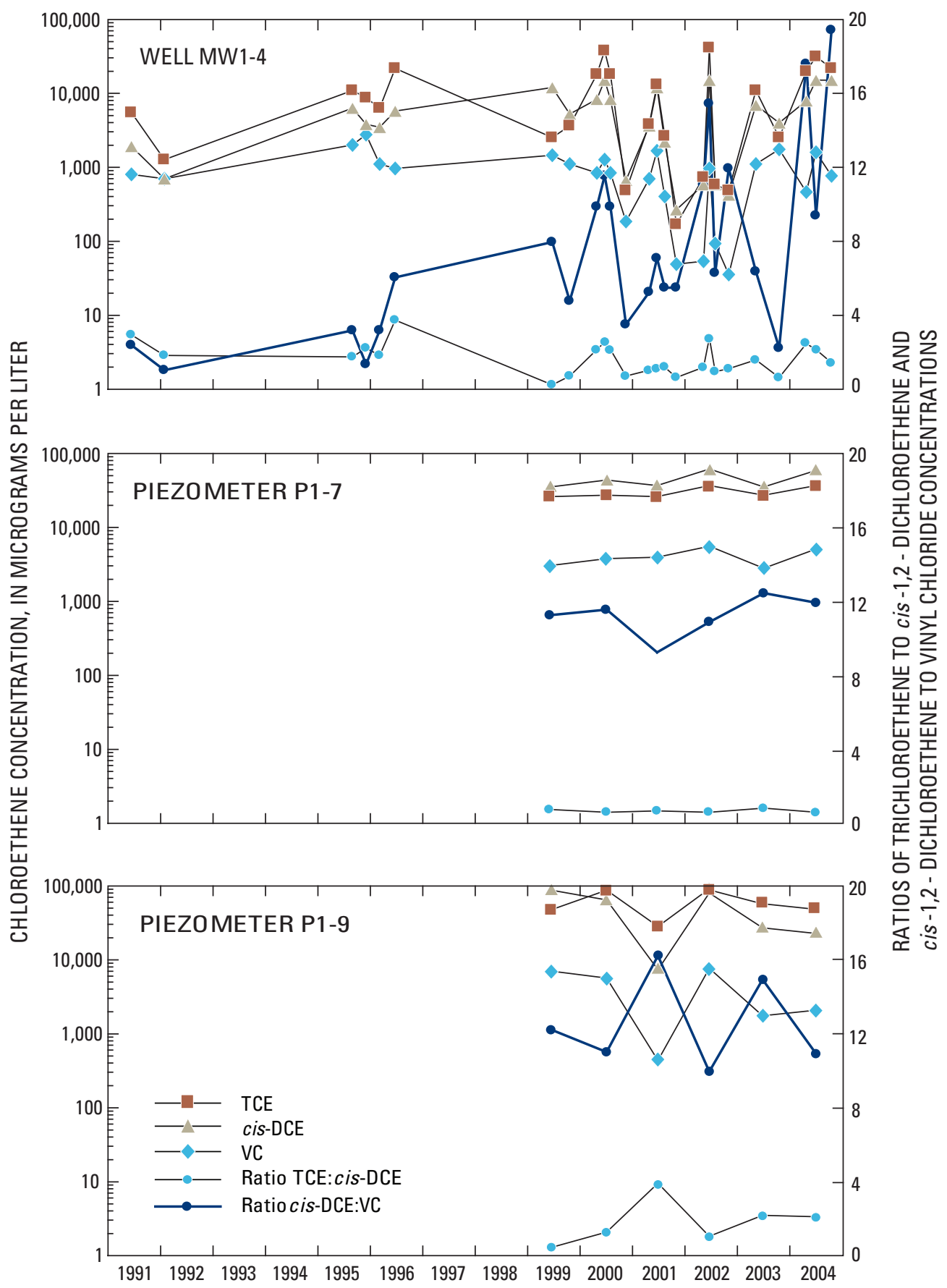

Figure 9. Chloroethene concentration and ratios of trichloroethene to cis-1,2-

dichloroethene and cis-1,2-dichloroethene to vinyl chloride concentrations at southern plantation sites MW1-4, P1-7, and P1-9 at Operable Unit 1, Naval Undersea Warfare Center, Division Keyport, Washington, 1991-2004. 


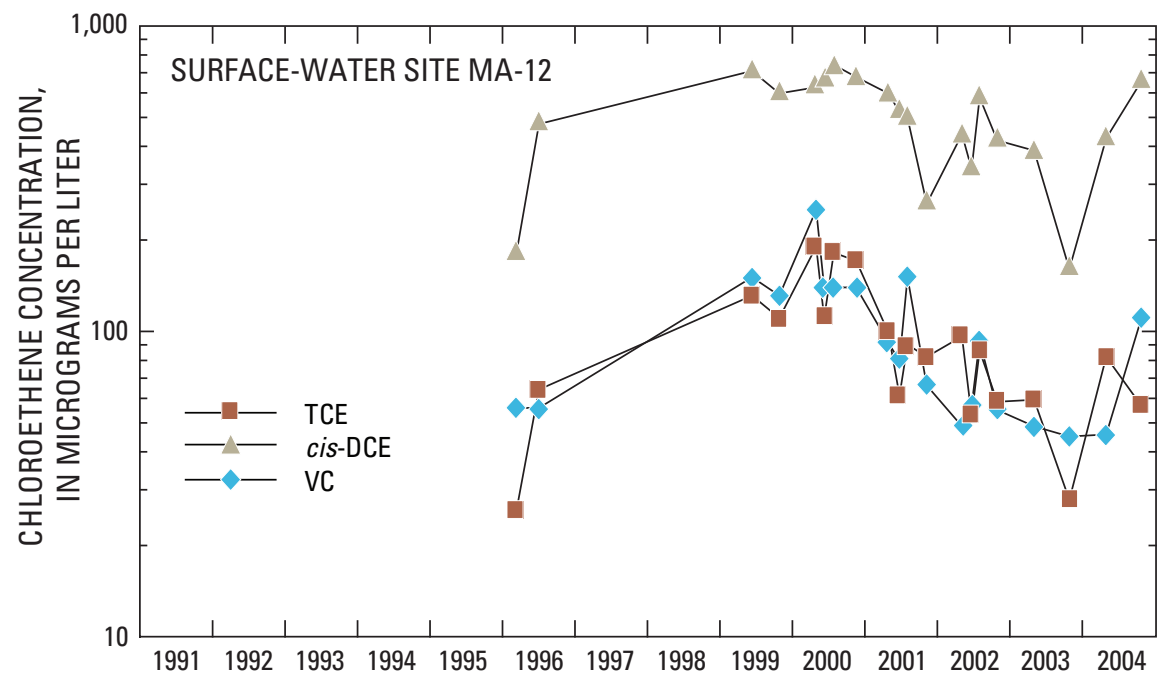

Figure 10. Chloroethene concentration at surface-water site MA-12 at Operable Unit 1, Naval Undersea Warfare Center, Division Keyport, Washington, 1996-2004.

\section{Intermediate Aquifer}

TCE concentrations measured in the intermediate aquifer near the downgradient margin of the landfill at well MW1-25 decreased between 1996 and 2004 (fig. 11). TCE concentrations also generally decreased at well MW1-28 with the exception of a measurement in 2002. Concentrations of cis-DCE and VC measured in those wells increased slightly between 1996 and 2000, but from 2001 to 2004, concentrations decreased or remained the same. Farther downgradient in the intermediate aquifer beneath the Highway 308 causeway (wells MW1-38 and MW1-39), TCE was never detected (table 3 and Dinicola and others, 2002; Dinicola and Huffman, 2004; and CH2M Hill Constructors, Inc., 2005). Concentrations less than $2 \mu \mathrm{g} / \mathrm{L}$ of cis-DCE and $\mathrm{VC}$ were consistently detected in the shallower of the adjacent intermediate aquifer wells (MW1-39) with no consistent trend in those concentrations (Dinicola and others, 2002; Dinicola and Huffman, 2004; and CH2M Hill Constructors, Inc., 2005).

Biodegradation of chloroethenes in the most contaminated part of the intermediate aquifer (represented by wells MW1-25 and MW1-28) was uncertain based on the 1995-2000 data (Dinicola and others, 2002). Data through 2004 reliably indicate that some reductive dechlorination in the intermediate aquifer occurred. In addition to decreases in TCE concentrations between 2000 and 2004 at wells MW1-25 and MW1-28 (fig. 11), TCE:cis-DCE ratios decreased from 0.02 to 0.005 at MW1-25 and from 0.001 to 0.0004 at MW1-28 during that period (calculated from data in table 3 and CH2M Hill Constructors, Inc., 2005). Those trends indicate reductive dechlorination of TCE. Reductive dechlorination of cis-DCE and VC is less certain. Concentrations of cis-DCE decreased moderately since 2002 after a more substantial increase measured between
1996 and 2000. In contrast, cis-DCE:VC ratios consistently increased during 1996-2004 (fig. 10) due to relatively stable VC concentrations. Ethane plus ethene concentrations ranging from 19.7 to $29.8 \mu \mathrm{g} / \mathrm{L}$ at MW1-25 and MW1-28 are reliable evidence for reductive dechlorination of VC (table 3 ), but those concentrations are low compared to many upper aquifer sites. Together, those data indicate some, but not substantial, biodegradation. Data from the contaminated well at Highway 308 (MW1-39) neither support nor refute ongoing biodegradation. VC concentrations during 1996-2004 ranged between 0.76 and $2 \mu \mathrm{g} / \mathrm{L}$, and cis-DCE concentrations ranged between 0.32 and $0.56 \mu \mathrm{g} / \mathrm{L}$ (CH2M Hill Constructors, Inc., 2005).

\section{Chloroethene Mass Degradation Rates and Discharge to Surface Water}

The rates at which the chloroethene mass at OU-1 was degraded in ground water in the upper aquifer or was discharged to surface water were estimated using 2004 data and compared to estimates made using 1999-2000 data. Rates were calculated according to a flux-based approach that estimated the flux of chloroethenes across two parallel transects oriented perpendicular to ground-water flow direction in the upper aquifer (fig. 12). The upgradient (landfill) transect follows the western and southern margin of the landfill, and the downgradient (marsh) transect follows the creek and pond in the adjacent marsh. The difference in chloroethene fluxes estimated for the two transects is an estimate of the mass of chloroethenes degraded in ground water over a given duration. The mass of non-dissolved chloroethenes in the landfill (non-aqueous phase liquids) is unknown, so calculations considered only the dissolved 


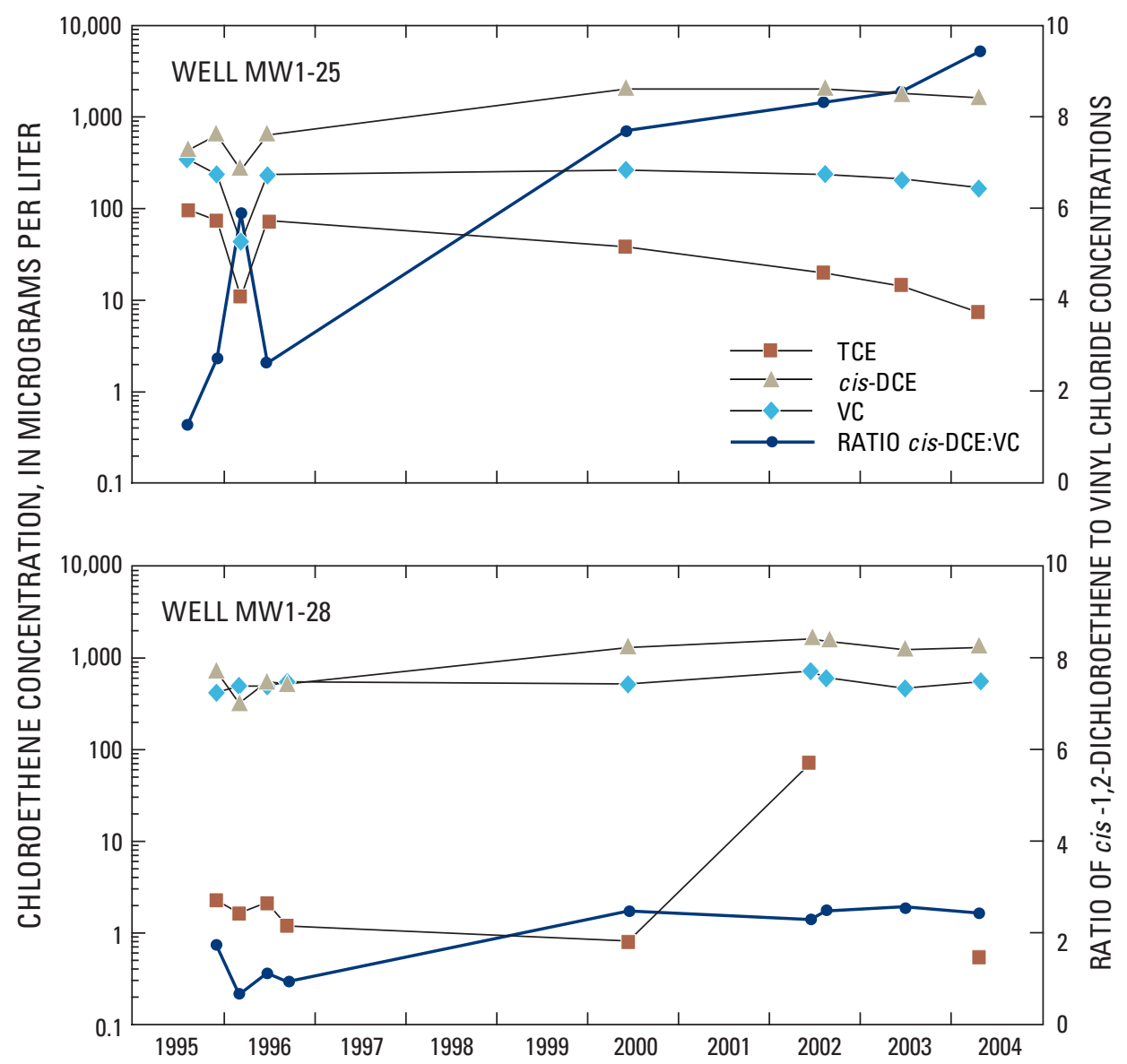

Figure 11. Chloroethene concentration at intermediate aquifer sites MW1-25 and MW1-28 at Operable Unit 1, Naval Undersea Warfare Center, Division Keyport, Washington, 1995-2004.

contaminants mass. Not enough data are available to estimate chloroethene mass degradation in the intermediate aquifer or chloroethene discharge to surface water from the intermediate aquifer.

To better characterize chloroethene degradation and discharge in different parts of the study area, chloroethene fluxes were calculated for five pairs of parallel sub-transects along the landfill and marsh transects. The upgradient landfill transect is bounded by well MW1-18 to the north and well MW1-4 to the south, and is divided into sub-transects as indicated in table 4 and figure 12. The downgradient transect is bounded by the passive-diffusion sampler sites N-1 and S-6, and is divided into similar sub-transects as indicated in table 4 and figure 12. Chloroethene fluxes were calculated by multiplying estimated ground-water fluxes by measured chloroethene concentrations in wells or passive-diffusion samplers on the transects. Ground-water fluxes across each landfill sub-transect were estimated by URS Consultants Inc. (1997b) using measured or estimated transmissivity and hydraulic gradient data. It was assumed that the ground-water fluxes across corresponding marsh sub-transects were the same as those estimated for the landfill sub-transects, and that all ground water discharged to marsh surface water immediately after passing the marsh transect. Measured chloroethene concentrations at sample sites along each sub-transect were proportionally weighted according to distance represented by each site to calculate average concentrations for each sub-transect.

The chloroethene mass degraded in ground water per day was calculated as the difference between fluxes across the landfill transect and across the marsh transect. Calculations for DCE (including both cis- and trans-isomers) assumed that the mass of degraded TCE resulted in the formation of a molar equivalent amount of DCE through reductive dechlorination, and the calculations for VC assumed that the mass of degraded DCE resulted in the formation of a molar equivalent amount of VC through reductive dechlorination. The amount of PCE available in the landfill to degrade into TCE was considered negligible. The rate of chloroethene discharge to surface water was conservatively assumed to be the chloroethene flux calculated for the marsh transect. Calculations were done using measured chloroethene data collected in 1999-2000 and 2004. The 1999-2000 results presented in this report differ somewhat from those reported by Dinicola and others (2002) because the average chloroethene concentrations for sub-transects were calculated for a different set of wells. 


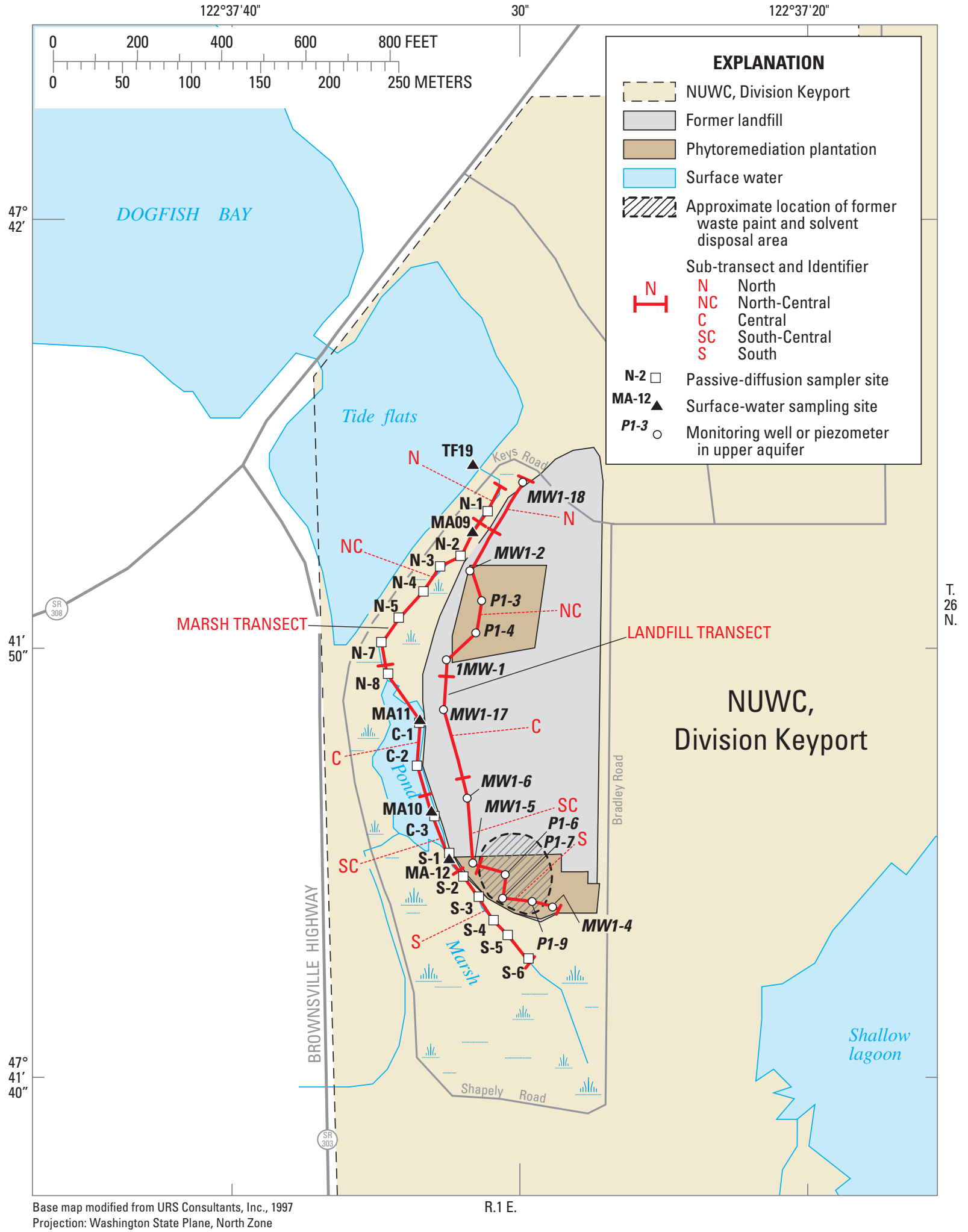

Figure 12. Transects and sub-transects where mass chloroethene fluxes were estimated for the upper aquifer at Operable Unit 1, Naval Undersea Warfare Center (NUWC), Division Keyport, Washington. 
Table 4. Estimated chloroethene mass degradation rates and fluxes to surface water at Operable Unit 1, Naval Undersea Warfare Center, Division Keyport, Washington, 1999-2000 and 2004.

[All values are in grams per day. Abbreviations: TCE, trichloroethene; cis-DCE, cis-1,2-dichloroethene; VC, vinyl chloride; g/d, gram per day; <, actual value is less than value shown]

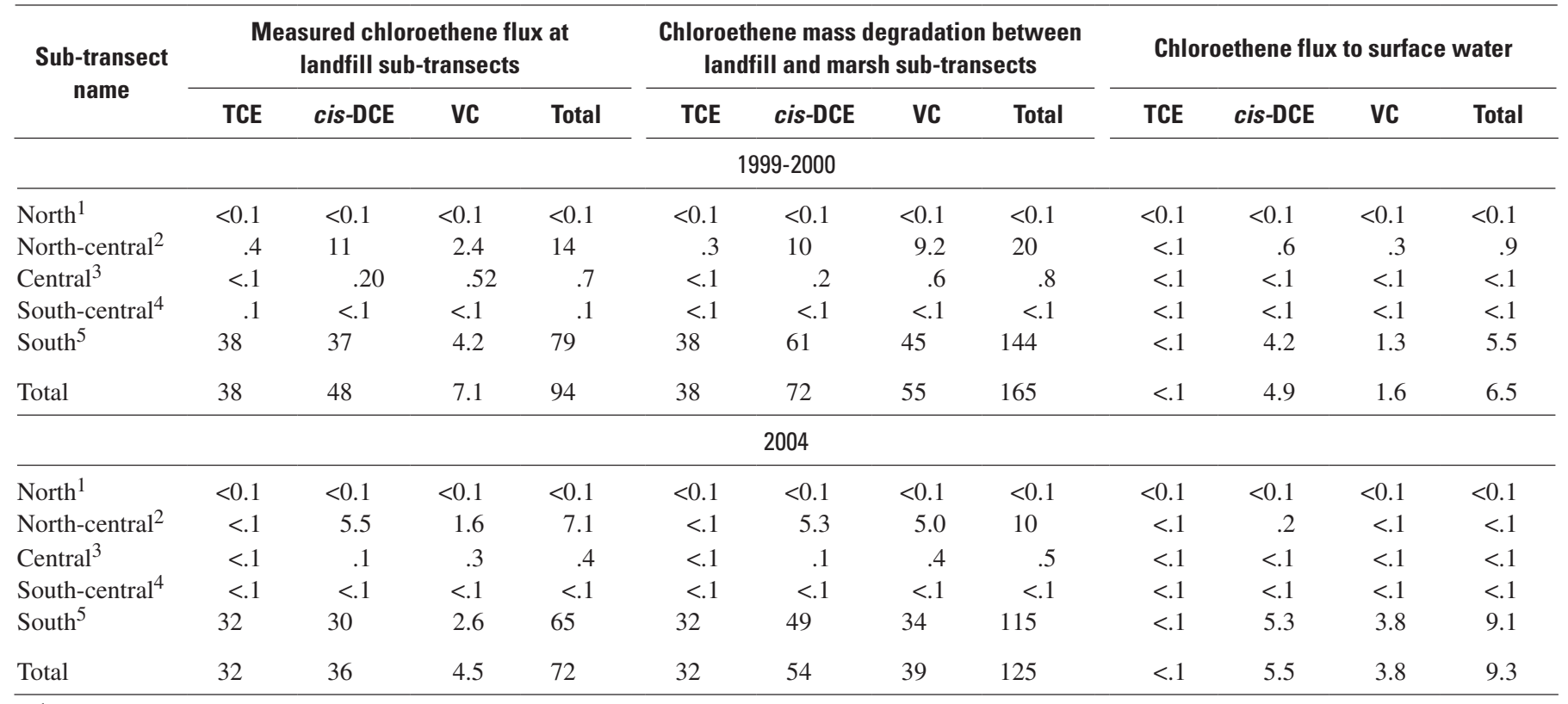

${ }^{1}$ Sample site in landfill sub-transect is MW1-18; sample site in parallel marsh sub-transect is N-1.

${ }^{2}$ Sample sites in landfill sub-transect are MW1-2, P1-3,P1-4, 1MW-1; sample sites in parallel marsh sub-transect are N-2, N-3, N-4, N-5, N-7.

${ }^{3}$ Sample sites in landfill sub-transect are 1MW-1, MW1-17; sample sites in parallel marsh sub-transect are N-8, C-1, C-2.

${ }^{4}$ Sample sites in landfill sub-transect are MW1-6, MW1-5; sample sites in parallel marsh sub-transect are C-3, S-1.

${ }^{5}$ Sample sites in landfill sub-transect are MW1-5, P1-6, P1-7, P1-9, MW1-4; sample sites in parallel marsh sub-transect are S-2, S-3, S-4, S-5, S-6.

Flux calculations required the following assumptions:

- Ground-water sampling sites represented conditions throughout the study area-This assumption is reasonable for the relatively dense spatial network of wells, piezometers, and passive-diffusion samplers in the study area, although the vertical distribution of contaminants was not as well represented; uniform contaminant concentrations throughout the saturated thickness of the upper aquifer were assumed.

- Ground-water flow, the supply of dissolved contaminants, and contaminant degradation rates were all at steady-state conditions-Steady-state ground-water flow is a reasonable assumption based on water-level data measured since 1996, and post-1999 water-level data, which do not indicate that phytoremediation has affected the flow and ground-water gradients (URS Greiner, Inc., 2000; CH2M Hill Constructors, Inc., 2004). A relatively steady supply of dissolved contaminants is indicated by stable or slowly decreasing CVOC concentrations in the most contaminated landfill wells. Steady-state contaminant degradation rates are suggested by generally consistent redox conditions between 1996 and 2004.
- No substantial contaminant loss in ground water was caused by sorption, volatilization, plant uptake beneath the phytoremediation plantations, or advective transport to the intermediate aquifer-Volatilization losses probably were minimal because volatilization of chemicals from ground water is greatly constrained by the rate of vapor transport upward through the unsaturated zone. Initially, sorption losses may have been significant in the organic-rich marsh sediments, but contaminants flowed through those sediments for many decades so the bulk of the sorption capacity probably was filled long ago. Contaminant uptake by plants from the unsaturated zone was detected beneath the plantations, but no evidence was detected indicating that contaminants are drawn out of the saturated zone (URS Greiner, Inc., 2002). Most of the advective transport of contaminants from the upper to the intermediate aquifer likely occurs upgradient from the landfill transect, so that advective transport will not affect the mass degradation calculations. The only downward gradient for ground-water flow between the upper and intermediate aquifers is beneath the northeastern one-third of the landfill, and an upward gradient is beneath the remainder of the landfill (URS Consultants, Inc., 1997a). Any minor contaminant losses through these mechanisms are implicitly included in the calculated mass degradation rates. 
Flux estimates based on 2004 data indicate that most dissolved-phase chloroethene mass in the upper aquifer beneath the landfill was degraded before it discharged to surface water (table 4). Of the $72 \mathrm{~g} / \mathrm{d}$ of chloroethene flux measured at the landfill transect during 2004, only 13 percent $(9.3 \mathrm{~g} / \mathrm{d})$ migrated and discharged to surface water in the marsh; therefore, the total chloroethene flux was reduced by 87 percent due to biodegradation in the upper aquifer. Flux estimates based on 1999-2000 data indicated that a larger dissolved contaminant flux from the landfill (94 g/d) was reduced by a larger percentage ( 93 percent) in the upper aquifer and resulted in less chloroethene discharged to surface water $(6.5 \mathrm{~g} / \mathrm{d})$ during 1999-2000.

During 1999-2000 and 2004, the chloroethene with the greatest calculated flux into marsh surface water was cis-DCE, followed by VC and TCE. However, the mass degradation rates for $c i s$-DCE (54 and $72 \mathrm{~g} / \mathrm{d}$ ) also were the greatest, followed by VC and TCE. The rate of DCE degradation was about 50 percent greater than the flux of DCE across the landfill transect, but DCE still reached the marsh because it was continually created by reductive dechlorination of TCE. The rate of $\mathrm{VC}$ degradation was about 10 times greater than the flux of VC across the landfill transect, but VC still reached the marsh because it was continually created by reductive dechlorination of DCE. During both periods, nearly all TCE flux to the marsh also was from the southern plantation. Most DCE and VC flux to the marsh also was from the southern plantation, although measurable fluxes also came from the northern plantation.

Although the mass degradation rates were greater during 1999-2000 and the rates of discharge to surface-water were greater during 2004, it cannot be concluded that biodegradation has become less effective. Flux estimates are extremely sensitive to measured chloroethene concentrations at the few highly contaminated wells and passive-diffusion samplers in and near the southern plantation, and the interannual variability in measured concentrations at those sites was high. Estimated mass degradation rates were exceptionally high during 1999-2000, in large part due to the large mass of degradable chloroethenes. At P1-9, for example, total CVOC concentrations were 160,000 $\mu \mathrm{g} / \mathrm{L}$ during June 2000 and 75,000 $\mu \mathrm{g} / \mathrm{L}$ during June 2004 (figs. 5 and $\underline{6}$ ). Similarly, calculated rates for chloroethene discharge to surface water were exceptionally high during 2004 in large part because of exceptionally high chloroethene concentrations measured at site $\mathrm{S}-4$, where total CVOC concentrations were 25,000 $\mu \mathrm{g} / \mathrm{L}$ during June 2000 and 40,000 $\mu \mathrm{g} / \mathrm{L}$ during June 2004 (figs. 5 and $\underline{6}$ ). In contrast to the site S-4 data, total chloroethene concentrations measured in surface water at MA-12 were $920 \mu \mathrm{g} / \mathrm{L}$ in June 2000, compared to 560 and
$830 \mu \mathrm{g} / \mathrm{L}$ in April and October 2004 (CH2M Hill Constructors, Inc., 2005). Too few data are available from site $\mathrm{S}-4$ to permit characterization of the interannual variability in chloroethene concentrations.

The accuracy of estimated mass degradation rates was indirectly assessed by evaluating the accuracy of estimated chloroethene flux to surface water in the southern part of the marsh. The accuracy of estimated chloroethene fluxes to surface water presented in table 4 was evaluated by comparing those estimates to an independent estimate of chloroethene flux to surface water in the southern part of the marsh. The independent estimate was determined by multiplying measured chloroethene concentrations in surface water at site MA-12 by estimated surface-water discharge at site MA-12 (table 5). No surface-water discharged into the marsh from surrounding areas during non-storm periods, so surface-water flow in the marsh was entirely due to ground-water discharge. Therefore, surface water flowing past site MA-12 included $0.2 \mathrm{gal} / \mathrm{min}$ of contaminated ground water from the landfill combined with $1.1 \mathrm{gal} / \mathrm{min}$ of uncontaminated ground water that discharged to the marsh from areas south of the marsh creek (URS Consultants Inc., 1997b).

The TCE flux to marsh surface water shown in table 4 was substantially underestimated for 1999-2000 and 2004, indicating that the TCE mass degradation rates in table 4 likely were overestimated. Clearly, not all TCE flux from the landfill was represented by the measured concentrations from the passive-diffusion sampler sites. The measured TCE concentration in surface water at site MA-12 in June 2000 was $110 \mu \mathrm{g} / \mathrm{L}$, while the highest TCE concentration measured in passive-diffusion samplers during 2000 was only $49 \mu \mathrm{g} / \mathrm{L}$ (Dinicola and others, 2002). The highest probable TCE concentration in passive-diffusion samplers during 2004 was poorly quantified [reported at less than $1,000 \mu \mathrm{g} / \mathrm{L}$ for $\mathrm{S}-4$ (table 3)], so a similar comparison could not be made.

In contrast to TCE, the flux of VC to marsh surface water shown in table 4 was overestimated by nearly 600 percent for 2004, indicating that the VC mass degradation rates in table 4 likely were underestimated. The measured VC concentrations in surface water at site MA-12 during 2000 and 2004 ranged from 46 to $250 \mu \mathrm{g} / \mathrm{L}$ (fig. 10), although the highest VC concentrations measured in passive-diffusion samplers ranged from 5,600 to 17,000 $\mu \mathrm{g} / \mathrm{L}$ (Dinicola and others, 2002 and table 3$)$. There appears to be additional attenuation of $\mathrm{VC}$ concentrations between shallow ground water in the marsh and site MA-12. The likely mechanisms behind that attenuation include microbial degradation of $\mathrm{VC}$ in the upper $2 \mathrm{ft}$ of organic-rich marsh sediments, and volatilization of VC from surface water before it reaches site MA-12. 
Table 5. Chloroethene flux comparison to southern marsh surface water estimated from ground-water flux and chloroethene concentrations from passive-diffusion samplers and surface-water flux and chloroethene concentrations from surface water, Operable Unit 1, Naval Undersea Warfare Center, Division Keyport, Washington, 1999-2000 and 2004.

[Water flux: Ground-water and surface-water flux estimates (from URS, Inc., 1997b, Appendix F). Measured chloroethene concentrations: For ground water, weighted average of concentrations for marsh passive-diffusion sampler sites S-4-S-6 for 2004 (table 4 and Dinicola and others, 2002), and for marsh passivediffusion sampler sites S-2-S-6 for 2000 (CH2M Hill Constructors, Inc., 2005); for surface water, concentrations from site MA-12 (CH2M Hill Constructors, Inc., 2005). Estimated chloroethene flux: For ground water, "South" sub-transect pair (table 5, fig. 12); for surface water, measured concentration multiplied by water flux. Abbreviations: TCE, trichloroethene; cis-DCE, cis-1,2-dichloroethene; VC, vinyl chloride; gal/min, gallon per minute; $\mu \mathrm{g} / \mathrm{L}$, microgram per liter; $\mathrm{g} / \mathrm{d}$, gram per day]

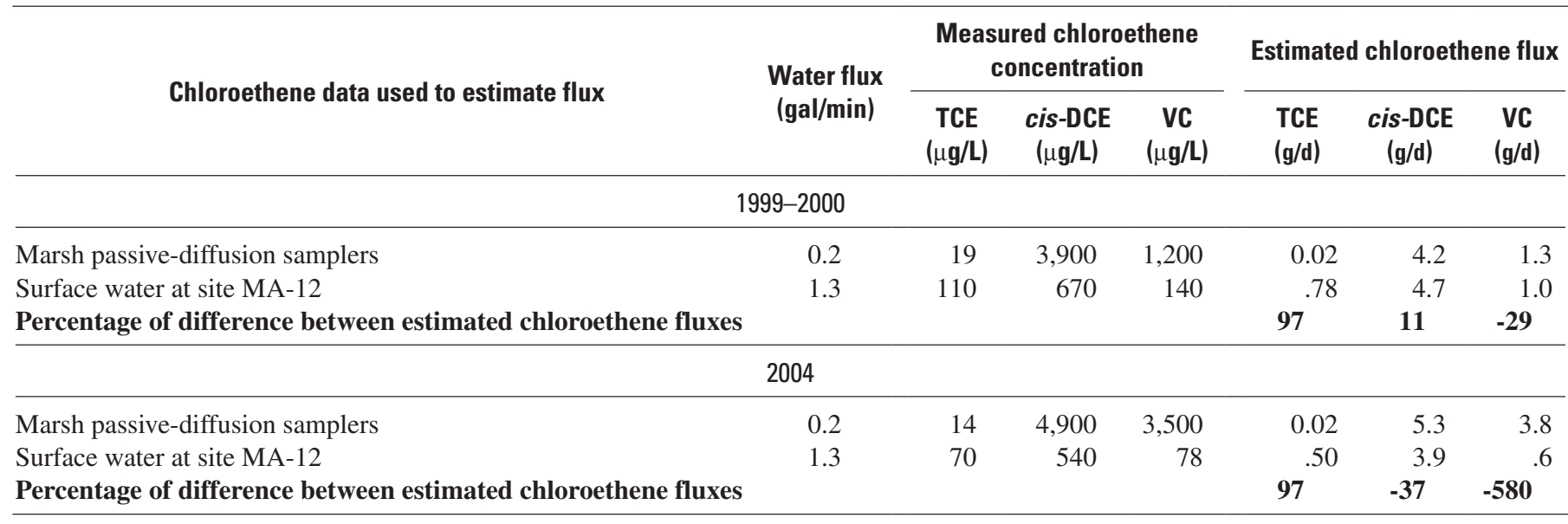

\section{Summary and Conclusions}

Geochemical and contaminant concentration data from 2001 to 2004 indicate that substantial biodegradation of chlorinated volatile organic compounds (CVOCs) in ground water beneath the landfill at Operable Unit 1 (OU-1) has continued. Contaminant concentrations in ground water decreased throughout much of the site, and biodegradation is a primary cause for the decrease. However, dissolved-phase contaminant concentrations in the tens of milligrams per liter persisted in a localized area in the southern part of the southern phytoremediation plantation. A residual source of non-aqueous phase liquid chloroethenes likely is present in that area, and biodegradation was only partly effective at reducing the dissolved-phase contaminants that are generated from that source. During 2004, chloroethenes continued to discharge to the adjacent marsh at concentrations that exceeded quantitative remediation goals for the site. Chloroethene concentrations in ground water discharging to a 100-foot long reach in the southern part of the marsh were at least 300 times greater than concentrations in ground water discharging elsewhere in the marsh.

No widespread changes in ground-water redox conditions were measured since 2000 that could result in either more or less efficient biodegradation. Anaerobic redox conditions have prevailed at the site, and despite inter-annual variation, no consistent trend developed towards either more strongly or more mildly reducing conditions. Detections of sulfide, widespread detection of methane, and frequent detection of dissolved hydrogen at concentrations greater than 1 nanomolar indicated that the strongly reducing conditions most favorable for reductive dechlorination of chloroethenes are present beneath much of the landfill and in the intermediate aquifer downgradient from the site. The mildly reducing conditions detected at the remainder of the site are less favorable for biodegradation through reductive dechlorination, but are more favorable for microbial oxidation of vinyl chloride (VC) and cis-1,2-dichloroethene (cis-DCE).

The 2004 concentrations of total CVOCs and chloroethenes in the upper aquifer generally were less than concentrations measured in 1999-2000. Lower concentrations were measured throughout the northern phytoremediation plantation, in the northern part of the southern plantation, and in areas outside of the plantations. CVOC concentrations for 2004 were as high as 103,000 micrograms per liter $(\mu \mathrm{g} / \mathrm{L})$ in the southern part of the southern plantation where non-aqueous phase liquids likely are present. Chloroethene concentrations measured in the intermediate aquifer near the downgradient margin of the landfill decreased less consistently between 2000 and 2004. At the farthest downgradient (western) monitoring points beneath the Highway 308 causeway, TCE remained undetected in the intermediate aquifer, and cis-DCE and VC consistently were measured at concentrations between 0.3 and $2 \mu \mathrm{g} / \mathrm{L}$. 
Biodegradation was a substantial cause for the downward trend in contaminant concentrations beneath the northern plantation. Continued reductive dechlorination of trichloroethene (TCE), cis-DCE, and VC was indicated, and reductive dechlorination to non-chlorinated end-products was reliably indicated by ethane plus ethene concentrations as high as $60 \mu \mathrm{g} / \mathrm{L}$. Microbial oxidation of VC and cis-DCE also may have occurred, but no unique diagnostic byproducts were detected to indicate that process. Chloroethenes migrating from beneath the northern plantation were further biodegraded beneath the adjacent marsh. Chloroethene concentrations at most passive-diffusion sampler sites in the northern part of the marsh decreased between 2000 and 2004, and the highest total CVOC concentration decreased from 570 to $130 \mu \mathrm{g} / \mathrm{L}$. Methane concentrations as much as 290 milligrams per liter at the passive-diffusion sampler sites indicate methanogenic redox conditions in marsh ground water that are favorable for reductive chlorination, and ethane plus ethene concentrations as high as $68 \mu \mathrm{g} / \mathrm{L}$ were reliable evidence for reductive dechlorination to non-chlorinated end-products.

In the northern part of southern plantation, increased dilution over time and biodegradation led to attenuation of CVOC concentrations. TCE and other chloroethene concentrations decreased over time, although no clear indication for reductive dechlorination of TCE exists. Continued reductive dechlorination of cis-DCE and VC were indicated by ethane plus ethene concentrations as high as $217 \mu \mathrm{g} / \mathrm{L}$. The attenuation of chloroethene concentrations was partially counteracted by a localized residual (albeit waning) source of dissolved TCE to ground water.

In contrast to the rest of the site, chloroethene concentrations in the southern part of the southern plantation have remained exceptionally high despite reliable evidence for continued reductive dechlorination of all chloroethene compounds. Data indicate a localized persistent source for dissolved TCE to ground water. Beneath the marsh near the southern plantation, chloroethene concentrations increased during 2000-04 even though reductive dechlorination to non-chlorinated end-products beneath the marsh was indicated by ethane plus ethene concentrations of $1,100 \mu \mathrm{g} / \mathrm{L}$. Methane concentrations during 2004 in the marsh were 530 milligrams per liter, indicating methanogenic redox conditions in marsh ground water, which are highly favorable for reductive chlorination. Increased chloroethene concentrations measured in 2004 beneath the marsh did not clearly indicate an increasing trend because the marsh ground water was sampled only twice. Chloroethene concentrations were more frequently monitored in marsh surface water just downgradient from the southern plantation. Chloroethene concentrations increased immediately after pavement removal from the southern plantation during early 1999, decreased through late 2003, and began to increase again during 2004. More data are needed to determine if the 2004 concentrations at site MA-12 represent an upward trend in contaminant discharge to the marsh.

Flux calculations based on 2004 data indicate that most dissolved-phase chloroethene mass in the upper aquifer beneath the landfill is degraded before discharging to surface water in the adjacent marsh. The total chloroethene flux of 72 grams per day estimated at the landfill transect during 2004 was reduced by 87 percent due to biodegradation in the upper aquifer before discharging to surface water. Most chloroethene flux from the landfill was from the southern plantation. Although the calculated mass degradation rates were greater during 1999-2000 and the discharge to surface-water rates was greater during 2004, the results are extremely sensitive to a few measured chloroethene concentrations at highly contaminated wells and passive-diffusion samplers in the southern plantation. Total chloroethene concentrations measured by the Navy in marsh surface water at site MA-12 actually were higher during 2000 compared to 2004 .

Calculated flux of TCE to marsh surface water was likely underestimated for both 1999-2000 and 2004, indicating that the TCE mass degradation rates were overestimated because not all TCE flux from the landfill was represented by measured concentrations from the passive-diffusion sampler sites. In contrast, the calculated flux of VC to marsh surface water was overestimated by nearly 600 percent for 2004, indicating that the VC mass degradation rates were underestimated. There appears to be additional attenuation of VC concentrations between shallow ground water in the marsh and site MA-12. Likely mechanisms behind that attenuation include microbial degradation of $\mathrm{VC}$ in the upper 2 feet of organic-rich marsh sediments, and volatilization of VC from surface water before reaching site MA-12. Overall, biodegradation of chloroethenes in ground water throughout OU-1 continued through 2004 and prevents most of the mass of dissolved-phase chloroethenes in the upper aquifer beneath the landfill from discharging to surface water. 


\section{References Cited}

American Public Health Association, 1980, Standard methods for the examination of water and wastewater: 15th Edition, Washington, D.C.

Bradley, P.M., 2003, History and ecology of chloroethene biodegradation: A review: Bioremediation Journal, v. 7, no. 2, p. 81-109.

Bradley, P.M., Landmeyer, J.E., and Dinicola, R.S., 1998, Anaerobic oxidation of $\left[1,2-{ }^{14} \mathrm{C}\right]$ dichloroethene under Mn(IV)-reducing conditions: Applied \& Environmental Microbiology, v. 64, no. 4, p. 1560-1562.

Brenton, R.W., and Arnett, T.L., 1993, Methods of analysis by the U.S. Geological Survey National Water Quality Laboratory-Determination of dissolved organic carbon by UV-promoted persulfate oxidation and infrared spectrometry: U.S. Geological Survey Open-File Report 92-480, 12 p.

CH2M Hill Constructors, Inc., 2002, 2001 annual report Operable Unit 1, Area 1, former base landfill, Naval Undersea Warfare Center Division, Keyport, Washington: Prepared under Contract Task Order 0062 for Engineering Field Activity, Northwest, Naval Facilities Engineering Command, Poulsbo, Wash.

CH2M Hill Constructors, Inc., 2003, 2002 annual report Operable Unit 1, Area 1, former base landfill, Naval Undersea Warfare Center Division, Keyport, Washington: Prepared under Contract Task Order 0062 for Engineering Field Activity, Northwest, Naval Facilities Engineering Command, Poulsbo, Wash.

CH2M Hill Constructors, Inc., 2004, 2003 annual report Operable Unit 1, Area 1, former base landfill, Naval Undersea Warfare Center Division, Keyport, Washington: Prepared under Contract Task Order 0062 for Engineering Field Activity, Northwest, Naval Facilities Engineering Command, Poulsbo, Wash.

CH2M Hill Constructors, Inc., 2005, Draft 2004 annual report Operable Unit 1, Area 1, former base landfill, Naval Undersea Warfare Center Division, Keyport, Washington: Prepared under Contract Task Order 0062 for Engineering Field Activity, Northwest, Naval Facilities Engineering Command, Poulsbo, Wash.

Chapelle, F.H., 1992, Ground-water microbiology and geochemistry: John Wiley and Sons, Inc., New York, 424 p. Chapelle, F.H., McMahon, P.B., Dubrovsky, N.M., Fujii, R.F., Oaksford, E.T., and Vroblesky, D.A., 1995, Hydrogen $\left(\mathrm{H}_{2}\right)$ concentrations as an indicator of terminal electron accepting processes (TEAP's) in diverse ground-water systems: Water Resources Research, v. 32, p. 359-371.
Chapelle, F.H., Vroblesky, D.A., Woodward, J.C., and Lovely, D.R., 1997, Practical considerations for measuring hydrogen concentrations in groundwater: Environmental Science and Technology, v. 31, no. 10, p. 2873-2877.

Christensen, T.H., Bjerg, P.L., Banwart, S.A., Jakobsen, R., Heron, G., and Albrechtsen, H.J., 2000, Characterization of redox conditions in groundwater contaminant plumes: Journal of Contaminant Hydrology, v. 45, p. 165-241.

Cozzarelli, I.M., Sulfita, J.M., Ulrich, G.A., Harris, S.H., Scholl, M.A., Schottmann, J.L., and Christenson, S., 2000, Geochemical and microbiological methods for evaluating anaerobic processes in an aquifer contaminated by landfill leachate: Environmental Science and Technology, v. 34, no. 18 , p. 4025-4033.

Dinicola, R.S., 2003, Selected natural attenuation monitoring data, Operable Unit 1, Naval Undersea Warfare Center, Division Keyport, Washington, June 2001: U.S. Geological Survey Open-File Report 03-344, 17 p.

Dinicola, R.S., 2004, Selected natural attenuation monitoring data, Operable Unit 1, Naval Undersea Warfare Center, Division Keyport, Washington, June 2002: U.S. Geological Survey Open-File Report 2004-1203, 19 p.

Dinicola, R.S., Cox, S.E., Landmeyer, J.E., and Bradley, P.M., 2002, Natural attenuation of chlorinated volatile organic compounds in ground water at Operable Unit 1, Naval Undersea Weapons Center, Division Keyport, Washington: U.S. Geological Survey Water-Resources Investigations Report 02-4119, 118 p.

Dinicola, R.S., and Huffman, R.L., 2004, Selected natural attenuation monitoring data, Operable Unit 1, Naval Undersea Warfare Center, Division Keyport, Washington, June 2003: U.S. Geological Survey Open-File Report 2004-1330, 19 p.

Fishman, M.J., ed., 1993, Methods of analysis by the U.S. Geological Survey National Water Quality LaboratoryDetermination of inorganic and organic constituents in water and fluvial sediments: U.S. Geological Survey Open-File Report 93-125, 217 p.

Fishman, M.J., and Friedman, L.C., 1989, Methods for determination of inorganic substances in water and fluvial sediments: U.S. Geological Survey Techniques of Water-Resources Investigations, book 5, chap. A1, 545 p.

Gillham, R.W., and O'Hannesin, S.F., 1994, Enhanced degradation of halogenated aliphatics by zero-valent iron: Ground Water, v. 32, no. 6, p. 959-967.

Hach Company, 1998, DR/2010 Spectrophotometer Procedures Manual: Hach Company, Loveland, Colo.

Hoehler, T.M., Alperin, M.J., Albert, D.B., and Martens, C.S., 1998, Thermodynamic controls on $\mathrm{H}_{2}$ concentrations in anoxic sediments: Geochemica et Cosmochimica Acta, v. 62 , p. $1745-1746$. 
Jakobsen, R., Albrechtsen, H.J., Rasmussen, M., Bay, H., Bjerg, P.L., and Christensen, T.H., 1998, $\mathrm{H}_{2}$ concentrations in a landfill leachate plume (Grinsted, Denmark): In situ energetics of terminal electron acceptor processes: Environmental Science and Technology, v. 32, no. 14, p. 2142-2148.

Jeffers, P.M., Ward, L.M., Woytowitch, L.M., and Wolfe, N.L., 1989, Homogeneous hydrolysis rate constants for selected chlorinated methanes, ethanes, ethenes, and propanes: Environmental Science and Technology, v. 23, no. 8, p. 965-969.

Kampbell, D.H. and Vandegrift, S.A., 1998, Analysis of dissolved methane, ethane, and ethylene in ground water by a standard gas chromatographic technique: Journal of Chromatographic Science, v. 36, p. 253-256.

Lovely, D.R, Chapelle, F.H., and Woodward, J.C., 1994, Use of dissolved $\mathrm{H}_{2}$ concentrations to determine distribution of microbially catalyzed redox reactions in anoxic groundwater: Environmental Science and Technology, v. 28 , p. $1205-1210$.

Lovely, D.R, and Goodwin, S., 1988, Hydrogen concentrations as an indicator of the predominant terminal electronaccepting reactions in aquatic sediments: Geochimica et Cosmochimica Acta, v. 52, p. 2993-3003.

URS Consultants Inc., 1993, Final remediation investigation report for Operable Unit 1, Naval Undersea Warfare Center Division Keyport, Washington: Prepared under Contract No. N62474-89-D-9295 for Engineering Field Activity Northwest, Naval Facilities Engineering Command, Poulsbo, Wash., 6 volumes.

URS Consultants Inc., 1997a, Final summary data assessment report for Operable Unit 1 Naval Undersea Warfare Center Division Keyport, Washington: Prepared under Contract Task Order 0189 for Engineering Field Activity, Northwest, Naval Facilities Engineering Command, Poulsbo, Wash., 3 volumes.

URS Consultants, Inc., 1997b, Final focused feasibility study for Operable Unit 1 Naval Undersea Warfare Center Division Keyport, Washington: Prepared by URS Consultants, Seattle, Wash., for Engineering Field Activity, Northwest, Naval Facilities Engineering Command, Poulsbo, Wash., 1 volume.

URS Consultants Inc., 1998, Final record of decision for Operable Unit 1 Naval Undersea Warfare Center Division Keyport, Washington: Prepared by URS Consultants, Seattle, Wash., for Engineering Field Activity, Northwest, Naval Facilities Engineering Command, Poulsbo, Wash., $111 \mathrm{p}$.

URS Greiner, Inc., 1999, Phytoremediation closure report for Operable Unit 1, Naval Undersea Warfare Center Division Keyport, Washington: Prepared under Contract Task Order 0189 for Engineering Field Activity, Northwest, Naval Facilities Engineering Command, Poulsbo, Wash.
URS Greiner, Inc., 2000, Phytoremediation status report, May-July 1999, Operable Unit 1, Naval Undersea Warfare Center Division Keyport, Washington: Prepared under CLEAN Contract No. N62474-89-D-9295 for Engineering Field Activity Northwest, Naval Facilities Engineering Command, Poulsbo, Wash.

URS Greiner, Inc., 2002, Phytoremediation status report, July-September 2002, Operable Unit 1, Naval Undersea Warfare Center Division Keyport, Washington: Prepared under CLEAN Contract No. N62474-89-D-9295 for Engineering Field Activity Northwest, Naval Facilities Engineering Command, Poulsbo, Wash.

URS Greiner, Inc., 2003, Phytoremediation status report, July-September 2003, Operable Unit 1, Naval Undersea Warfare Center Division Keyport, Washington: Prepared under CLEAN Contract No. N62474-89-D-9295 for Engineering Field Activity Northwest, Naval Facilities Engineering Command, Poulsbo, Wash.

U.S. Environmental Protection Agency, 1983, Methods for chemical analysis of water and wastes: Office of Research and Development Report EPA 600/4-79-020, Washington D.C., 552 p.

U.S. Geological Survey, 1997 to 2004, National field manual for the collection of water-quality data: U.S. Geological Survey Techniques of Water-Resources Investigations, book 9, chaps. A1-A9, available at http://pubs.water.usgs. gov/twri9A. Chapters originally were published from 1997-1999; updates and revisions are ongoing and are summarized at http://water.usgs.gov/owq/FieldManual/ mastererrata.html

Vogel, T.M., 1994, Natural bioremediation of chlorinated solvents: in Norris, R.D., and others, Handbook of Bioremediation: Boca Raton, Lewis Publishers, p. 201-225.

Weidemeier, T.H., and Chapelle, F.H., 1998, Technical guidelines for evaluating monitored natural attenuation of petroleum hydrocarbons and chlorinated solvents in ground water at Naval and Marine Corps facilities: Internal report prepared for Southwest Division Naval facilities Engineering Command, Southern Division Naval facilities Engineering Command, and Engineering Field Activity, Northwest.

Weidemeier, T.H., Swanson, M.A., Wilson, J.T., Wilson, B.H., Kampbell, D.K., Hass, P.E., Miller, R.N., Hansen, J.E., and Chapelle, F.H., 1998, Technical protocol for evaluating natural attenuation of chlorinated solvents in ground water: EPA/600/R-98/128, 78 p. 
Table 6. Predominant redox conditions at selected wells and piezometers, and ground-water geochemical data collected at Operable Unit 1, Naval Undersea Warfare Center, Division Keyport, Washington, 1996-2004.

[Shaded rows indicate previously unpublished data. All other data were published in Dinicola and others (2002), Dinicola (2003; 2004); prior to 2000, bicarbonate was calculated from an unfiltered sample. Reported concentrations less than the detection limit usually are estimated. A range of dissolved hydrogen concentrations are shown when equilibration at a single value was never achieved. Predominant redox conditions: A, aerobic; An, anaerobic, but specific redox condition could not be determined; Fe, iron reducing; $\mathrm{M}$, methanogenic; Mn, manganese reducing; S, sulfate reducing. Abbreviations: nM, nanomolar; $\mathrm{mg} / \mathrm{L}$, milligram per liter; $\mu \mathrm{S} / \mathrm{cm}$, microsiemen per centimeter at 25 degrees Celsius; ORP, oxidation-reduction potential; mV, millivolt. Symbols: R, data rejected (selected 1996 dissolved-oxygen data were rejected because of inadequate well purging; selected 2002 dissolved-hydrogen data were rejected because of interference from downhole instruments); <, actual value is less than value shown; >, actual value is greater than value shown; -, not analyzed]

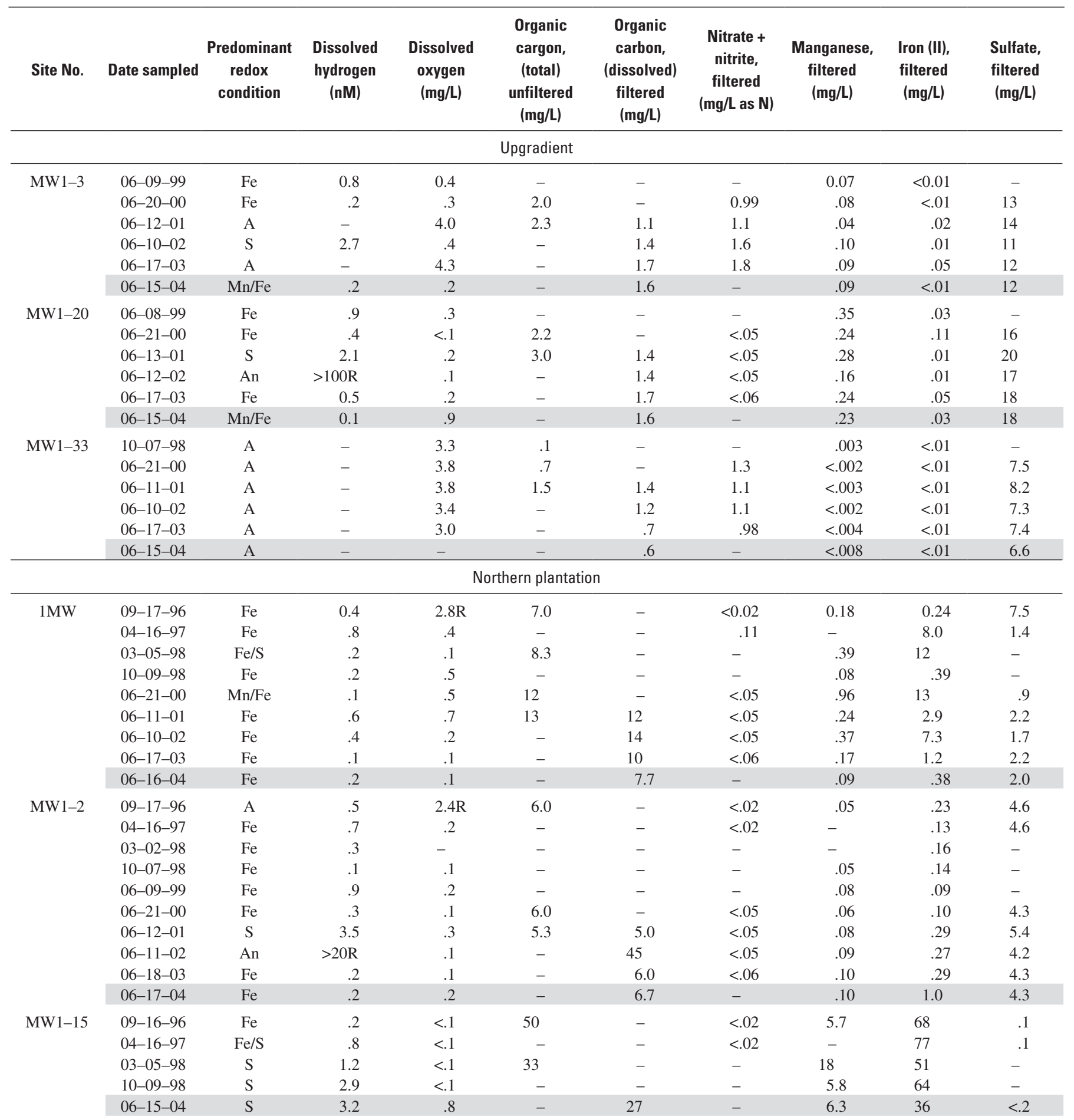


Table 6. Predominant redox conditions at selected wells and piezometers, and ground-water geochemical data collected at Operable Unit 1, Naval Undersea Warfare Center, Division Keyport, Washington, 1996-2004._Continued

[Shaded rows indicate previously unpublished data. All other data were published in Dinicola and others (2002), Dinicola (2003; 2004); prior to 2000, bicarbonate was calculated from an unfiltered sample. Reported concentrations less than the detection limit usually are estimated. A range of dissolved hydrogen concentrations are shown when equilibration at a single value was never achieved. Predominant redox conditions: A, aerobic; An, anaerobic, but specific redox condition could not be determined; Fe, iron reducing; M, methanogenic; Mn, manganese reducing; S, sulfate reducing. Abbreviations: nM, nanomolar; $\mathrm{mg} / \mathrm{L}$, milligram per liter; $\mu \mathrm{S} / \mathrm{cm}$, microsiemen per centimeter at 25 degrees Celsius; ORP, oxidation-reduction potential; mV, millivolt. Symbols: R, data rejected (selected 1996 dissolved-oxygen data were rejected because of inadequate well purging; selected 2002 dissolved-hydrogen data were rejected because of interference from downhole instruments); <, actual value is less than value shown; >, actual value is greater than value shown; -, not analyzed]

\begin{tabular}{|c|c|c|c|c|c|c|c|c|c|c|}
\hline Site No. & Date sampled & $\begin{array}{c}\text { Predominant } \\
\text { redox } \\
\text { condition }\end{array}$ & $\begin{array}{c}\text { Sulfide, } \\
\text { unfiltered } \\
\text { (mg/L) }\end{array}$ & $\begin{array}{c}\text { Methane, } \\
\text { dissolved } \\
\text { (mg/L) }\end{array}$ & $\begin{array}{l}\text { Dissolved } \\
\text { carbon } \\
\text { dioxide } \\
\text { (mg/L) }\end{array}$ & $\begin{array}{c}\text { Bicarbonate, } \\
\text { filtered } \\
\text { (mg/L) }\end{array}$ & pH (units) & $\begin{array}{c}\text { Specific } \\
\text { conductance } \\
(\mu \mathrm{S} / \mathrm{cm})\end{array}$ & $\mathrm{ORP}(\mathrm{mV})$ & $\begin{array}{c}\text { Chloride, } \\
\text { filtered } \\
\text { (mg/L) }\end{array}$ \\
\hline \multicolumn{11}{|c|}{ Upgradient } \\
\hline \multirow[t]{4}{*}{ MW1-3 } & 06-09-99 & $\mathrm{Fe}$ & $<0.01$ & - & - & 81 & 6.0 & 202 & - & - \\
\hline & $06-20-00$ & $\mathrm{Fe}$ & $<.01$ & 0.02 & - & 82 & 5.9 & 205 & 180 & 8.4 \\
\hline & $06-17-03$ & A & - & .02 & 80 & - & 6.0 & 199 & 200 & 10 \\
\hline & $06-15-04$ & $\mathrm{Mn} / \mathrm{Fe}$ & $<.01$ & .01 & - & 73 & 5.7 & 205 & 195 & 9.1 \\
\hline \multirow[t]{3}{*}{ MW1-20 } & 06-08-99 & $\mathrm{Fe}$ & $<.01$ & - & - & 260 & 6.7 & 546 & - & - \\
\hline & $06-21-00$ & $\mathrm{Fe}$ & $<.01$ & .01 & - & 240 & 6.8 & 530 & 79 & 14 \\
\hline & $06-13-01$ & $\mathrm{~S}$ & $<.01$ & .27 & - & 260 & 6.4 & 544 & 250 & 33 \\
\hline \multirow{5}{*}{ MW1-33 } & $06-21-00$ & $\mathrm{~A}$ & $<.01$ & .05 & - & 74 & 6.7 & 164 & 160 & 4.0 \\
\hline & $06-11-01$ & $\mathrm{~A}$ & $<.01$ & .07 & - & 71 & 6.2 & 154 & 300 & 3.6 \\
\hline & 06-10-02 & $\mathrm{A}$ & $<.01$ & .004 & 31 & 81 & 6.5 & 138 & 360 & 3.4 \\
\hline & $06-17-03$ & $\mathrm{~A}$ & $<.01$ & .01 & 25 & - & 6.3 & 156 & 110 & 3.7 \\
\hline & 06-15-04 & A & - & $<.005$ & 13 & 70 & 6.7 & 165 & - & 4.0 \\
\hline \multicolumn{11}{|c|}{ Northern plantation } \\
\hline \multirow[t]{5}{*}{$1 \mathrm{MW}-1$} & 09-17-96 & $\mathrm{Fe}$ & $<0.01$ & 10 & - & 640 & 7.9 & - & - & 43 \\
\hline & $04-16-97$ & $\mathrm{Fe}$ & .01 & 29 & - & 1,100 & 7.2 & - & - & - \\
\hline & 03-05-98 & $\mathrm{Fe} / \mathrm{S}$ & .06 & - & - & - & - & - & - & - \\
\hline & $10-09-98$ & $\mathrm{Fe}$ & .01 & - & - & 660 & 7.7 & 1,080 & - & - \\
\hline & $06-21-00$ & $\mathrm{Mn} / \mathrm{Fe}$ & $<.01$ & .39 & - & 590 & 7.0 & 1,070 & -92 & 44 \\
\hline \multirow{6}{*}{ MW1-2 } & 06-09-99 & $\mathrm{Fe}$ & $<.01$ & - & - & 490 & 6.8 & 901 & - & - \\
\hline & $06-21-00$ & $\mathrm{Fe}$ & $<.01$ & .04 & - & 460 & 6.8 & 870 & 37 & 36 \\
\hline & $06-12-01$ & $\mathrm{~S}$ & $<.01$ & .78 & - & 470 & 6.5 & 853 & 27 & 48 \\
\hline & $06-11-02$ & An & $<.01$ & .92 & 200 & 500 & 6.6 & 829 & 200 & 37 \\
\hline & $06-18-03$ & $\mathrm{Fe}$ & $<.01$ & .98 & 160 & - & 6.4 & 870 & 62 & 41 \\
\hline & $06-17-04$ & $\mathrm{Fe}$ & - & .33 & 50 & - & 6.6 & 858 & - & 40 \\
\hline \multirow[t]{5}{*}{ MW1-15 } & 09-16-96 & $\mathrm{Fe}$ & $<.01$ & 8.8 & - & 1,200 & - & - & - & 18 \\
\hline & 04-16-97 & $\mathrm{Fe} / \mathrm{S}$ & .03 & 44 & - & 1,600 & 6.3 & - & - & - \\
\hline & 03-05-98 & $\mathrm{S}$ & $<.01$ & - & - & - & - & - & - & - \\
\hline & $10-09-98$ & $\mathrm{~S}$ & $<.01$ & - & - & 750 & 6.3 & 1,110 & - & - \\
\hline & $06-15-04$ & $\mathrm{~S}$ & $<.01$ & .22 & 760 & - & 6.3 & 1,200 & - & 16 \\
\hline
\end{tabular}


Table 6. Predominant redox conditions at selected wells and piezometers, and ground-water geochemical data collected at Operable Unit 1, Naval Undersea Warfare Center, Division Keyport, Washington, 1996-2004._Continued

[Shaded rows indicate previously unpublished data. All other data were published in Dinicola and others (2002), Dinicola (2003; 2004); prior to 2000, bicarbonate was calculated from an unfiltered sample. Reported concentrations less than the detection limit usually are estimated. A range of dissolved hydrogen concentrations are shown when equilibration at a single value was never achieved. Predominant redox conditions: A, aerobic; An, anaerobic, but specific redox condition could not be determined; Fe, iron reducing; $\mathrm{M}$, methanogenic; Mn, manganese reducing; S, sulfate reducing. Abbreviations: nM, nanomolar; $\mathrm{mg} / \mathrm{L}$, milligram per liter; $\mu \mathrm{S} / \mathrm{cm}$, microsiemen per centimeter at 25 degrees Celsius; ORP, oxidation-reduction potential; mV, millivolt. Symbols: R, data rejected (selected 1996 dissolved-oxygen data were rejected because of inadequate well purging; selected 2002 dissolved-hydrogen data were rejected because of interference from downhole instruments); <, actual value is less than value shown; >, actual value is greater than value shown; -, not analyzed]

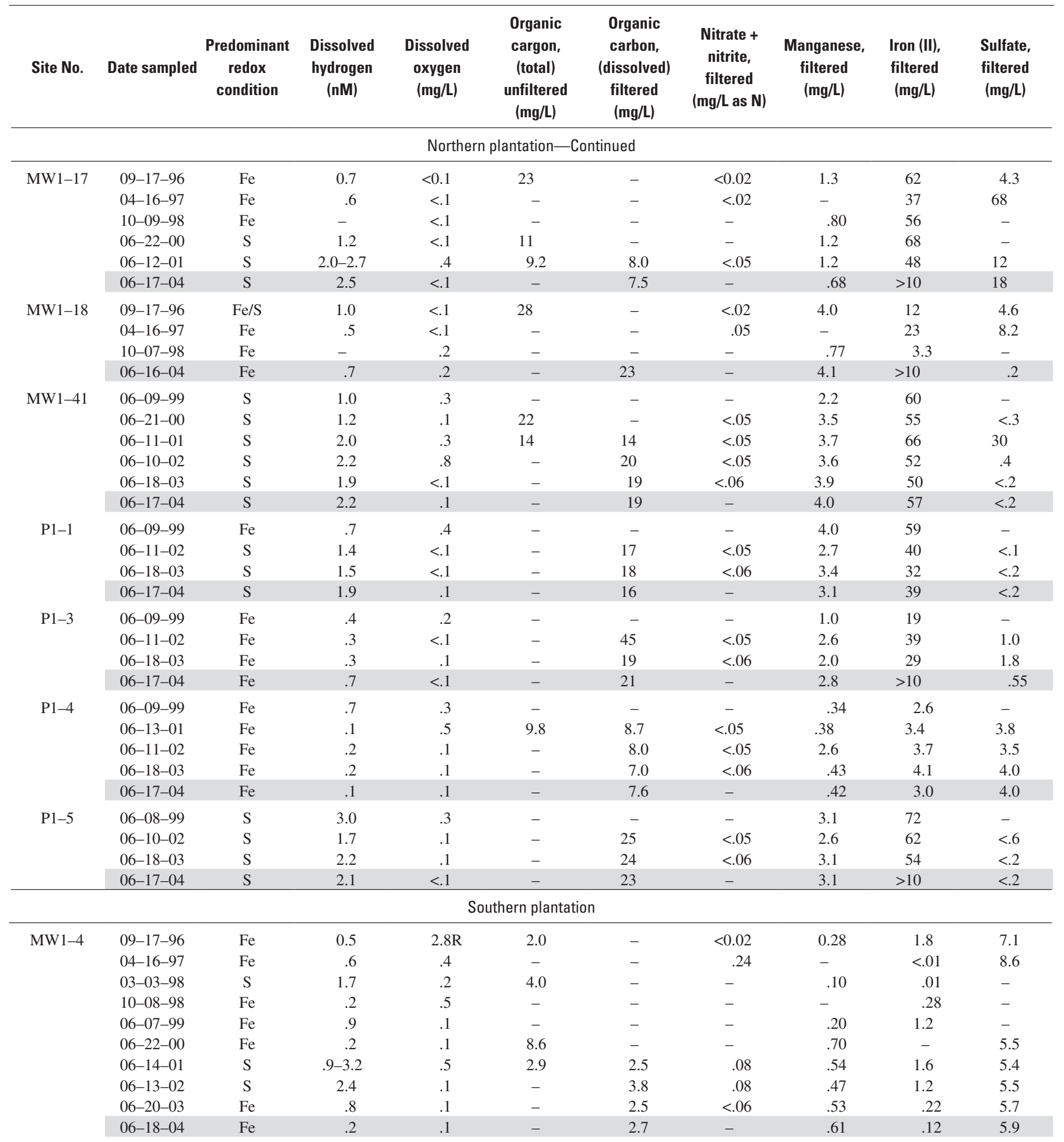


Table 6. Predominant redox conditions at selected wells and piezometers, and ground-water geochemical data collected at Operable Unit 1, Naval Undersea Warfare Center, Division Keyport, Washington, 1996-2004._Continued

[Shaded rows indicate previously unpublished data. All other data were published in Dinicola and others (2002), Dinicola (2003; 2004); prior to 2000, bicarbonate was calculated from an unfiltered sample. Reported concentrations less than the detection limit usually are estimated. A range of dissolved hydrogen concentrations are shown when equilibration at a single value was never achieved. Predominant redox conditions: A, aerobic; An, anaerobic, but specific redox condition could not be determined; Fe, iron reducing; M, methanogenic; Mn, manganese reducing; S, sulfate reducing. Abbreviations: nM, nanomolar; $\mathrm{mg} / \mathrm{L}$, milligram per liter; $\mu \mathrm{S} / \mathrm{cm}$, microsiemen per centimeter at 25 degrees Celsius; ORP, oxidation-reduction potential; mV, millivolt. Symbols: R, data rejected (selected 1996 dissolved-oxygen data were rejected because of inadequate well purging; selected 2002 dissolved-hydrogen data were rejected because of interference from downhole instruments); <, actual value is less than value shown; >, actual value is greater than value shown; -, not analyzed]

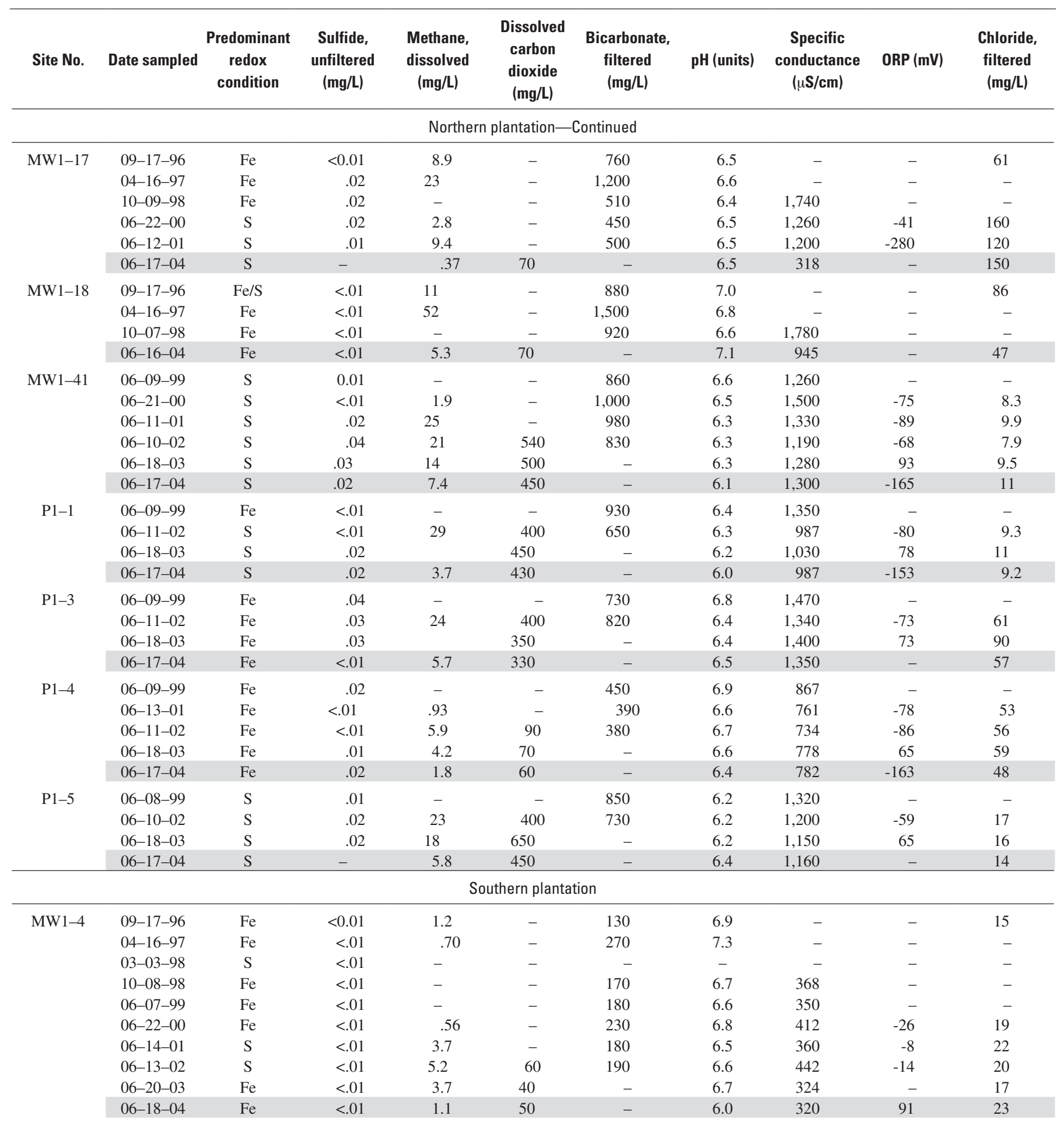


Table 6. Predominant redox conditions at selected wells and piezometers, and ground-water geochemical data collected at Operable Unit 1, Naval Undersea Warfare Center, Division Keyport, Washington, 1996-2004._Continued

[Shaded rows indicate previously unpublished data. All other data were published in Dinicola and others (2002), Dinicola (2003; 2004); prior to 2000, bicarbonate was calculated from an unfiltered sample. Reported concentrations less than the detection limit usually are estimated. A range of dissolved hydrogen concentrations are shown when equilibration at a single value was never achieved. Predominant redox conditions: A, aerobic; An, anaerobic, but specific redox condition could not be determined; Fe, iron reducing; $\mathrm{M}$, methanogenic; Mn, manganese reducing; S, sulfate reducing. Abbreviations: nM, nanomolar; $\mathrm{mg} / \mathrm{L}$, milligram per liter; $\mu \mathrm{S} / \mathrm{cm}$, microsiemen per centimeter at 25 degrees Celsius; ORP, oxidation-reduction potential; mV, millivolt. Symbols: R, data rejected (selected 1996 dissolved-oxygen data were rejected because of inadequate well purging; selected 2002 dissolved-hydrogen data were rejected because of interference from downhole instruments); <, actual value is less than value shown; >, actual value is greater than value shown; -, not analyzed]

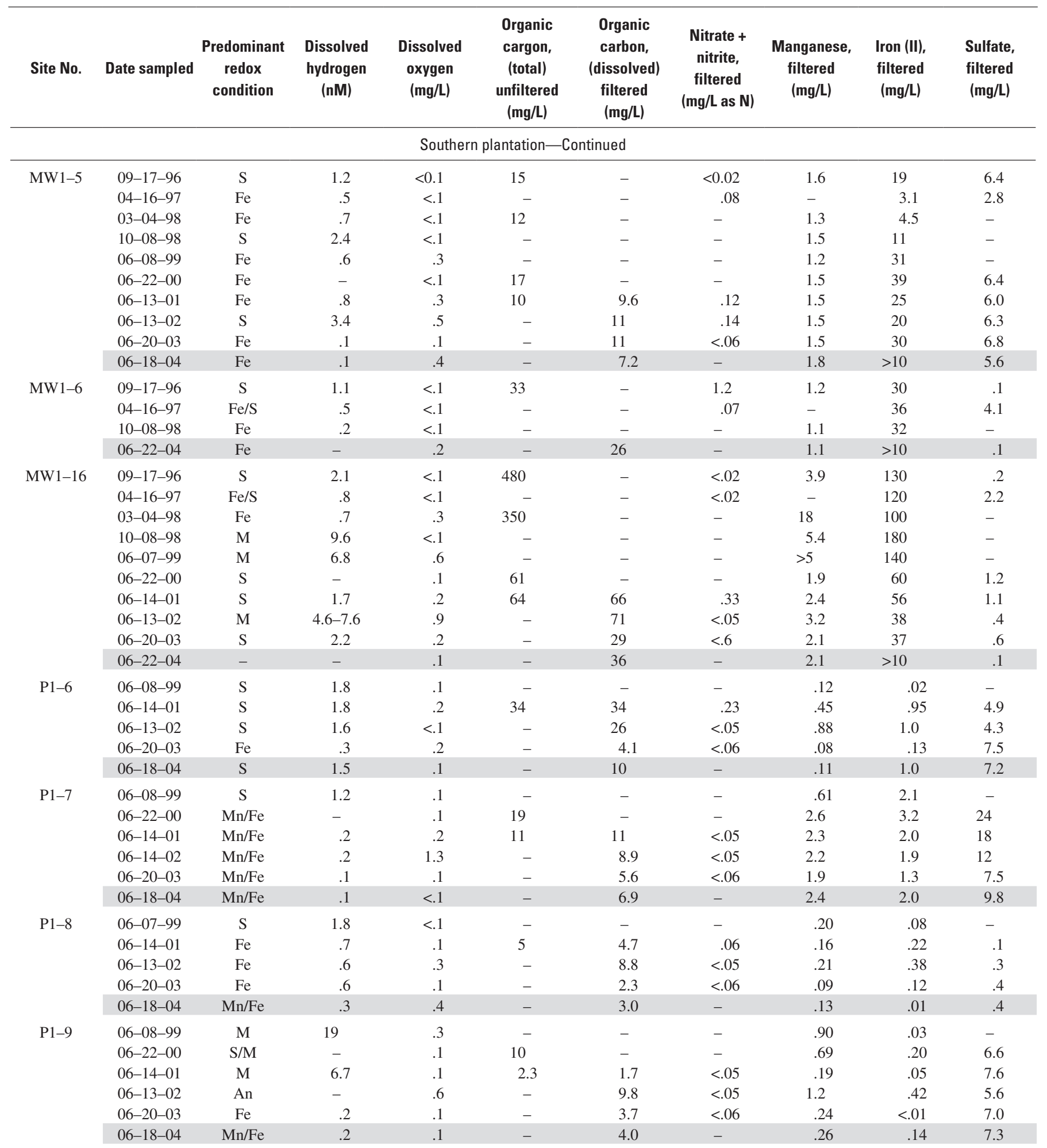


Table 6. Predominant redox conditions at selected wells and piezometers, and ground-water geochemical data collected at Operable Unit 1, Naval Undersea Warfare Center, Division Keyport, Washington, 1996-2004._Continued

[Shaded rows indicate previously unpublished data. All other data were published in Dinicola and others (2002), Dinicola (2003; 2004); prior to 2000, bicarbonate was calculated from an unfiltered sample. Reported concentrations less than the detection limit usually are estimated. A range of dissolved hydrogen concentrations are shown when equilibration at a single value was never achieved. Predominant redox conditions: A, aerobic; An, anaerobic, but specific redox condition could not be determined; Fe, iron reducing; M, methanogenic; Mn, manganese reducing; S, sulfate reducing. Abbreviations: nM, nanomolar; $\mathrm{mg} / \mathrm{L}$, milligram per liter; $\mu \mathrm{S} / \mathrm{cm}$, microsiemen per centimeter at 25 degrees Celsius; ORP, oxidation-reduction potential; mV, millivolt. Symbols: R, data rejected (selected 1996 dissolved-oxygen data were rejected because of inadequate well purging; selected 2002 dissolved-hydrogen data were rejected because of interference from downhole instruments); <, actual value is less than value shown; >, actual value is greater than value shown; -, not analyzed]

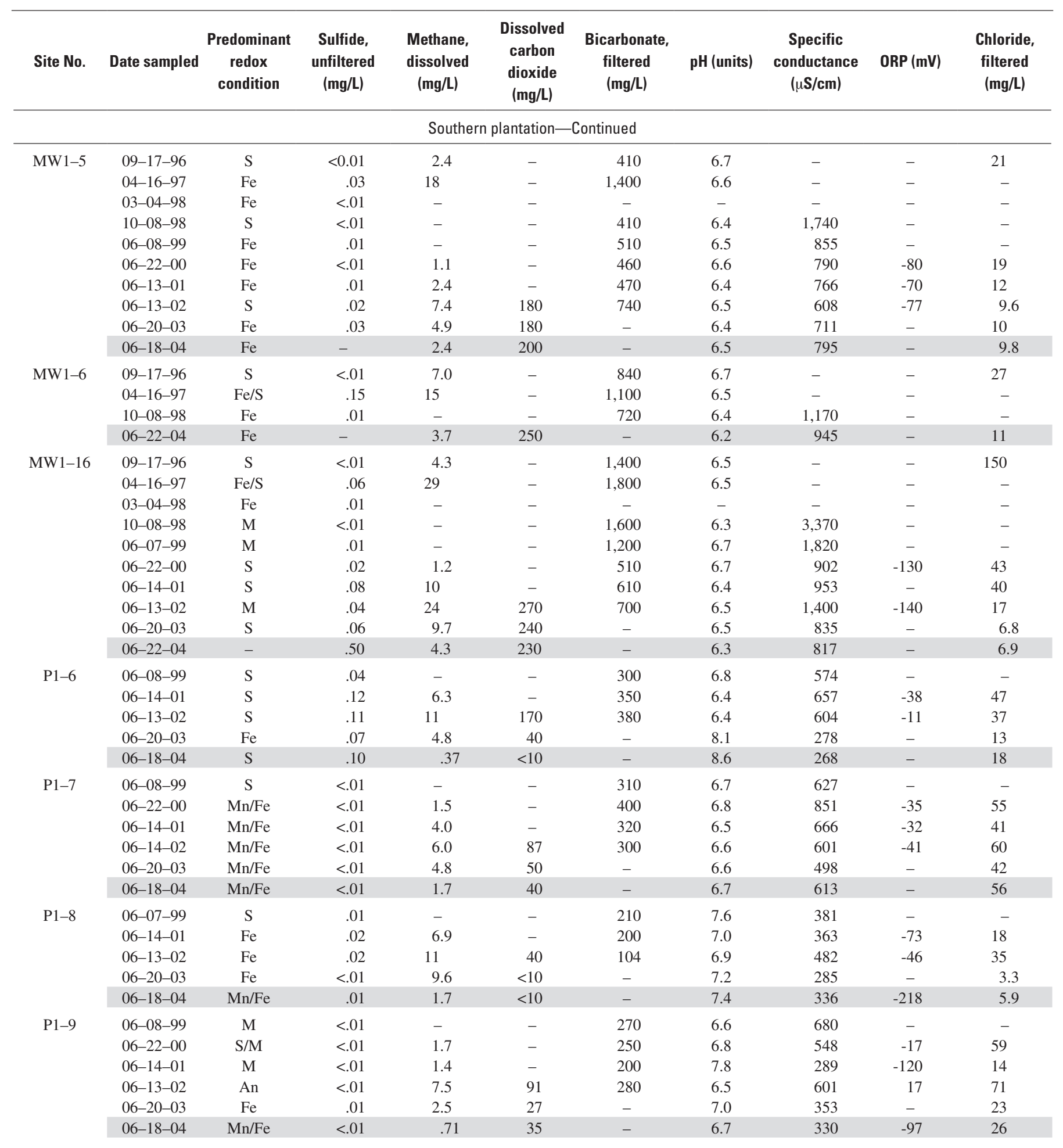


Table 6. Predominant redox conditions at selected wells and piezometers, and ground-water geochemical data collected at Operable Unit 1, Naval Undersea Warfare Center, Division Keyport, Washington, 1996-2004._Continued

[Shaded rows indicate previously unpublished data. All other data were published in Dinicola and others (2002), Dinicola (2003; 2004); prior to 2000, bicarbonate was calculated from an unfiltered sample. Reported concentrations less than the detection limit usually are estimated. A range of dissolved hydrogen concentrations are shown when equilibration at a single value was never achieved. Predominant redox conditions: A, aerobic; An, anaerobic, but specific redox condition could not be determined; Fe, iron reducing; $\mathrm{M}$, methanogenic; Mn, manganese reducing; S, sulfate reducing. Abbreviations: nM, nanomolar; $\mathrm{mg} / \mathrm{L}$, milligram per liter; $\mu \mathrm{S} / \mathrm{cm}$, microsiemen per centimeter at 25 degrees Celsius; ORP, oxidation-reduction potential; mV, millivolt. Symbols: R, data rejected (selected 1996 dissolved-oxygen data were rejected because of inadequate well purging; selected 2002 dissolved-hydrogen data were rejected because of interference from downhole instruments); <, actual value is less than value shown; >, actual value is greater than value shown; -, not analyzed]

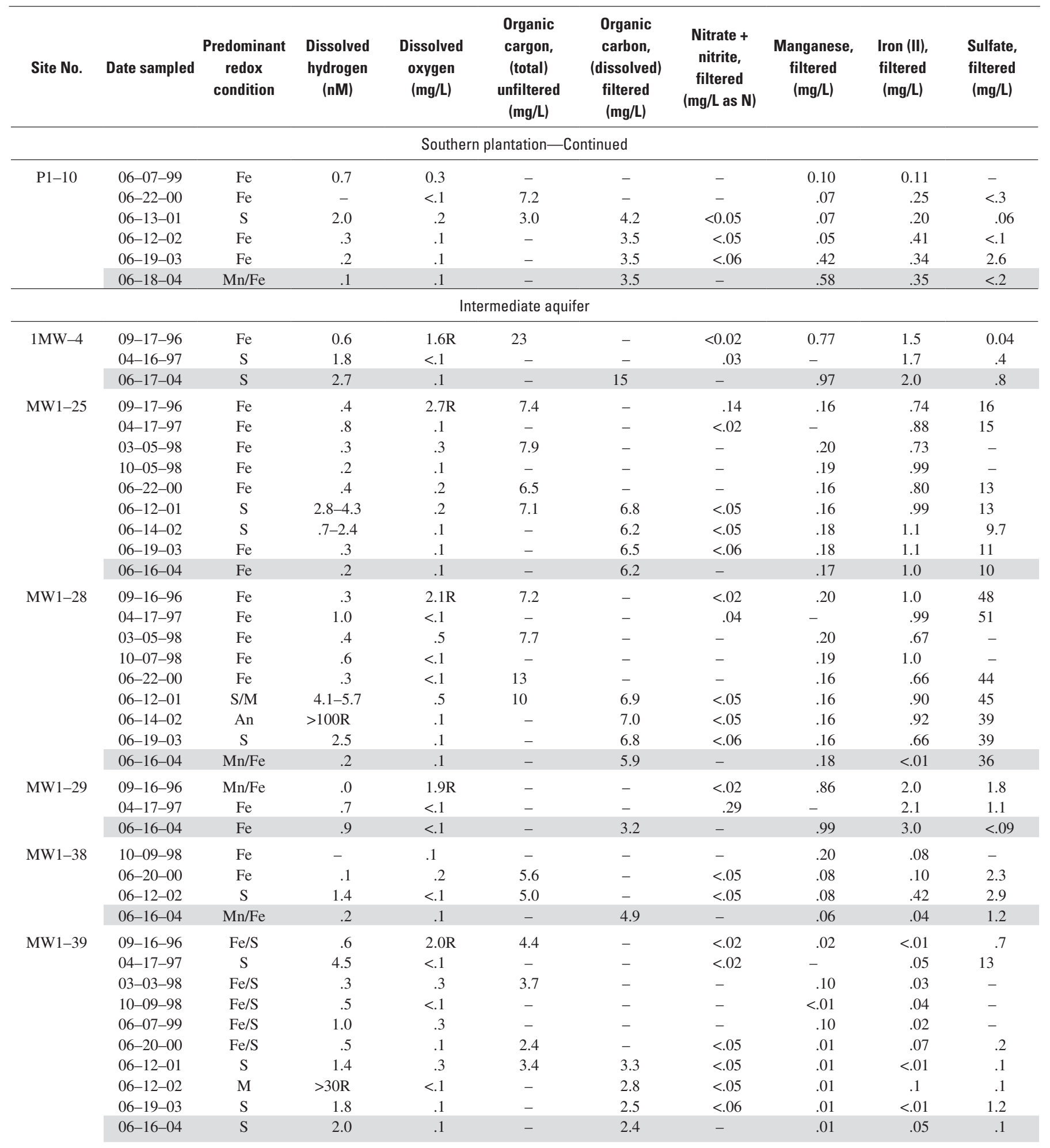


Table 6. Predominant redox conditions at selected wells and piezometers, and ground-water geochemical data collected at Operable Unit 1, Naval Undersea Warfare Center, Division Keyport, Washington, 1996-2004._Continued

[Shaded rows indicate previously unpublished data. All other data were published in Dinicola and others (2002), Dinicola (2003; 2004); prior to 2000, bicarbonate was calculated from an unfiltered sample. Reported concentrations less than the detection limit usually are estimated. A range of dissolved hydrogen concentrations are shown when equilibration at a single value was never achieved. Predominant redox conditions: A, aerobic; An, anaerobic, but specific redox condition could not be determined; Fe, iron reducing; M, methanogenic; Mn, manganese reducing; S, sulfate reducing. Abbreviations: nM, nanomolar; $\mathrm{mg} / \mathrm{L}$, milligram per liter; $\mu \mathrm{S} / \mathrm{cm}$, microsiemen per centimeter at 25 degrees Celsius; ORP, oxidation-reduction potential; mV, millivolt. Symbols: R, data rejected (selected 1996 dissolved-oxygen data were rejected because of inadequate well purging; selected 2002 dissolved-hydrogen data were rejected because of interference from downhole instruments); <, actual value is less than value shown; >, actual value is greater than value shown; -, not analyzed]

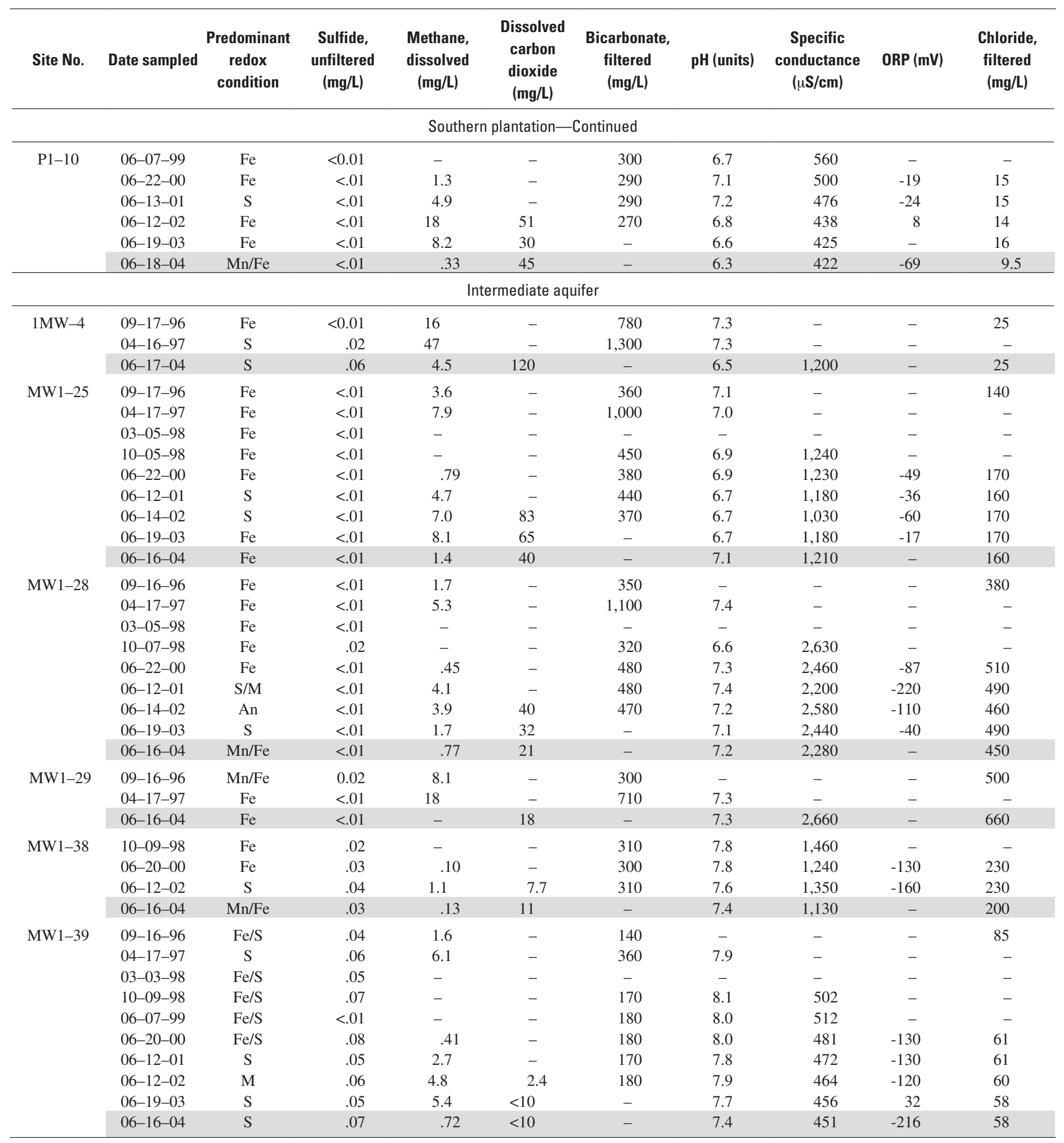




\section{Appendix A. Quality Assurance and Control of U.S. Geological Survey 2004 Geochemical Sampling}

Quality assurance and control of geochemical sampling included collecting duplicate samples for selected redoxsensitive analytes and volatile organic compounds (VOCs) and analyzing a field blank sample for VOCs. The field blank was collected by pumping VOC-free water through previously used and cleaned tubing. Those results represent possible sampling contamination in samples collected at known contaminated wells only; new tubing was used to sample from wells that were known to be uncontaminated or slightly contaminated and from piezometers sampled for the first time. Complete laboratory quality assurance and control data from Severn-Trent Laboratories is on file in the USGS office in Tacoma, Wash.
Duplicate sample results compared favorably for all constituents (table A1). The relatively high variation (30 percent) in duplicate TCE and cis-DCE analyses for site P1-9 sample may be attributed to the dilutions required to quantify such high concentrations. Chloroethenes, chloroethanes, and BTEX were not detected in the field blank sample of pumped VOC-free water (site MW1-41FB). A trace amount of methane $(0.0085 \mathrm{mg} / \mathrm{L})$ was detected in the field blank, and methane was detected in laboratory method blanks at concentrations ranging from 0.0032 to $0.027 \mathrm{mg} / \mathrm{L}$, indicating low-level contamination at the laboratory. No ethene, ethane, or chloroethene or chloroethane compounds of interest were detected in laboratory method blanks.

Table A1. Quality assurance and control data collected by the U.S. Geological Survey at Operable Unit 1, Naval Undersea Warfare Center, Division Keyport, Washington, 2004.

[Site No.: D denotes duplicate sample; FB denotes field blank sample. Abbreviations: PCE, tetrachloroethene; TCE, trichloroethene; cis-DCE, cis-1,2dichloroethene; trans-DCE, trans-1,2-dichloroethene; VC, vinyl chloride; TCA, 1,1,-trichloroethane; 1,1-DCE, 1,1-dichloroethene, CA, chloroethane; total BTEX, sum of benzene, toluene, ethylbenzene, and xylene concentrations shown in table; total CVOCs, sum of all chloroethene and chloroethane concentrations shown in table; $\mathrm{mg} / \mathrm{L}$, milligram per liter; $\mu \mathrm{g} / \mathrm{L}$, microgram per liter; nd, none detected. Symbols: <, actual value is less than the value shown; -, not analyzed]

\begin{tabular}{|c|c|c|c|c|c|c|c|c|c|c|c|c|}
\hline Site No. & $\begin{array}{c}\text { Date } \\
\text { sampled }\end{array}$ & $\begin{array}{c}\text { PCE } \\
(\mu \mathrm{g} / \mathrm{L})\end{array}$ & $\begin{array}{c}\text { TCE } \\
(\mu \mathrm{g} / \mathrm{L})\end{array}$ & $\begin{array}{c}\text { cis-DCE } \\
(\mu \mathrm{g} / \mathrm{L})\end{array}$ & $\begin{array}{c}\text { trans-DCE } \\
\quad(\mu \mathrm{g} / \mathrm{L})\end{array}$ & $\begin{array}{c}\text { VC } \\
(\mu g / L)\end{array}$ & $\begin{array}{l}\text { Ethane } \\
(\mu \mathbf{g} / \mathbf{L})\end{array}$ & $\begin{array}{c}\text { Ethene } \\
(\mu \mathrm{g} / \mathrm{L})\end{array}$ & $\begin{array}{c}\text { 1,1,1-TCA } \\
(\mu \mathrm{g} / \mathrm{L})\end{array}$ & $\begin{array}{c}\text { 1,1-DCA } \\
(\mu \mathrm{g} / \mathrm{L})\end{array}$ & $\begin{array}{c}\text { CA } \\
(\mu \mathrm{g} / \mathrm{L})\end{array}$ & $\begin{array}{c}\text { 1,1-DCE } \\
(\mu \mathrm{g} / \mathrm{L})\end{array}$ \\
\hline MW1-41 & 06-17-04 & $<1.0$ & $<1.0$ & 0.27 & $<1.0$ & 0.23 & 10 & $<100$ & $<1.0$ & $<1.0$ & 1.7 & $<1.0$ \\
\hline MW1-41FB & $06-17-04$ & $<1.0$ & $<1.0$ & $<1.0$ & $<1.0$ & $<1.0$ & $<5.0$ & $<5.0$ & $<1.0$ & $<1.0$ & $<2.0$ & $<1.0$ \\
\hline P1-9 & 06-18-04 & $<1,300$ & 50,000 & 23,000 & $<1,300$ & 2,100 & 16 & 200 & $<1,300$ & $<1,300$ & $<2,700$ & $<1,300$ \\
\hline P1-9D & 06-18-04 & $<2,000$ & 65,000 & 30,000 & $<2,000$ & 2,500 & 23 & 300 & $<2,000$ & $<2,000$ & $<4,000$ & $<2,000$ \\
\hline MW1-41 & 06-17-04 & nd & 2.2 & 0.1 & 19 & 4.0 & 57 & $<0.2$ & 0.02 & 7.4 & 450 & 11 \\
\hline
\end{tabular}


This page intentionally left blank. 
Manuscript approved for publication, February 22, 2006

Prepared by the U.S. Geological Survey Publishing Network

Publishing Service Center, Tacoma, Washington

Bill Gibbs

Debra Grillo

Sharon Wahlstrom

For more information concerning the research in this report, contact the Director, Washington Water Science Center

U.S. Geological Survey, 1201 Pacific Avenue - Suite 600

Tacoma, Washington 98402

http://wa.water.usgs.gov 
